University of Tennessee Health Science Center

UTHSC Digital Commons

\title{
The Design and Synthesis of Novel Antimicrobial Agents for Use in the Battle Against Bacterial Resistance
}

Joshua Randal Brown

University of Tennessee Health Science Center

Follow this and additional works at: https://dc.uthsc.edu/dissertations

Part of the Pharmacy and Pharmaceutical Sciences Commons

\section{Recommended Citation}

Brown, Joshua Randal , "The Design and Synthesis of Novel Antimicrobial Agents for Use in the Battle Against Bacterial Resistance" (2010). Theses and Dissertations (ETD). Paper 31. http://dx.doi.org/ 10.21007/etd.cghs.2010.0035.

This Dissertation is brought to you for free and open access by the College of Graduate Health Sciences at UTHSC Digital Commons. It has been accepted for inclusion in Theses and Dissertations (ETD) by an authorized administrator of UTHSC Digital Commons. For more information, please contact jwelch30@uthsc.edu. 


\title{
The Design and Synthesis of Novel Antimicrobial Agents for Use in the Battle Against Bacterial Resistance
}

\begin{abstract}
There is an ever increasing need to develop new antimicrobial agents with novel mechanisms of action. These new agents will help to combat the steady rise of antibiotic-resistant bacteria which are becoming more and more difficult to treat due to the dwindling number of antibiotics available to treat such organisms. This body of work brings to light the many ways in which medicinal chemistry plays a vital role in the discovery of novel antimicrobial agents. Chapter 1 is an introduction into antimicrobial agents. It provides a brief history of the discovery of antimicrobial agents, and delves into reasons why new agents are urgently needed. It also examines the recent antimicrobial agents approved by the Food and Drug Administration for use in the United States, and looks into the current antimicrobial drug pipeline. Chapter 2 explores the current therapy regime for combating tuberculosis and expresses the need for novel agents in this arena. It also shows how current medicinal chemistry techniques are being utilized to develop a novel class of potential anti-tuberculosis agents with novel mechanisms of action. Chapter 3 discusses the treatment of gram-negative bacterial infections with novel hybrid antimicrobial agents. These agents afford current antimicrobial agents, which have difficulty penetrating the gram-negative cell wall, a way into the gram-negative cell in order to exert their intended mechanism of action. This chapter explores the rationale and design behind the making of such agents. Chapter 4 provides an overview of the work detailed in the dissertation; as well as future directions that will help further the scope of these projects.
\end{abstract}

\section{Document Type \\ Dissertation}

\section{Degree Name}

Doctor of Philosophy (PhD)

\section{Program}

Pharmaceutical Sciences

\section{Research Advisor}

Richard Lee, Ph.D.

\section{Keywords}

Antimicrobial, Tuberculosis, Urea, Tetramic Acid

\section{Subject Categories}

Medicine and Health Sciences | Pharmacy and Pharmaceutical Sciences 
THE DESIGN AND SYNTHESIS OF NOVEL ANTIMICROBIAL AGENTS FOR USE IN THE BATTLE AGAINST BACTERIAL RESISTANCE

\author{
A Dissertation \\ Presented for \\ The Graduate Studies Council \\ The University of Tennessee \\ Health Science Center

\begin{abstract}
In Partial Fulfillment
Of the Requirements for the Degree

Doctor of Philosophy

From The University of Tennessee
\end{abstract}

By

Joshua Randal Brown

May 2010 
Copyright (C) 2010 by Joshua R. Brown All rights reserved 


\begin{abstract}
There is an ever increasing need to develop new antimicrobial agents with novel mechanisms of action. These new agents will help to combat the steady rise of antibioticresistant bacteria which are becoming more and more difficult to treat due to the dwindling number of antibiotics available to treat such organisms. This body of work brings to light the many ways in which medicinal chemistry plays a vital role in the discovery of novel antimicrobial agents. Chapter 1 is an introduction into antimicrobial agents. It provides a brief history of the discovery of antimicrobial agents, and delves into reasons why new agents are urgently needed. It also examines the recent antimicrobial agents approved by the Food and Drug Administration for use in the United States, and looks into the current antimicrobial drug pipeline. Chapter 2 explores the current therapy regime for combating tuberculosis and expresses the need for novel agents in this arena. It also shows how current medicinal chemistry techniques are being utilized to develop a novel class of potential anti-tuberculosis agents with novel mechanisms of action. Chapter 3 discusses the treatment of gram-negative bacterial infections with novel hybrid antimicrobial agents. These agents afford current antimicrobial agents, which have difficulty penetrating the gram-negative cell wall, a way into the gram-negative cell in order to exert their intended mechanism of action. This chapter explores the rationale and design behind the making of such agents. Chapter 4 provides an overview of the work detailed in the dissertation; as well as future directions that will help further the scope of these projects.
\end{abstract}




\section{TABLE OF CONTENTS}

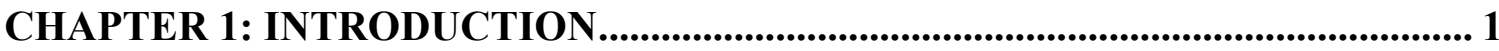

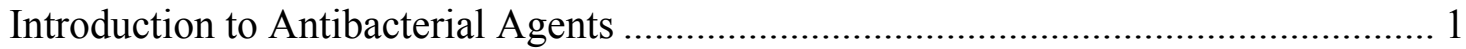

Inhibitors of Bacterial Cell Wall Biosynthesis …………......................................... 1

Inhibitors of Protein Biosynthesis......................................................................... 3

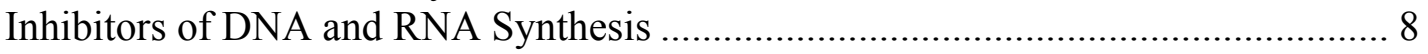

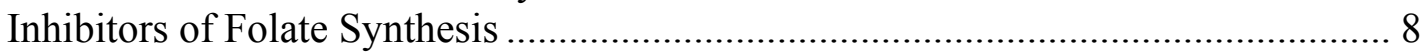

The Need for Novel Antibacterial Agents ............................................................... 11

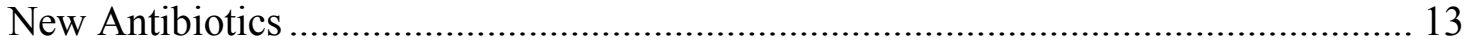

Recently Approved Antibiotics ........................................................................ 13

Antibiotics in the Pipeline: Gram-Positive ......................................................... 18

Antibiotics in the Pipeline: Gram-Negative........................................................ 29

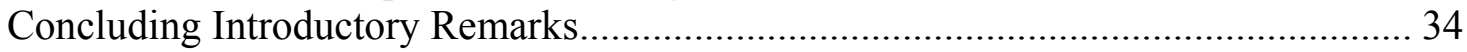

\section{CHAPTER 2: NOVEL UREA DERIVATIVES AS ANTI-TUBERCULOSIS}

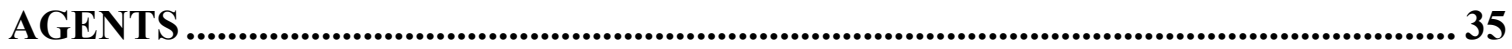

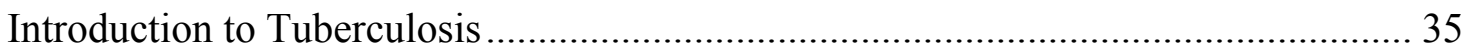

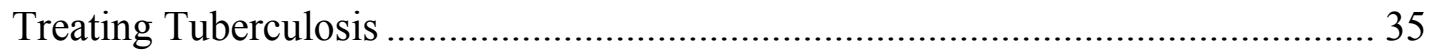

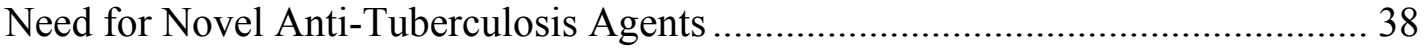

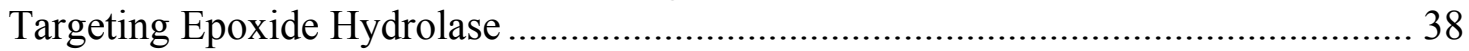

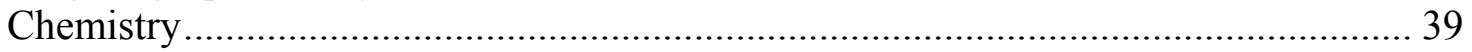

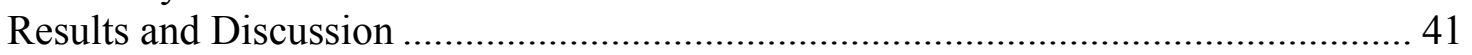

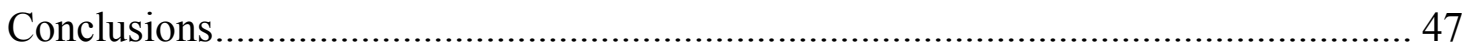

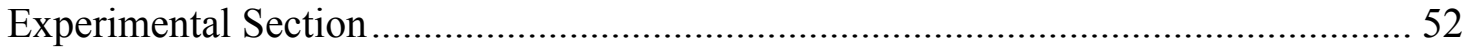

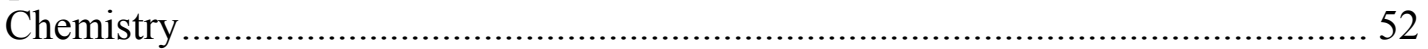

General Method for the Synthesis of Urea Compounds .......................................... 52

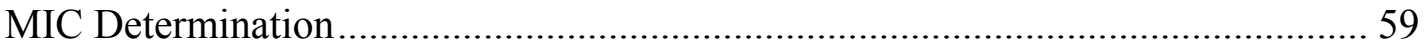

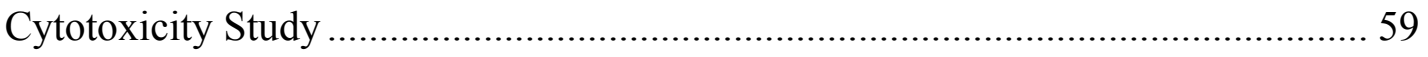

CHAPTER 3: DESIGN OF NOVEL SIDEROPHORE ANTIMICROBIAL AGENTS FOR THE TREATMENT OF GRAM-NEGATIVE BACTERIA ............60

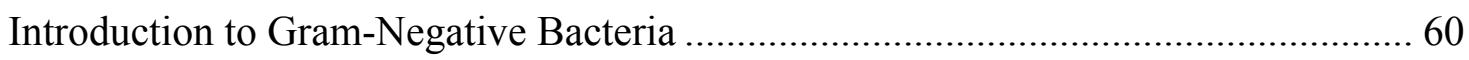

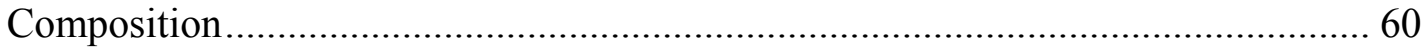

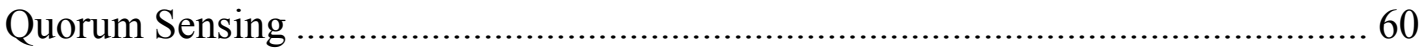

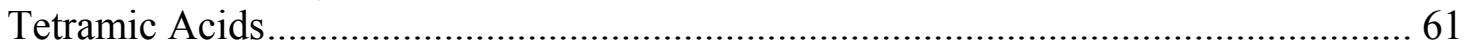

Synthesis of Quorum Sensing Molecule 1 and Its Degradation Product....................... 61

Significance of the Tetramic Acid Degradation Product as a Siderophore ................... 64

Synthesis of Iron(III) Chelation Product of Tetramic Acids ....................................... 65

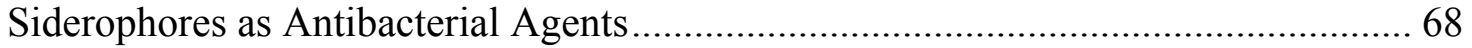

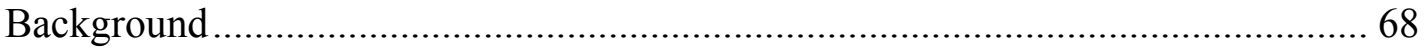

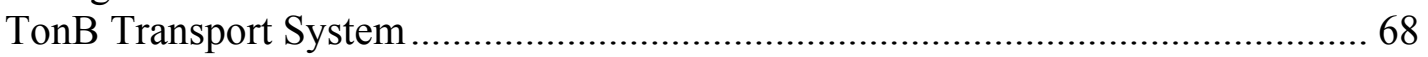

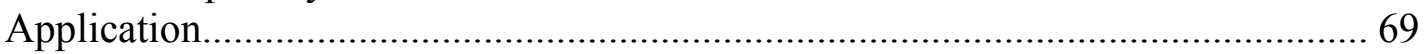

Synthesis of Tetramic Acid Core......................................................................... 71

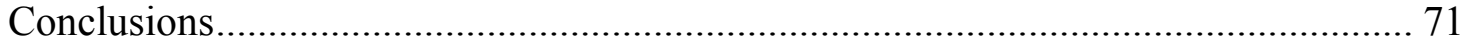

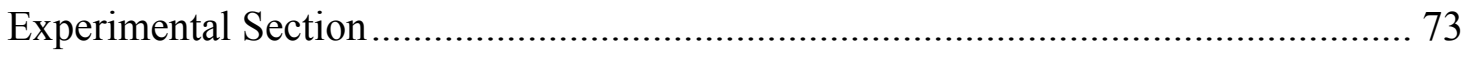


CHAPTER 4: OVERALL DISCUSSION OF DISSERTATION............................ 76

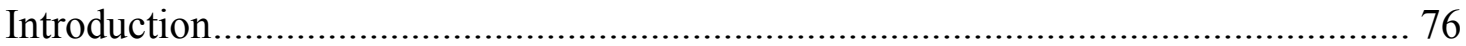

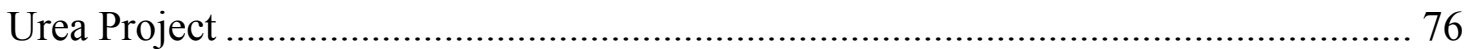

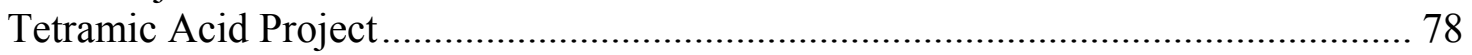

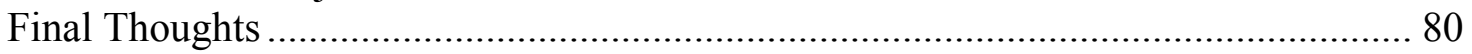

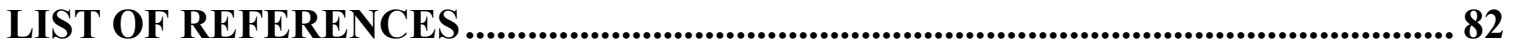

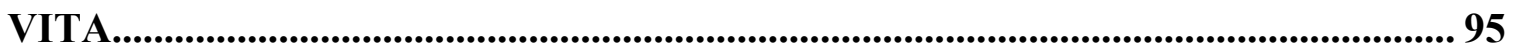




\section{LIST OF FIGURES}

Figure 1.1: Activation of Prontosil to Sulfanilamide ………….................................... 2

Figure 1.2: General Structures of the Four Classes of $\beta$-Lactam Antibiotics.................. 2

Figure 1.3: Structures of Vancomycin and Teicoplanin................................................. 4

Figure 1.4: Structures of Aminoglycoside Antibiotics ..................................................... 6

Figure 1.5: Structures of Macrolide and Ketolide Antibiotics ........................................ 6

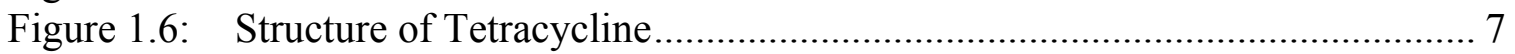

Figure 1.7: Structures of Quinolone Antibiotics ....................................................... 9

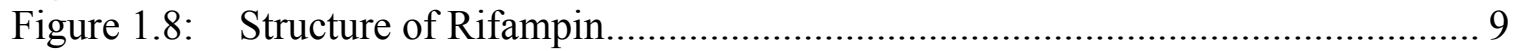

Figure 1.9: Structure of Sulfamethoxazole ............................................................. 10

Figure 1.10: Structure of Trimethoprim ............................................................. 12

Figure 1.11: Structure of Linezolid ...................................................................... 14

Figure 1.12: Structure of Cefditoren..................................................................... 16

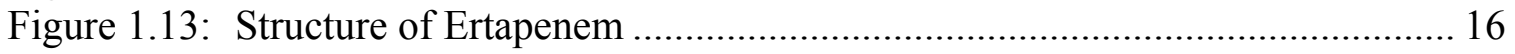

Figure 1.14: Structure of Gemifloxacin................................................................. 16

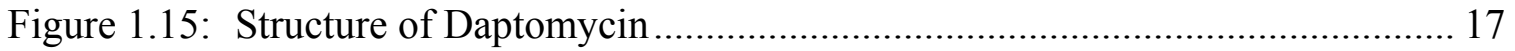

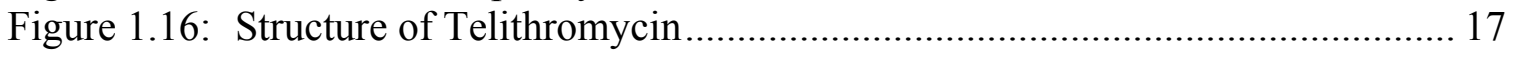

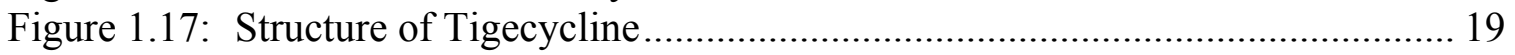

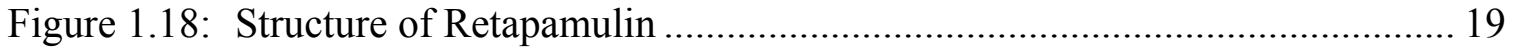

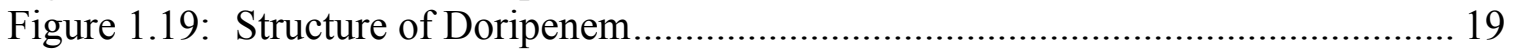

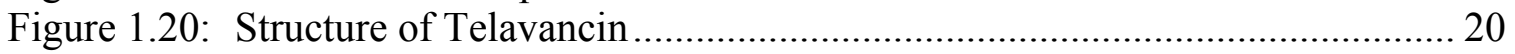

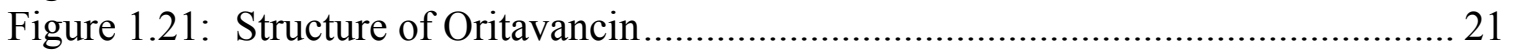

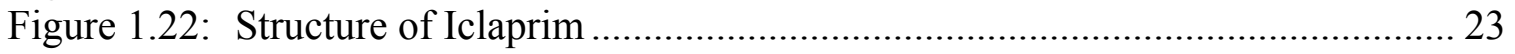

Figure 1.23: Structure of Ceftobiprole ................................................................... 23

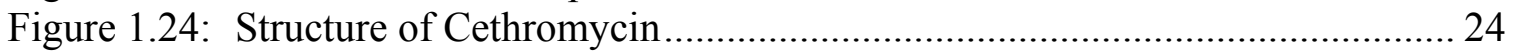

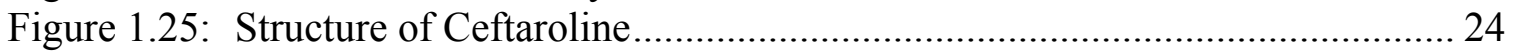

Figure 1.26: Structure of Fidaxomicin .................................................................... 25

Figure 1.27: Structure of Ramoplanin .................................................................... 25

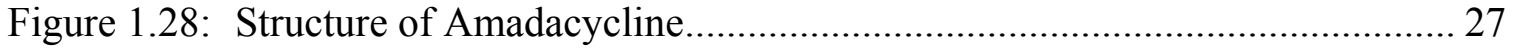

Figure 1.29: Structure of Delafloxacin ....................................................................... 27

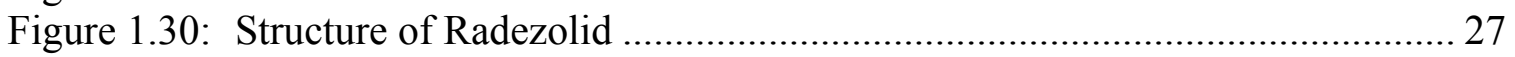

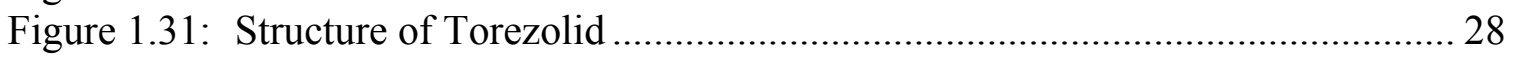

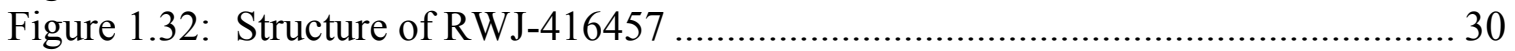

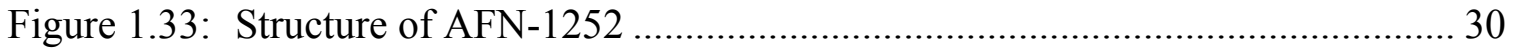

Figure 1.34: Structure of Platensimycin ................................................................ 30

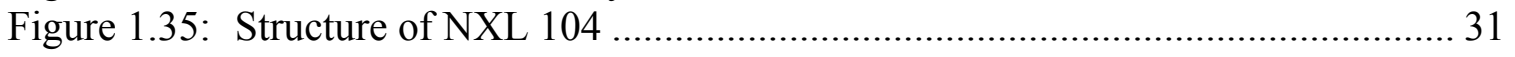

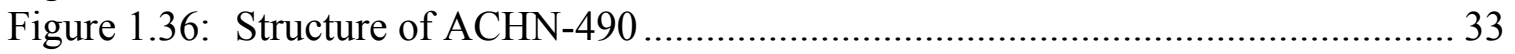

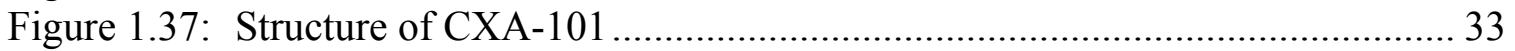

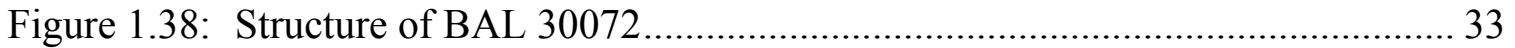

Figure 2.1: Structures of Anti-Tuberculosis Agents.................................................... 36

Figure 2.2: Structures of Second-Line Agents ....................................................... 36

Figure 2.3: Lead Compound 1 ................................................................................

Figure 2.4: Inhibitors of Mammalian Soluble Epoxide Hydrolase .................................40 


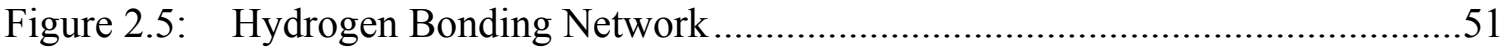

Figure 3.1: Quorum Sensing Molecules 1 and 2 .................................................62

Figure 3.2: Tautomers of Tetramic Acid Moeity ........................................................62

Figure 3.3: Structures of Tetramic Acid Containing Natural Products ..........................62

Figure 3.4: Preliminary Biological Evaluation of Tetramic Acid 1 ............................66

Figure 3.5: Repeat of Preliminary Biological Evaluation of Tetramic Acid 1 ..............66

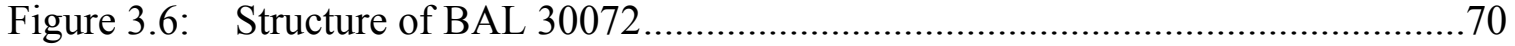

Figure 3.7: Relationship of BAL 30072 to Proposed Compound ..................................70

Figure 4.1: $\quad$ Structures for Future Direction of Urea Project..........................................79

Figure 4.2: Structure of Proposed Siderophore Antibiotic ...........................................79 


\section{LIST OF SCHEMES}

Scheme 2.1: Synthesis of First Urea Series ................................................................40

Scheme 2.2: Synthesis of Variations around Urea Moiety ..........................................42

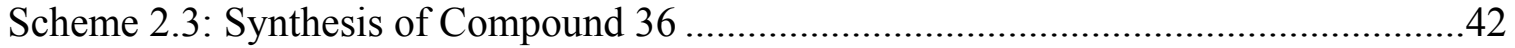

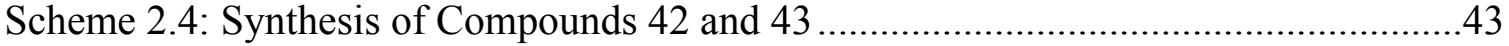

Scheme 3.1: Synthesis of Quorum Sensing Molecule 1 and Its Degradation Product......63

Scheme 3.2: Synthesis of Chelation Product for Tetramic Acid 1 .................................67

Scheme 3.3: Synthesis of Chelation Product for Lee 867 ..........................................67

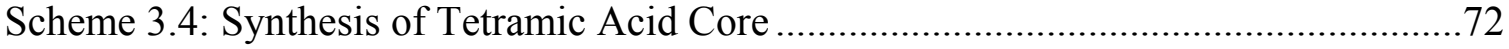

Scheme 3.5: Alternate Synthesis of Tetramic Acid Core ..............................................72 


\section{LIST OF ABBREVIATIONS}

\begin{tabular}{|c|c|}
\hline $\mathrm{ABC}$ & ATP-Binding Cassette \\
\hline AHLs & N-acylhomoserine lactones \\
\hline ATP & Adenosine Triphosphate \\
\hline cSSTI & Complicated Skin and Soft Tissue Infections \\
\hline DCCI & $N, N^{\prime}$-dicyclohexylcarbodiimide \\
\hline DHFR & Dihydrofolate Reductase \\
\hline DHPS & Dihydropteroate Synthase \\
\hline DMAP & 4-(dimethylamino)pyridine \\
\hline DMF & Dimethylformamide \\
\hline DNA & Deoxyribonucleic Acid \\
\hline $\mathrm{EH}$ & Epoxide Hydrolase \\
\hline EMB & Ethambutol \\
\hline $\mathrm{Fab}$ & Fatty Acid Biosynthesis \\
\hline FDA & Food and Drug Administration \\
\hline HIV & Human Immunodeficiency Virus \\
\hline $\mathrm{Hz}$ & Hertz \\
\hline INH & Isoniazid \\
\hline M & Molar \\
\hline MDR & Multidrug-Resistant \\
\hline MDR-TB & Multidrug-Resistant Tuberculosis \\
\hline $\mathrm{MeOH}$ & Methanol \\
\hline MIC & Minimum Inhibitory Concentration \\
\hline MRSA & Methicillin-Resistant Staphylococcus aureus \\
\hline $\mathrm{N}$ & Normal \\
\hline NADH & Nicotinamide Adenine Dinucleotide \\
\hline $\mathrm{NIH}$ & National Institutes of Health \\
\hline $\mathrm{nm}$ & Nanometer \\
\hline NMR & Nuclear Magnetic Resonance \\
\hline PABA & Para Amino Benzoic Acid \\
\hline PBPs & Penicillin Binding Protiens \\
\hline PDR & Pandrug-Resistant \\
\hline $\mathrm{PK} / \mathrm{PD}$ & Pharmacokinetic/Pharmacodymanic \\
\hline PZA & Pyrazinamide \\
\hline RIF & Rifampin \\
\hline RNA & Ribonucleic Acid \\
\hline rRNA & Ribosomal Ribonucleic Acid \\
\hline RT & Room Temperature \\
\hline SAR & Structure Activity Relationship \\
\hline sEH & Soluble Epoxide Hydrolase \\
\hline SM & Streptomycin \\
\hline TAACF & Tuberculosis Antimicrobial Acquisition and Coordinating Facility \\
\hline TB & Tuberculosis \\
\hline TFA & Trifluoroacetic Acid \\
\hline
\end{tabular}




$\begin{array}{ll}\text { THF } & \text { Tetrahydrofuran } \\ \text { TLC } & \text { Thin-layer Chromatography } \\ \text { tRNA } & \text { Transfer Ribonucleic Acid } \\ \text { UV } & \text { Ultraviolet } \\ \text { VRSA } & \text { Vancomycin-resistant Staphylococcus aureus } \\ \text { WHO } & \text { World Health Organization } \\ \text { XDR } & \text { Extensively Drug-Resistant } \\ \text { XDR-TB } & \text { Extensively Drug-Resistant Tuberculosis }\end{array}$




\section{CHAPTER 1: INTRODUCTION}

\section{Introduction to Antibacterial Agents}

Infectious diseases have been one of the greatest blights in the history of humanity. ${ }^{1}$ It was not until the discovery of the first antibacterial agent in the 1930s that a glimmer of hope was seen. That agent was Prontosil, and it was discovered by Gerhard Domagk in 1935 . $^{1-3}$ Prontosil was later found to be a prodrug that was metabolized in vivo to its active metabolite sulfanilamide (Figure 1.1). ${ }^{4}$ Prontosil was the first of the "sulfa" drugs discovered, and its discovery ushered in the era of antibiotics.

Antibacterial agents, or antibiotics, are a class of a much larger group of compounds called antimicrobial agents. Antibiotics used to refer to only naturally occurring molecules produced by a variety of microorganisms. ${ }^{5}$ However, the term has evolved to include man-made synthetic compounds as well. ${ }^{6}$ Antibiotics can be broken down into four distinct classes based upon their mechanism of action. Those four classes are (1) the agents that inhibit bacterial cell wall biosynthesis, (2) the agents that inhibit protein biosynthesis, (3) the agents that inhibit deoxyribonucleic acid (DNA) or ribonucleic acid (RNA) synthesis, and (4) the agents that inhibit folate synthesis. ${ }^{6}$

\section{Inhibitors of Bacterial Cell Wall Biosynthesis}

The bacterial cell wall plays a vital role in the survival and proliferation of the bacteria. There are also substantial differences between the mammalian cell wall and the bacterial cell wall, thus creating an attractive target for bacterial chemotherapy. This class of antibiotics contains two families of compounds that act upon various targets within the biosynthetic cascade of cell wall formation. Those two families are the $\beta$ lactams and the glycopeptides.

\section{$\beta$-lactams}

This family of compounds is comprised of four groups of molecules: (1) the penicillins, (2) the cephalosporins, (3) the carbapenems, and (4) the monobactams (Figure 1.2). This family of compounds all act via the same mechanism of action, and that is by binding and inhibiting the penicillin binding proteins (PBPs); more specifically they inhibit peptidoglycan transpeptidase causing lysis and cell death. ${ }^{1,6}$ The core structure of this family consists of an $\beta$-lactam core, which contains a carbonyl lactam structure this is essential for the activity of these molecules. ${ }^{1,7}$ To differentiate the various groups of molecules within this family, one must look at the ring that is fused to the $\beta$-lactam core. ${ }^{1}$ The first group of molecules is the penicillins, and they contain a saturated pentacyclic ring system fused to the core ring structure.

The penicillins have been greatly modified from the initial compound isolated, Penicillin G. These modifications occur off of the carbonyl position on the amide side 


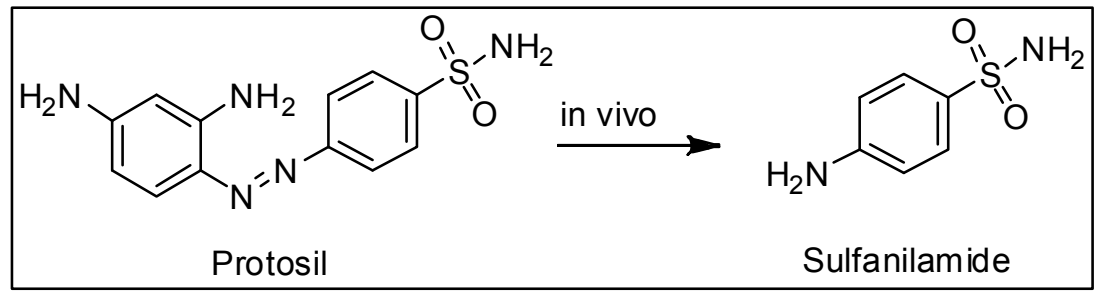

Figure 1.1: Activation of Prontosil to Sulfanilamide

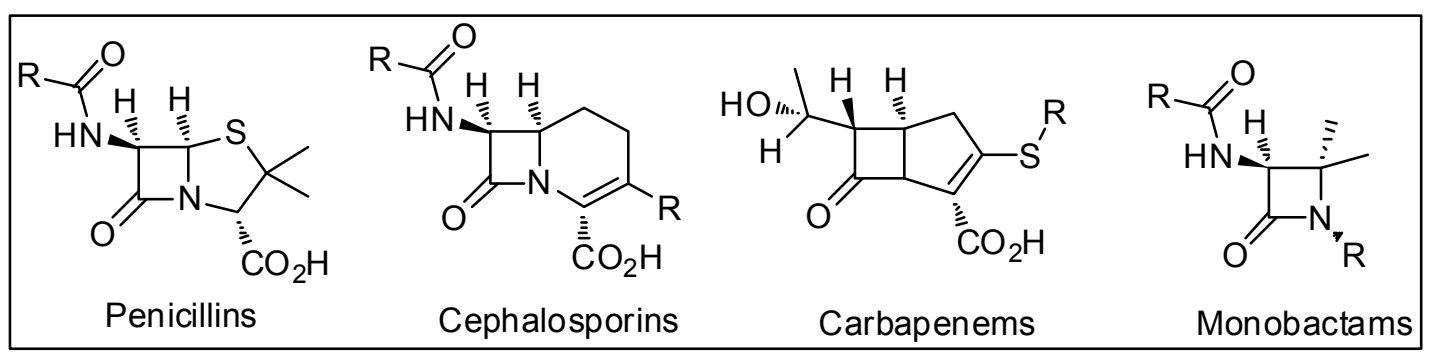

Figure 1.2: General Structures of the Four Classes of $\beta$-Lactam Antibiotics 
chain. ${ }^{8}$ The modifications have been made in an effort to improve the potency, oral bioavailability, antibacterial spectrum of activity, and decrease sensitivity to $\beta$ lactamases. $^{9}$

The next group of molecules in this family are the cephalosporins. This group is recognized by its unsaturated hexacyclic ring structure attached to the azetidinone core. The cephalosporins are the most widely prescribed and largest-selling group of the $\beta$ lactams. ${ }^{6}$ Since their discovery in the 1960 s, thousands of derivatives have been synthesized in an effort to increase the spectrum of activity and decrease the $\beta$-lactamase susceptibility of this group of compounds. ${ }^{1,5}$

The carbapenems are recognized by their unsaturated pentacyclic ring structure attached to the core $\beta$-lactam structure. These molecules exhibit a broad spectrum of activity, but have low oral bioavailability. ${ }^{1,5,10,11}$ This group of molecules possesses an added benefit of being resistant to most $\beta$-lactamases, thus increasing their potency and spectrum of action. 6,9

The final group of molecules in this family are the monobactams. These molecules are very easy to identify due to the fact that they only possess azetidinone core with no other fused ring system. These compounds are only active against gram negative pathogens, with good activity against $P$. aeruginosa. ${ }^{6,12-16}$ These molecules have a similar mechanism of action as the other $\beta$-lactam antibiotics, but they possess a specificity for PBP3 and can be complementary to other $\beta$-lactams. ${ }^{6,9}$

\section{Glycopeptides and Lipoglycopeptides}

This family of compounds was first discovered with vancomycin in 1956, and was later expanded to include lipoglycopeptides by Lancini in 1989 after the discovery of teicoplanin in 1978 (Figure 1.3). ${ }^{1,17}$ The mechanism of action of the family differs slightly from that of the $\beta$-lactams. The glycopeptides are able to cross the bacterial cell wall of gram-positive bacteria and bind to the terminal D-ala-D-ala dipeptide of the peptidoglycan precursor. The steric hindrance caused by these molecules blocks two key enzymatic reactions of peptidoglycan synthesis, transglycosylation and transpeptidation, ultimately causing inhibition of growth and death. ${ }^{1}$ These compounds are reserved as drugs of last resort due to their excellent activity against gram-positive bacteria, especially methicillin-resistant Staphylococcus aureus (MRSA). ${ }^{18}$

Inhibitors of Protein Biosynthesis

This class of compounds exert their antibacterial action by blocking one or more of the steps in protein biosynthesis that occur on either the $30 \mathrm{~S}$ or $50 \mathrm{~S}$ subunits of the bacterial ribosome. There are a number of families of molecules that make up this family including the macrolides, lincosamides, streptogramins, oxazolidinones, aminoglycosides, and tetracyclines. ${ }^{6}$ However, the major families that compose this 


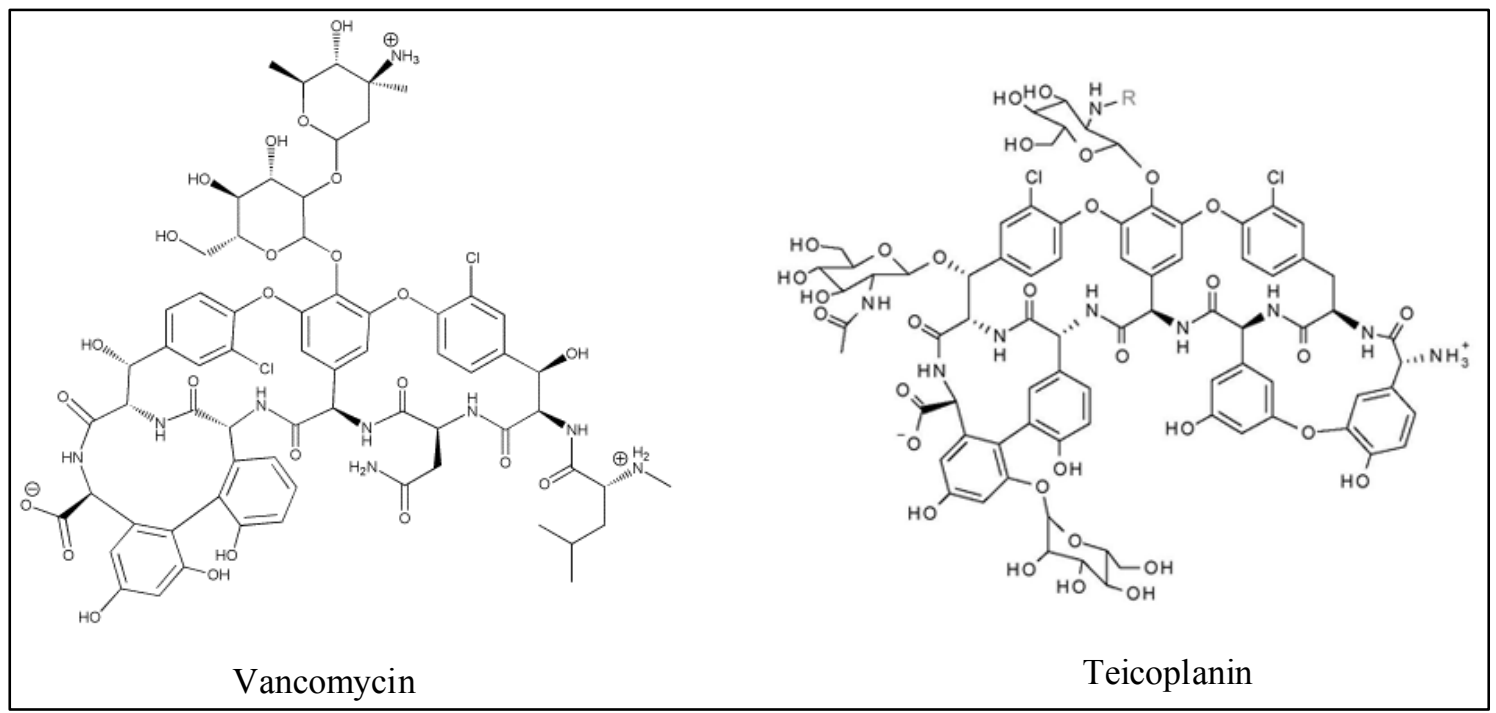

Figure 1.3: Structures of Vancomycin and Teicoplanin 
family are the aminoglycosides, macrolides, and tetracylines. Therefore these three groups will be discussed further in this section.

\section{Aminoglycosides}

This family of molecules all contain a pharmacophoric 1,3-diaminoinositol moiety (Figure 1.4). ${ }^{5}$ This family of compounds acts on the $30 \mathrm{~S}$ ribosomal subunit, more specifically the $16 \mathrm{~S}$ ribosomal ribonucleic acid (rRNA). ${ }^{19}$ Upon binding, they impair the proofreading ability of the ribosome; therefore causing mistranslation of RNA templates and consequent selection of wrong amino acids leading to the formation of nonsense proteins. ${ }^{5}$ This prevents the proper joining of the $30 \mathrm{~S}$ and $50 \mathrm{~S}$ ribosomal subunits leading to the inhibition of protein synthesis. These antibiotics are structurally diverse, and it has been suggested that the name of this family change to aminocyclitols in order to encompass the wide array of structures found in this class. ${ }^{20}$ These agents alone show potent activity against gram-negative bacteria, but lack potent activity against most grampositive bacteria. However, they are used in combination with $\beta$-lactams to treat some enterococcal infections. ${ }^{6,8}$

\section{Macrolides}

The name for this family of molecules is derived from the large lactone, cyclic ester, ring structure found in each of these compounds (Figure 1.5). ${ }^{5}$ These compounds exert their antibacterial action by binding reversibly to the $50 \mathrm{~S}$ ribosomal subunit and preventing protein elongation by blocking peptidyltransferase from forming peptide bonds between amino acids. ${ }^{21,22}$ These agents also block the assembly of the 50S ribosomal subunit through an interaction with the $23 \mathrm{~S}$ rRNA. ${ }^{23}$ A new derivation of this family has recently been discovered and approved for use in the United States, and they are the ketolides. In this subfamily, the $3-\mathrm{OH}$ is oxidized to a ketone, thus removing the site of attachment of the cladinose sugar. ${ }^{24}$ This entire family of agents is considered broad-spectrum antibiotics, especially as newer agents continue to be developed.

\section{Tetracyclines}

This family consists of molecules with a highly functionalized and partially reduced naphthacene (four linearly fused six-membered rings) ring system (Figure 1.6). ${ }^{5}$ These agents work at the $30 \mathrm{~S}$ ribosomal subunit and block the binding of incoming aminoacyl-transfer ribonucleic acid (t-RNA) to the A site resulting in termination of peptide chain elongation. ${ }^{5,6}$ This family of antibiotics are classified as broad-spectrum. However, due to their adverse side effects (staining of teeth and impairment of bone structure development) they are rarely the drug of choice for treatment, especially for children. ${ }^{5,25}$ 


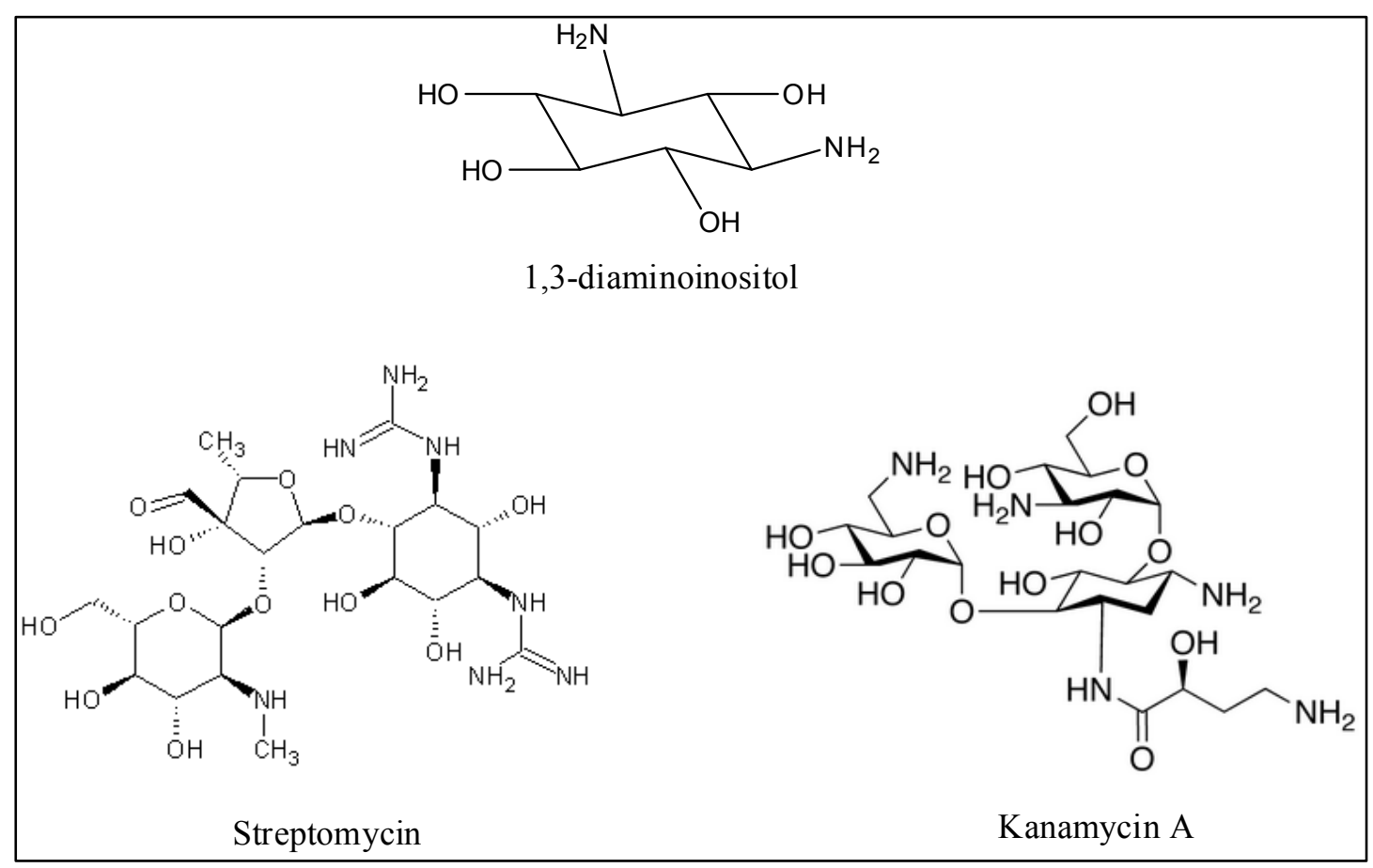

Figure 1.4: Structures of Aminoglycoside Antibiotics

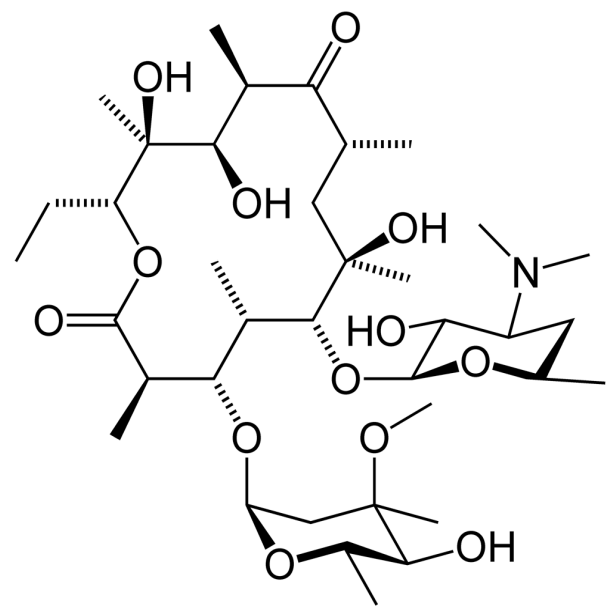

Erythromycin

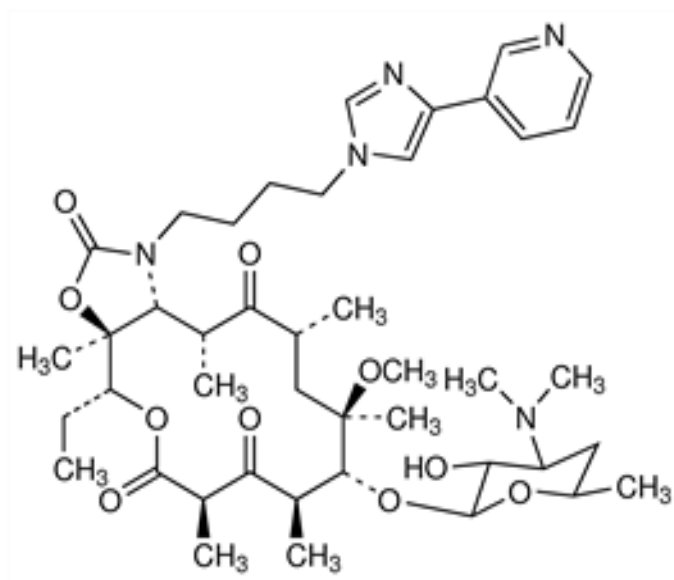

Telithromycin

Figure 1.5: Structures of Macrolide and Ketolide Antibiotics 


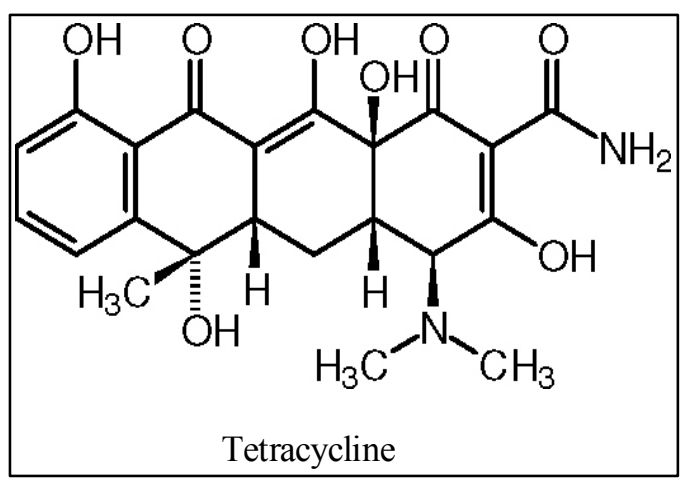

Figure 1.6: Structure of Tetracycline 
Inhibitors of DNA and RNA Synthesis

This class of antibiotics works on one of three targets: DNA gyrase, topoisomerase IV, or DNA-directed RNA polymerase. There are two families of antibiotics included within this class, and those are the quinolones and the rifamycins. The activity of the quinolones (Figure 1.7) is derived from their inhibition of DNA gyrase and topoisomerase IV. ${ }^{5}$ While DNA gyrase and topoisomerase IV have similar mechanisms of action, the difference is the fact that DNA gyrase is more important for gram-negative organisms and topoisomerase IV is more important for gram-positive organisms. ${ }^{9,26}$ The quinolones work by binding to DNA gyrase or topoisomerase IV and preventing the supercoiling of DNA, thereby inhibiting synthesis of DNA. ${ }^{6}$ The quinolones were not widely used until the discovery of the fluoroquinolones in the 1980 s. $^{27}$ There are currently four generations of quinolones that have been developed and are in clinical use.

The rifamycin family of antibiotics works on DNA-directed RNA polymerase. These agents bind to the $\beta$-subunit of DNA-directed RNA polymerase and inhibit the initiation of chain formation in RNA synthesis. ${ }^{6}$ Rifamycin is a natural product with several natural analogs, but three semisynthetic analogs have since been synthesized. Those agents are rifampin (Figure 1.8), rifabutin, and rifapentine. These agents are frontline agents in the treatment of tuberculosis.

Inhibitors of Folate Synthesis

Folate is critical to the survival of all living organisms. ${ }^{28}$ It plays a role in DNA synthesis by serving in the transfer of methyl, formyl, and other single-carbon fragments in the biosynthesis of purine nucleotides. ${ }^{29}$ Humans and bacteria obtain folate via different routes. Humans obtain folate through their diet, while bacteria synthesis folate through the folate biosynthetic pathway. This difference makes the folate biosynthetic pathway a very attractive drug target. ${ }^{28}$ There are two enzymes in this pathway that are currently targeted by antibacterial agents: dihydropteroate synthesis (DHPS) and dihydrofolate reductase (DHFR). The family of agents that act on DHPS is the sulfonamides. DHFR is acted upon by a single agent, and that is trimethoprim. ${ }^{5}$

\section{Sulfonamides}

The sulfonamides work by inhibiting DHPS, which catalyses the conversion of $p$ aminobenzoic acid (PABA) to dihydroteroate. ${ }^{30,31}$ Due to resistance issues, most of the originally developed sulfonamide drugs are no longer in use as a monotherapy. However, there are some still in use for acne and urinary tract infections. The most commonly used drug is in this class is sulfamethoxazole (Figure 1.9). This agent is often used in combination with trimethoprim, which expands it antibacterial spectrum and reduces the potential for the development of drug resistance. ${ }^{9}$ 


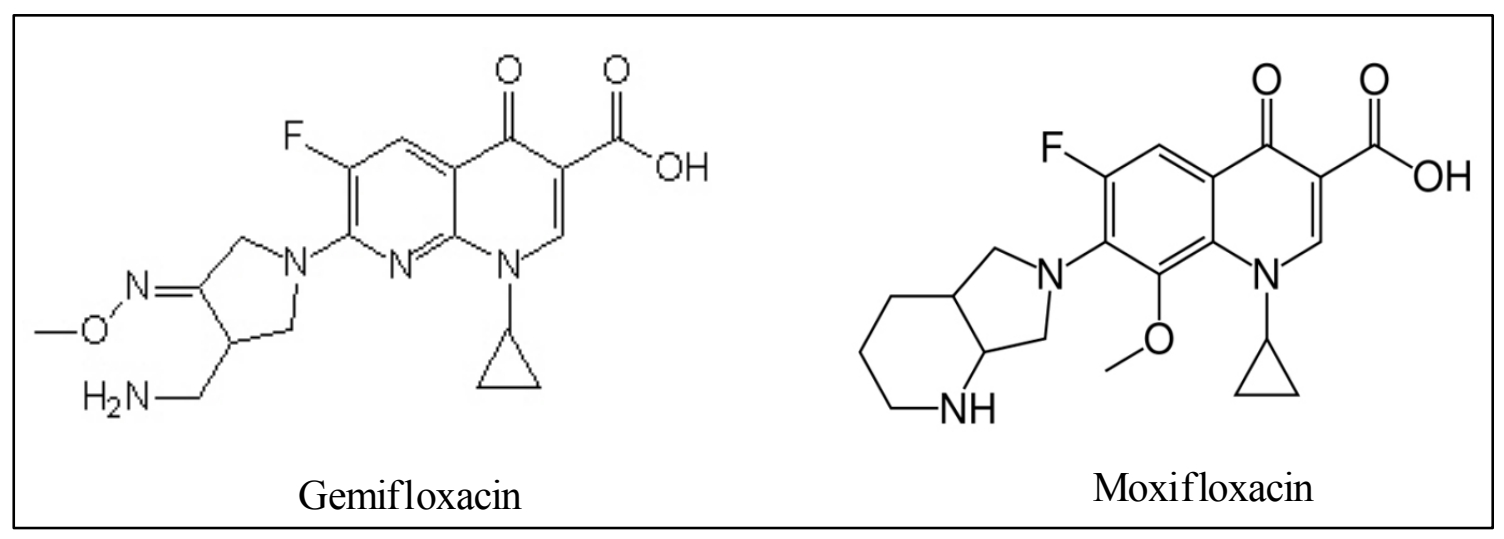

Figure 1.7: Structures of Quinolone Antibiotics

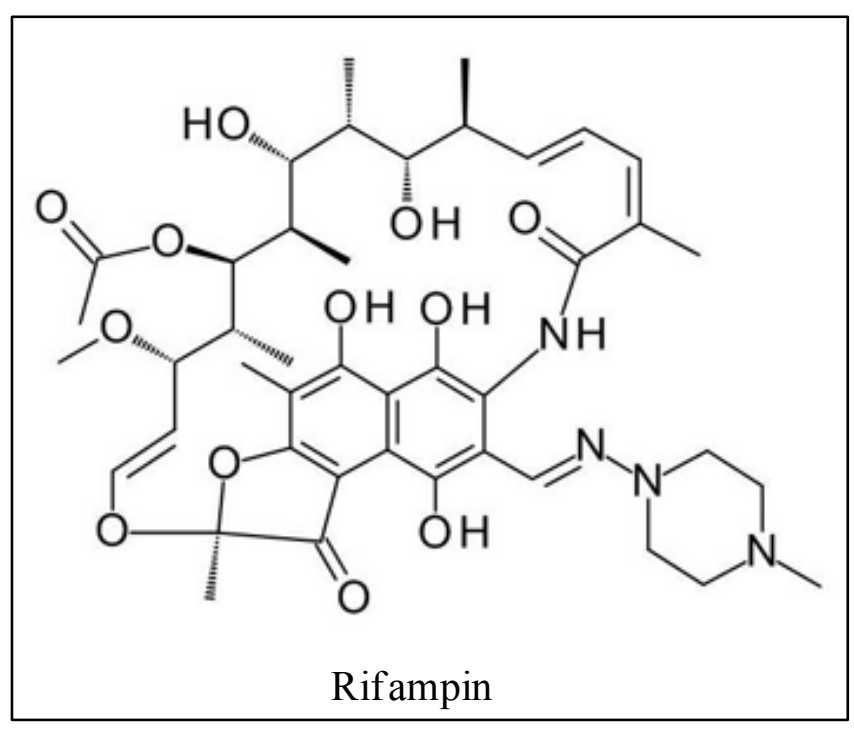

Figure 1.8: Structure of Rifampin 


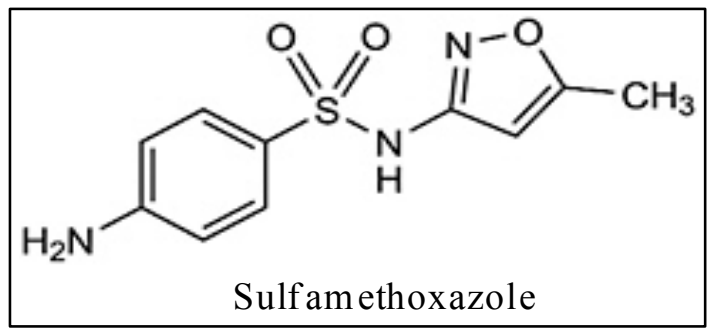

Figure 1.9: Structure of Sulfamethoxazole 


\section{Trimethoprim}

Trimethoprim works by inhibiting DHFR, which converts dihydrofolate into tetrahydrofolate. ${ }^{32}$ This enzyme is found in humans as well as bacteria, thus it is important that trimethoprim selectively inhibit the bacterial form of the enzyme. It is found that trimethoprim inhibits bacterial DHFR at a much lower concentration than the human DHFR, thus providing the basis for its selectivity. ${ }^{5}$ While trimethoprim (Figure $1.10)$ is often used in combination with sulfamethoxazole, it can also be utilized as a standalone agent. ${ }^{33}$

\section{The Need for Novel Antibacterial Agents}

The prevalence of drug resistant bacteria is growing at an alarming rate in both developing and developed countries. ${ }^{34}$ From this statement alone, it should be clear that the need for the development of novel antibacterial agents is of utmost importance. In the current antibacterial drug pipeline, there is only a miniscule glimmer of hope. ${ }^{34-38}$ This rapid increase in resistant bacteria coupled with the slow development of novel agents has lead some experts to call this time the "dawn of the post-antibiotic era."39-41

There exists a perpetual need for new antibiotics. Most drugs will be just as effective in the future as they are today, but that is not the case with antibiotics. Eventually, the inevitable rise of resistance will erode the utility of today's antibiotics. ${ }^{6,36}$ There are three factors that intensify this supply problem by discouraging antibiotic development. ${ }^{42}$ First, antibiotics are used in smaller quantities than other drugs. The standard antibiotic course lasts only weeks compared to treatment for chronic illness which can last a lifetime. Therefore, antibiotics yield lower revenues than most drugs. Second, the use of newly approved antibiotics is often limited to serious bacterial infections. The third reason is an increase in regulatory requirements to get a drug licensed, which makes clinical trials cost prohibitive. However, most newly approved drugs can be prescribed to all who may benefit from their use. These factors ultimately result in this quandary: Resistance is on the rise while antibiotic discovery and development are on the decline. ${ }^{36,43,44}$

Three classes of antibiotic-resistant pathogens are emerging as major threats to public health. The first pathogen of concern is MRSA. It is estimated that MRSA is responsible for approximately 19,000 deaths per year in the United States. The rising prevalence of MRSA increases the likelihood that vancomycin-resistant Staphylococcus aureus (VRSA), which is just as deadly as MRSA but more challenging to treat, will become a major concern in hospitals. ${ }^{45,46}$ The second class of pathogens are multidrugresistant (MDR) and pandrug-resistant (PDR) gram-negative bacteria. These bacteria may be less prevalent than MRSA, but they pose a severe risk of infections that are truly untreatable. These strains of Acinetobacter baumannii, Esherichia coli, Klebsiella pneumonia, and Pseudomonas aeruginosa are resistant to some (MDR) or all (PDR) of the antibiotics used to treat gram-negative bacteria: penicillins, cephalosporins, carbamenems, monobactams, quinolones, aminoglycosides, tetracyclines, and 


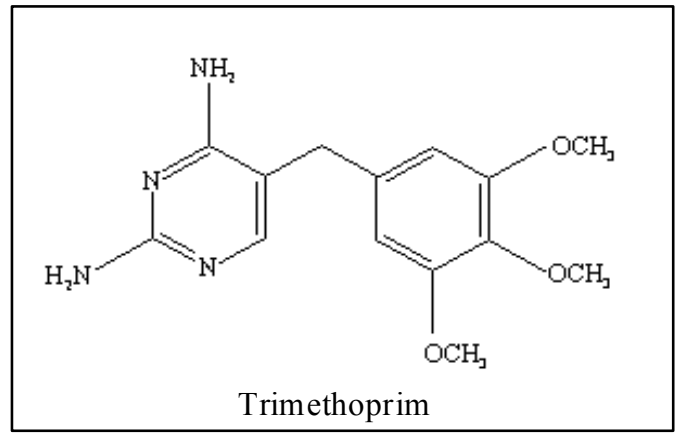

Figure 1.10: Structure of Trimethoprim 
polymixins. ${ }^{47}$ The third class of pathogens are MDR and extensively drug-resistant (XDR) strains of Mycobacterium tuberculosis. These strains are an ever increasing threat in developing nations. ${ }^{48}$ MDR-TB treatments requires a 2-year course of antibiotics with serious side effects; XDR-TB is even more difficult to treat and often fatal. ${ }^{49}$

The number of new antibiotic agents approved by the Food and Drug Administration (FDA) has fallen steadily since $1980 .{ }^{39}$ It is also pertinent to note that during that time 75 percent of the drugs approved were in two classes, beta-lactams and quinolones. Between 1935 and 1968 there were 14 classes of antibiotics introduced for human used; since then, only five have been introduced. Those five classes are; the oxazolidinones, lipopeptides, glycylcyclins, pleuromutilins, and mupirocin. ${ }^{39}$ While most new antibiotics come from existing classes, there is now more diversity within these classes. Also, these new agents may be more effective and safer than earlier drugs in their class. ${ }^{50}$

\section{New Antibiotics}

The FDA is the approving body for new antibiotics in the United States. Once a new drug has the approval of the FDA, it can be sold for use in the United States. Since 1998 , the FDA has approved a number of new antibiotics. However, only a limited number of these agents possess a novel mechanism of action. Having new antibiotics approved for use is a great thing, but those antibiotics which utilize the same mechanism of action as previously approved drugs always run the risk of increasing the rate of resistance. Drugs possessing a novel mechanism of action are greatly needed to help alleviate this burden.

Recently Approved Antibiotics

This section contains a list and description of each new antibacterial agent that has been approved since $2000 .^{39}$

\section{Linezolid}

This drug is sold under the brand name Zyvox (Figure 1.11). It was approved for use by the FDA in 2000. Sales of this drug are now over $\$ 1$ billion dollars per year. It is approved to treat VRE infections, as well as hospital- and community-acquired pneumonia and cSSTI caused by gram-positive organisms; including methicillin-resistant Staphylococcus aureus (MRSA). This is the first and only commercially available drug in the oxazolidinone class. This is a new class of antibiotics which acts by inhibiting protein synthesis in a novel way compared to currently known mechanisms of other antibiotics. 


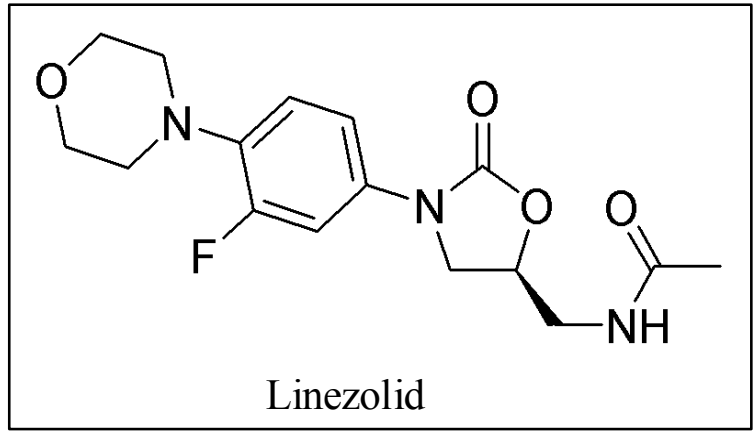

Figure 1.11: Structure of Linezolid 


\section{Cefditoren}

Sold under the brand name Spectracef, it was approved for use by the FDA in 2001 (Figure 1.12). It is approved for the treatment of bronchitis and communityacquired pneumonia caused by drug-susceptible gram-positive and gram-negative organisms. It is also used to treat uncomplicated skin- and soft-tissue infections caused by MSSA, as well as pharyngitis and tonsillitis caused by Streptococcus pyogenes. This drug is a third generation cephalosporin antibiotic.

\section{Ertapenem}

This drug is sold under the brand name Invanz (Figure 1.13). It was approved by the FDA in 2001. It can be used to treat intra-abdominal infections, community-acquired pneumonia, urinary tract infections, cSSTI, and acute pelvic infections caused by grampositive and gram-negative organisms. However, it lacks activity against Pseudomonas aeruginosa. This drug belongs to the carbapenem class of antibiotics.

\section{Gemifloxacin}

Sold under the brand name Factive (Figure 1.14), it was approved for use by the FDA in 2003. It is approved for the treatment of community-acquired pneumonia and bronchitis caused by gram-positive and gram-negative organisms; including multi-drug resistant Streptococcus pneumoniae. This drug belongs to the fluoroquinolone class of antibiotics.

\section{Daptomycin}

This drug is sold under the brand name Cubicin (Figure 1.15). It was approved for use by the FDA in 2003. Sales of this drug have reached over $\$ 600$ million dollars per year in the United States. It is approved for the treatment of cSSTI and bacteremia caused by gram-positive bacteria; including MRSA. Daptomycin belongs to the new lipopeptide class of antibiotics. It presents a novel mechanism of action by disrupting multiple aspects of bacterial cell membrane function.

\section{Telithromycin}

Sold under the brand name Ketek, telithromycin (Figure 1.16) was approved for use by the FDA in 2004. It is approved for use in the treatment of community-acquired pneumonia caused by gram-positive and gram-negative bacteria; including multi-drug resistant strains of Streptococcus pneumoniae. When first approved by the FDA, telithromycin was approved for use in treating numerous bacterial infections. However, due to safety issues with the drug, the FDA removed its approval to treat some infections and issued a black box warning for the drug in 2007 stating that patients with myasthenia gravis should not take this drug. ${ }^{51}$ Telithromycin is the first ketolide antibiotic to enter clinical use. 


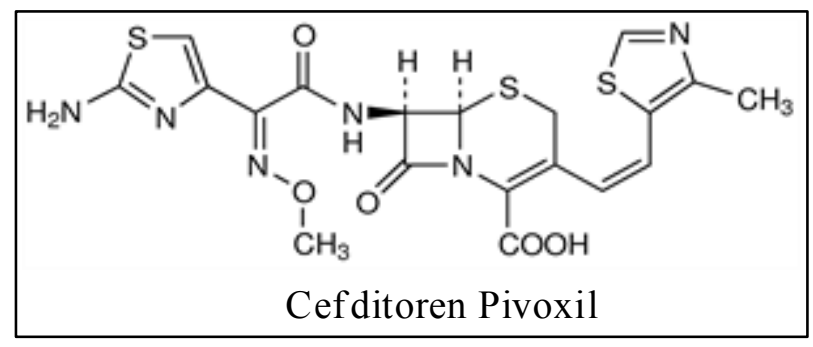

Figure 1.12: Structure of Cefditoren

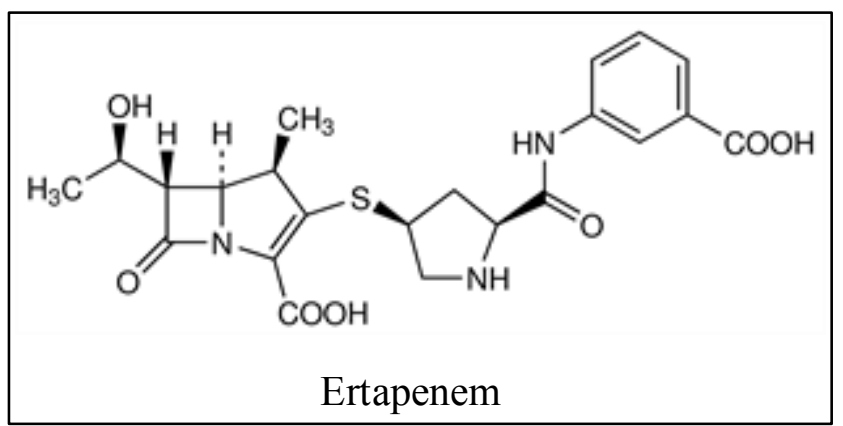

Figure 1.13: Structure of Ertapenem

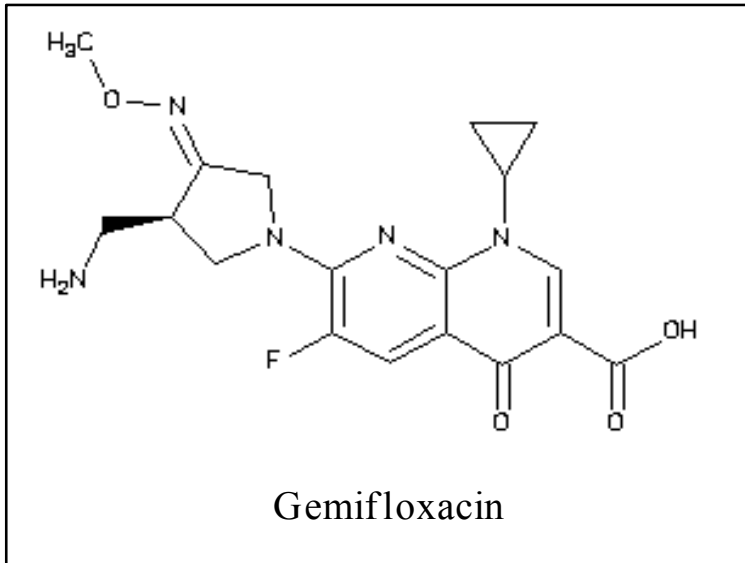

Figure 1.14: Structure of Gemifloxacin 


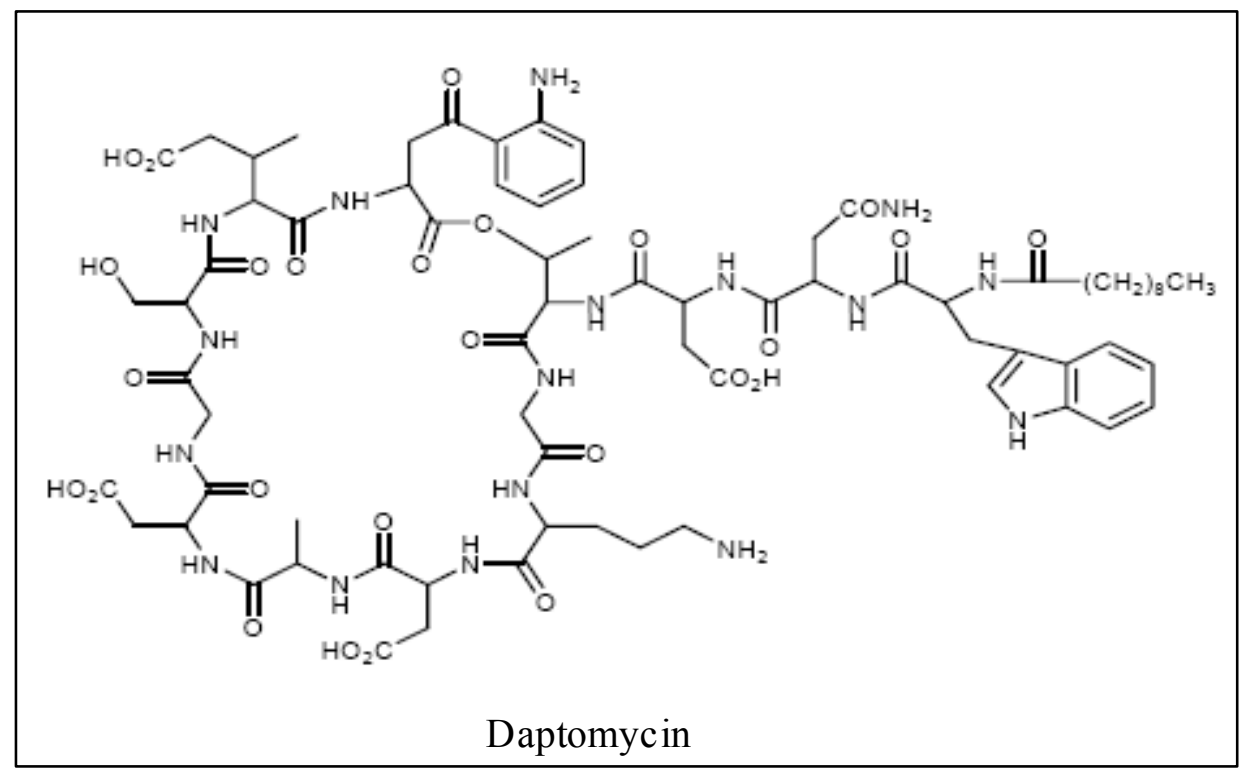

Figure 1.15: Structure of Daptomycin

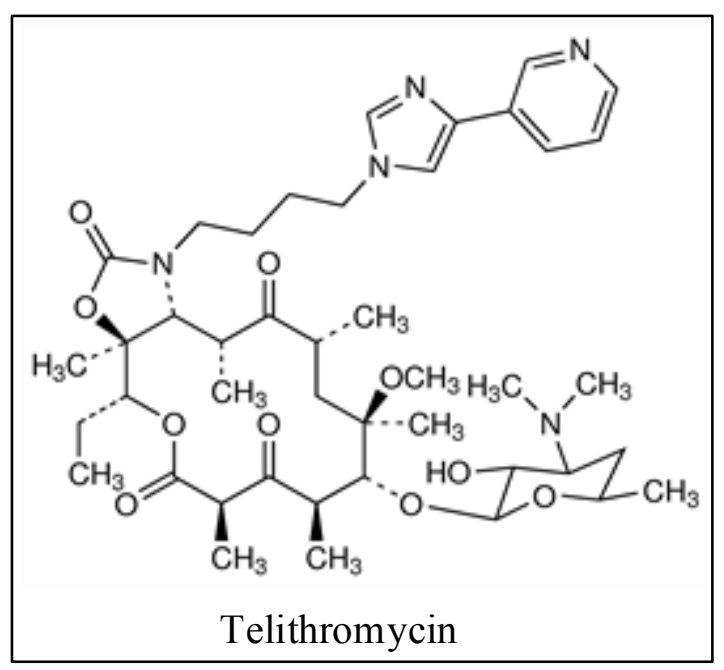

Figure 1.16: Structure of Telithromycin 


\section{Tigecycline}

Tigecycline is sold under the brand name Tygacil (Figure 1.17). It was approved by the FDA in 2005. It is used for the treatment of cSSTI and intra-abdominal infections caused by gram-positive and gram-negative bacteria; including MRSA. This agent belongs to the recently discovered glycylcycline subclass of tetracycline antibiotics.

\section{Retapamulin}

This drug is sold under the brand name Altabax (Figure 1.18). It was approved for use by the FDA in 2007. This agent is only approved for topical use in the treatment of impetigo caused by gram-positive infections. This drug is the first drug in the new class of pleuromutilin antibiotics to be approved for human use.

\section{Doripenem}

Sold under the brand name Doribax, Doripenem (Figure 1.19) was approved for use by the FDA in 2007. It is approved for the treatment of intra-abdominal infections and urinary tract infections caused by gram-positive and gram-negative bacteria. This agent is an ultra-broad spectrum injectable antibiotic belonging to the carbapenem class of antibiotics. It shows very good efficacy against Pseudomonas aeruginosa.

\section{Telavancin}

Telavancin is sold under the brand name Vibativ (Figure 1.20). It was approved for use by the FDA in 2009. It is approved for the treatment of cSSTI caused by grampositive bacteria; including MRSA. Telavancin is a member of the lipoglycopeptide class of antibiotics, and is a synthetic derivative of vancomycin.

\section{Antibiotics in the Pipeline: Gram-Positive}

This section contains information about agents that are currently in the pipeline for the treatment of gram-positive bacteria. ${ }^{35}$ In the current antibiotic pipeline, there are numerous potentially new agents that can be utilized to treat bacterial infections. The majority of those agents are aimed at treating infections caused by gram-positive organisms. A high percentage of these agents build upon previously known antibiotic groups. However, there are a handful of novel agents coming through the pipeline which have novel scaffolds and/or novel mechanisms of action.

\section{Oritavancin}

Oritavancin (Figure 1.21) is in the final stages of approval by the FDA. It has been temporarily rejected by the ruling body pending further clinical investigations into its safety profile. It belongs to the glycopeptides family of antibiotics, and is pending approval for the treatment of cSSTI. 


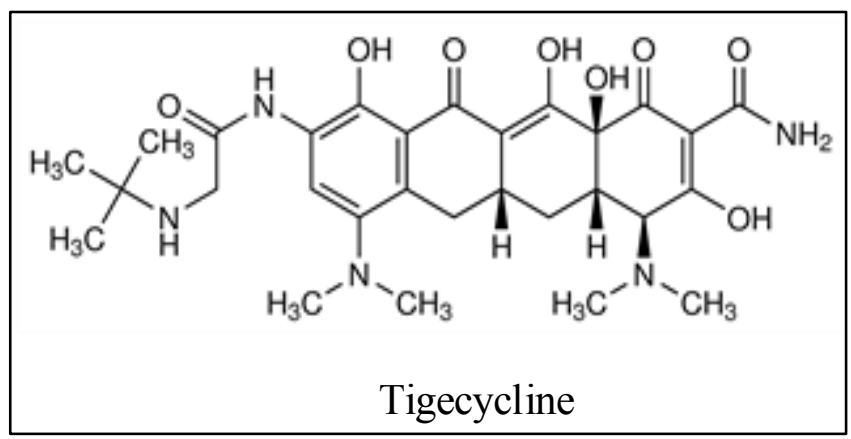

Figure 1.17: Structure of Tigecycline

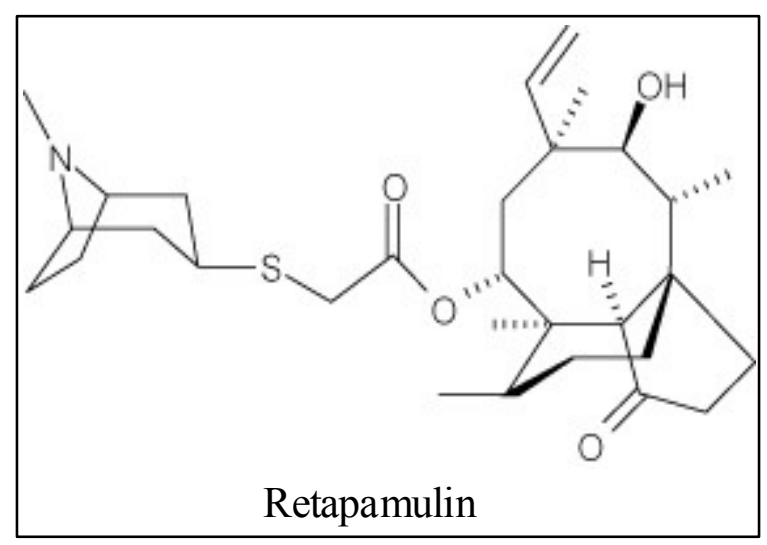

Figure 1.18: Structure of Retapamulin

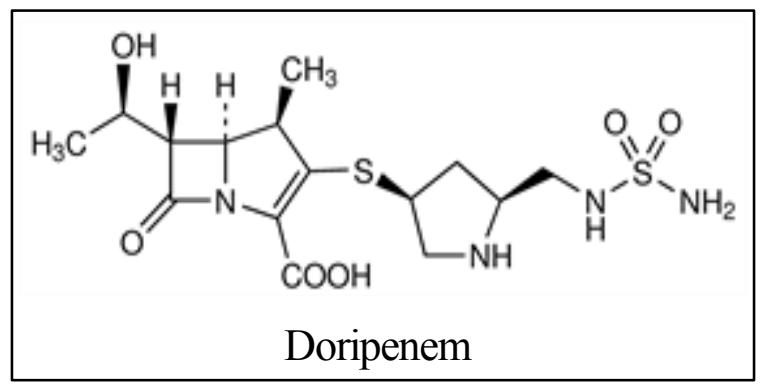

Figure 1.19: Structure of Doripenem 


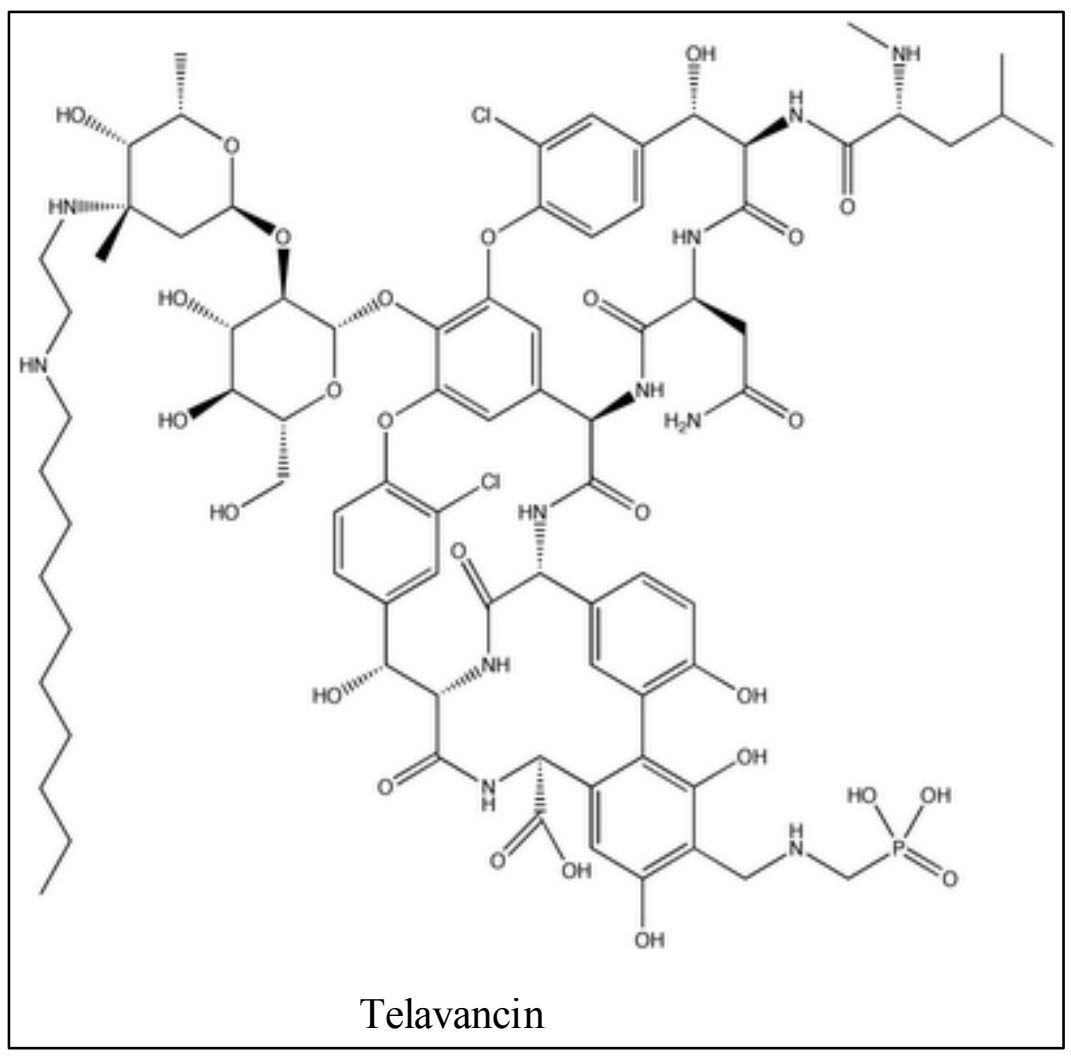

Figure 1.20: Structure of Telavancin 


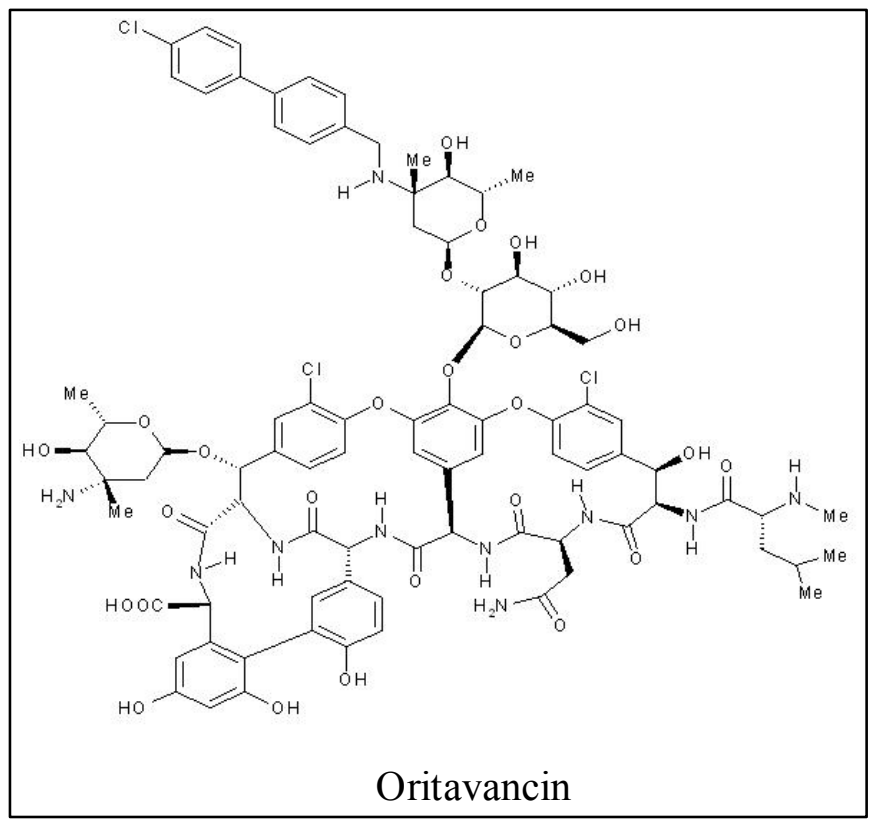

Figure 1.21: Structure of Oritavancin 
Iclaprim

This agent is currently under review by the FDA, but the FDA has ruled that it is not approvable in its current form. Iclaprim (Figure 1.22) is a 2,4-Diaminopyrimidine (structurally related to trimethoprim) which acts as a dihydrofolate reductase inhibitor. It is pending approval for the treatment of cSSTI.

\section{Ceftobiprole}

Ceftobiprole (Figure 1.23) is currently under review by the FDA, but the FDA has deemed that further clinical-site audits are necessary before a final review can be obtained. Ceftobiprole is a fifth-generation cephalosporin. This agent is being reviewed for the treatment of cSSTI; including diabetic foot infections. It is also currently undergoing Phase 3 clinical trials for the treatment of hospital-acquired pneumonia and severe community-acquired pneumonia. This agent is notable for its activity against MRSA.

\section{Cethromycin}

This agent is currently under review by the FDA (Figure 1.24). The FDA has deemed that further clinical site studies are needed in order for an approval to be obtained. This agent belongs to the macrolide subclass of antibiotics known as ketolides. It is being investigated for effectiveness against community-acquired pneumonia and against biodefense pathogens such as anthrax, plague, tularemia, and melloidosis.

\section{Ceftaroline}

This has completed Phase 3 clinical trials for the treatment of cSSTI and is currently in Phase 3 trials for the treatment of community-acquired pneumonia. It is a fifth-generation cephalosporin (Figure 1.25). This agent also shows promising activity against MRSA.

\section{Fidaxomicin}

This agent is currently undergoing Phase 3 clinical trials for the treatment of Clostridium difficile-associated diseases (Figure 1.26). This agent represents a new class of antibiotics for the treatment of these diseases; RNA polymerase inhibitor.

\section{Ramoplanin}

This agent is currently undergoing Phase $2 / 3$ trials for the treatment of Clostridium difficile-associated diseases resistant to vancomycin/metronidazole (Figure 1.27). It belongs to the glycolipdepsipeptide class of antibiotics and works by inhibiting cell wall biosynthesis. It has been fast-tracked by the FDA in hopes to expedite its approval. 


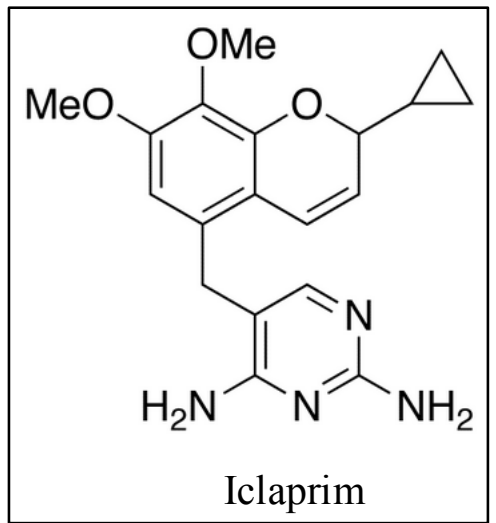

Figure 1.22: Structure of Iclaprim

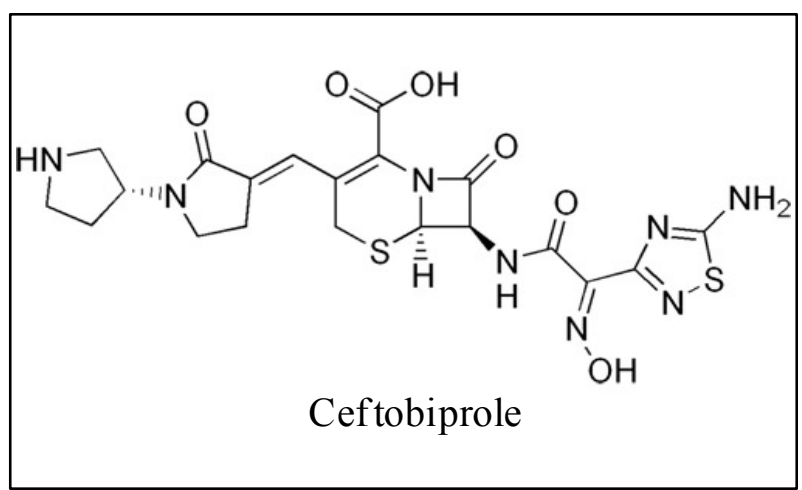

Figure 1.23: Structure of Ceftobiprole 


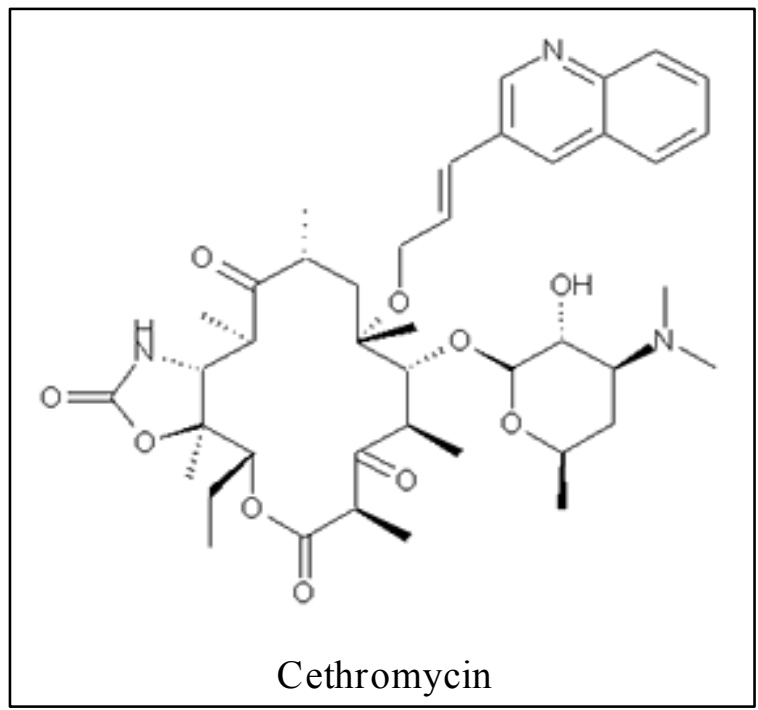

Figure 1.24: Structure of Cethromycin

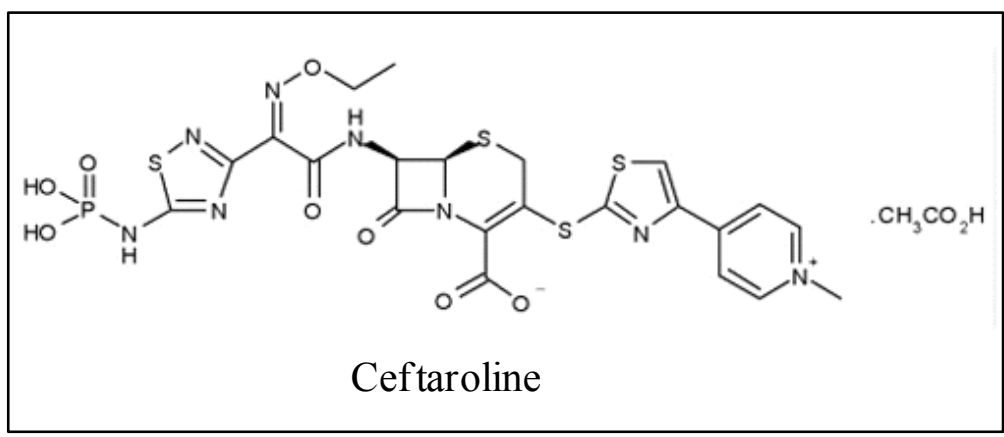

Figure 1.25: Structure of Ceftaroline 


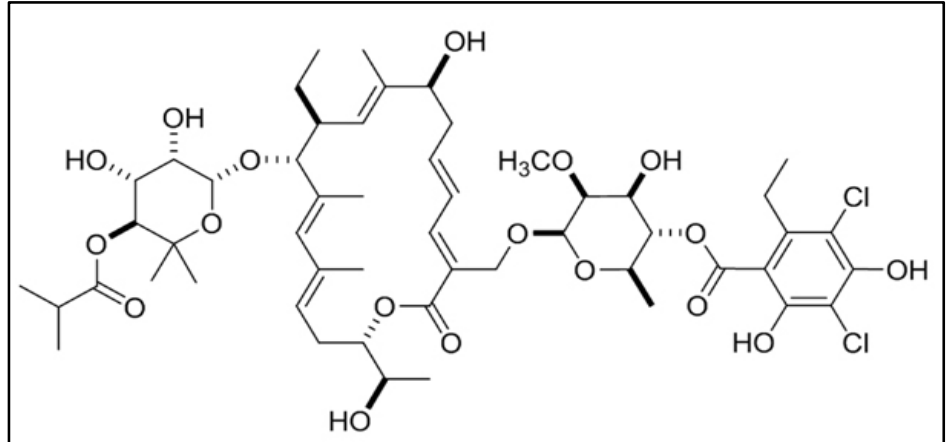

Fidaxomicin

Figure 1.26: Structure of Fidaxomicin

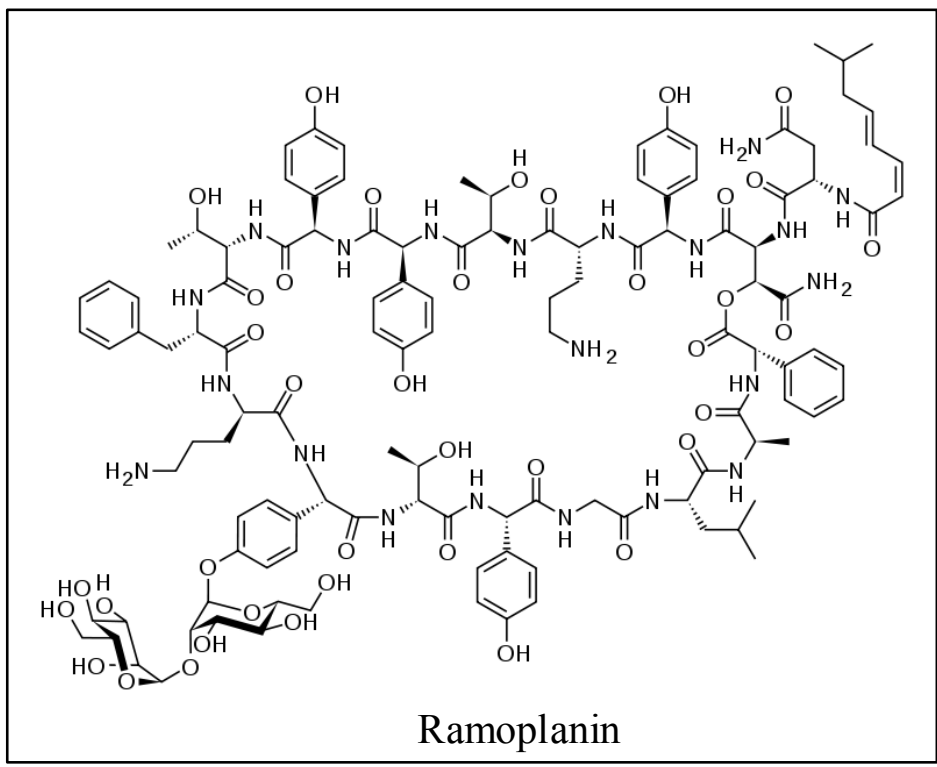

Figure 1.27: Structure of Ramoplanin 


\section{Pagibaximab}

Pagibaximab is a chimeric monoclonal antibody against lipoteichoic acid. This agent represents an agent with a novel mechanism of action in the treatment of bacterial infections. It is currently undergoing Phase $2 b / 3$ clinical trials as a staphylococcal prophylaxis in very low birth weight neonates.

\section{Phase 2 Completed}

All of the agents discussed in the section have all completed Phase 2 clinical trials, but have not yet moved on to Phase 3. The first agent is amadacycline (Figure 1.28). This drug is a tetracycline derivate, and is being investigated for the treatment of cSSTI, diabetic foot infections, and community-acquired pneumonia. The second agent that has completed Phase 2 trials is delafloxacin (Figure 1.29). It is a quinolone derivative that is being investigated for the treatment of cSSTI and community-acquired pneumonia. The final agent that has completed Phase 2 clinical trials is V710. This agent is a Staphylococcus aureus vaccine, which represents another novel mechanism of action in the treatment of gram-positive bacteria infections. It is being considered for a single dose treatment for patients scheduled for cardiothoracic surgery and kidney disease patients.

\section{Phase 2 Ongoing}

There are a number of agents in the antibacterial pipeline that are currently in Phase 2 clinical trials. The first agent is nemonoxacin. It is a non-fluorinated quinolone that is being investigated for the treatment of community- and hospital-acquired pneumonia and diabetic foot infections. The next agent, TD-1792, is a unique hybrid antibiotic. It combines the potency and efficacy of vancomycin and a cephalosporin in one antibacterial agent. It is targeted toward the treatment of cSSTI and bacteraemia. Radezolid (Figure 1.30) is the next agent currently undergoing Phase 2 clinical trials. It is a member of the oxazolidinone class of antibiotics. It is being tested for the treatment of mild-to-moderate community-acquired pneumonia and uncomplicated skin and soft tissue infections. PZ-601 is another agent in the pipeline undergoing Phase 2 trials. It is a carbapenem antibiotic that is being investigated for the treatment of cSSTI.

The next agent undergoing Phase 2 trials is NXL 103. This drug belongs to the streptogramin class of antibiotics. It is a combination of the agents linopristin and floprisitin. It is being investigated for the treatment of community-acquired pneumonia. Another agent currently undergoing Phase 2 trials is torezolid (Figure 1.31). Torezolid is an oxazolidinone antibiotic that is being investigated for the treatment of cSSTI and hospital-acquired pneumonia. WCK-771 is in Phase 2 clinical trials for the treatment of gram-positive infections. It is a quinolone antibiotic. More specifically, it is the active isomer of nadifloxacin. Finally, zabofloxacin is a quinolone antibiotic in Phase 2 trials for the treatment of community-acquired respiratory infections. 


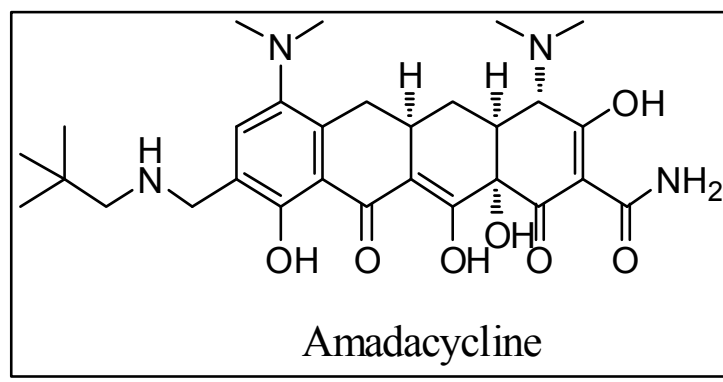

Figure 1.28: Structure of Amadacycline

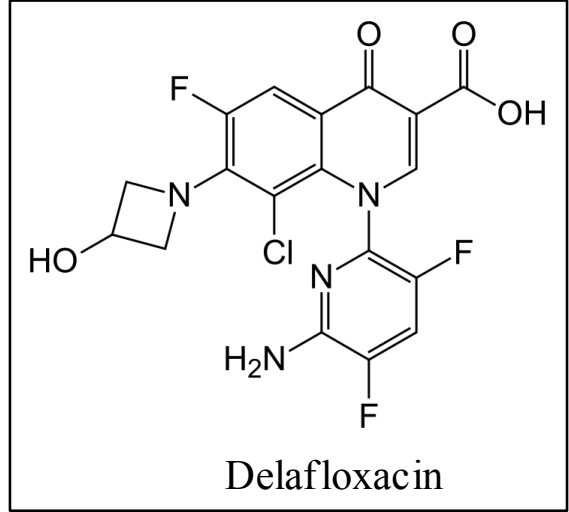

Figure 1.29: Structure of Delafloxacin

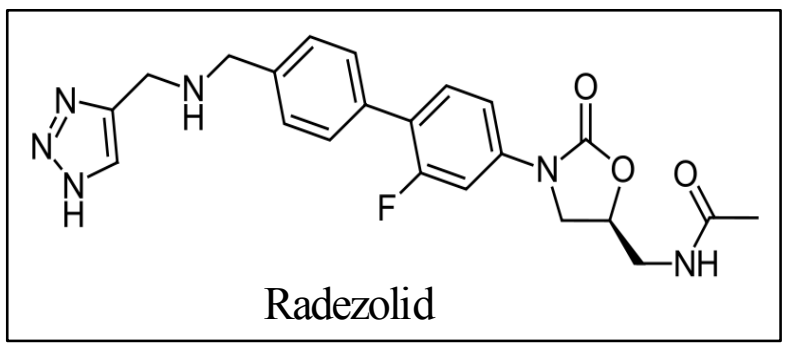

Figure 1.30: Structure of Radezolid 


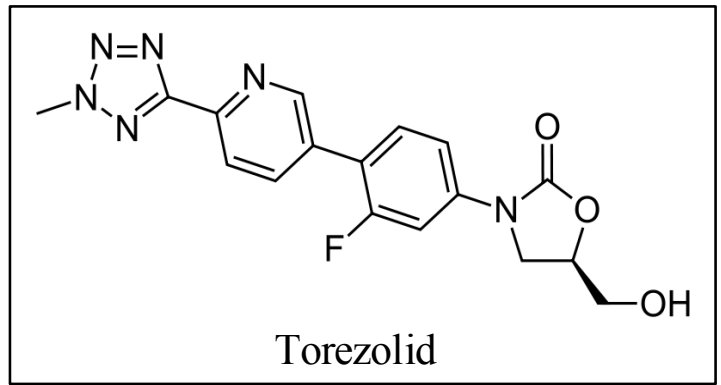

Figure 1.31: Structure of Torezolid 


\section{Phase 1 Completed}

There are two agents that have completed Phase 1 clinical trials, but have yet to advance on to Phase 2. The first agent is CEM-101. This agent is an oral macrolide antibiotic that is being investigated for the treatment of community-acquired pneumonia. The second agent that has completed Phase 1 clinical trials is BC-3205. This agent belongs to the pleuromutilin class of antibiotics, but unlike the current pleuromutilins which are topical agents, BC-3205 is an oral antibiotic. It is being investigated for the treatment of cSSTI and community-acquired pneumonia.

\section{Phase 1 Ongoing}

The agents in the section are currently involved in Phase 1 clinical trials. The first agent is RWJ-416457 (Figure 1.32). This agent belongs to the oxazolidinone class of antibiotics and is being investigated for the treatment of gram-positive infections. The next drug is PMX-30063. This is a very unique and novel agent. It is classified as a small molecule mimetic of a host defense protein, defensin. It is the first known small molecule mimetic of a host defense protein to enter human clinical trials for systemic use. This agent represents an entirely new class of antibiotic drugs. It is being investigated for the treatment of staphylococcal infections. The last two agents that are currently in Phase 1 clinical trials both represent a novel class of antibiotics, fatty acid biosynthesis (Fab) inhibitors. ${ }^{52}$ The first agent is AFN-1252 (Figure 1.33), and it is a FabI inhibitor. The second agent is platensimycin (Figure 1.34), and it is a FabF inhibitor. Both of these agents are being investigated for the treatment of staphylococcal infections.

Antibiotics in the Pipeline: Gram-Negative

Over the past several years, there has been a drastic increase in the number of multi-drug resistant isolates of gram-negative bacteria. ${ }^{53}$ The outlook for antibiotics that treat gram-negative infections is not as positive as in the gram-positive arena. This is causing major concern within the scientific community. There are currently no antibiotics being review for final approval by the FDA. There are not even any agents currently in Phase 3 clinical trials. This is a major issue because without any agents that have advanced past Phase 2 clinical trials, it will be at least 5 years before the first agent becomes routinely available in the clinic. While most of the agents in the pipeline are modifications of existing classes of antibiotics, there are a few novel classes rising through the pipeline as well. Given the widespread resistance problem and the propensity to intensify the effect of class-specific resistance, most scientists would prefer to have more novel classes with no pre-existing potential cross-resistance. ${ }^{54}$

\section{Phase 2 Ongoing}

There are currently three agents that are in Phase 2 clinical trials for the treatment of gram-negative bacteria. The first agent is combination agent. It combines ceftazidime and NXL 104 (Figure 1.35). Ceftazidime is a cephalosporin, and NXL 104 is a new 


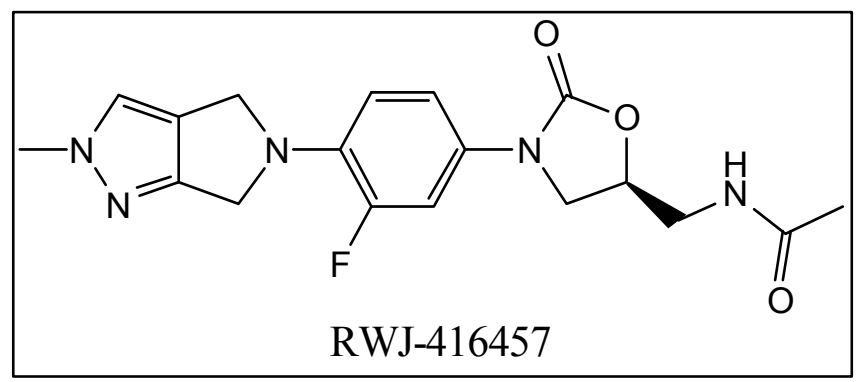

Figure 1.32: Structure of RWJ-416457

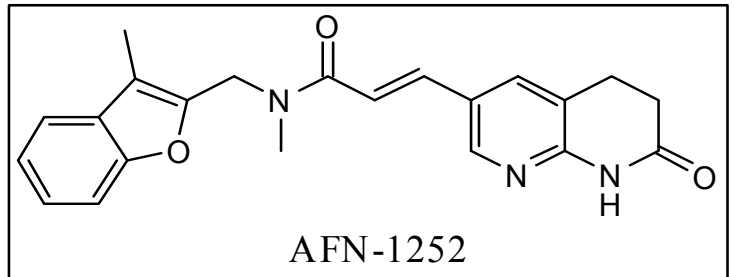

Figure 1.33: Structure of AFN-1252

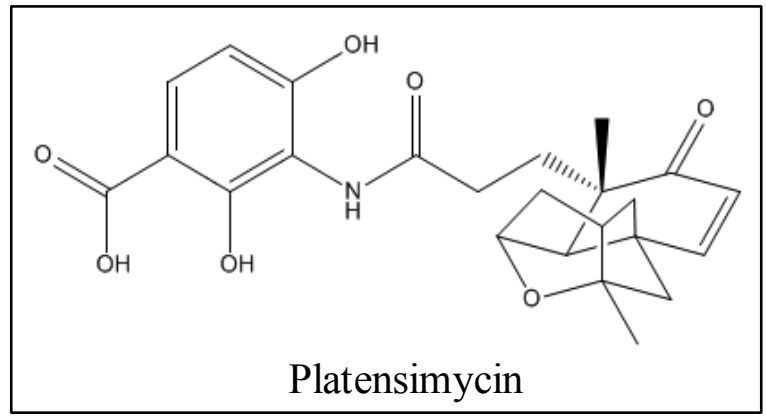

Figure 1.34: Structure of Platensimycin 


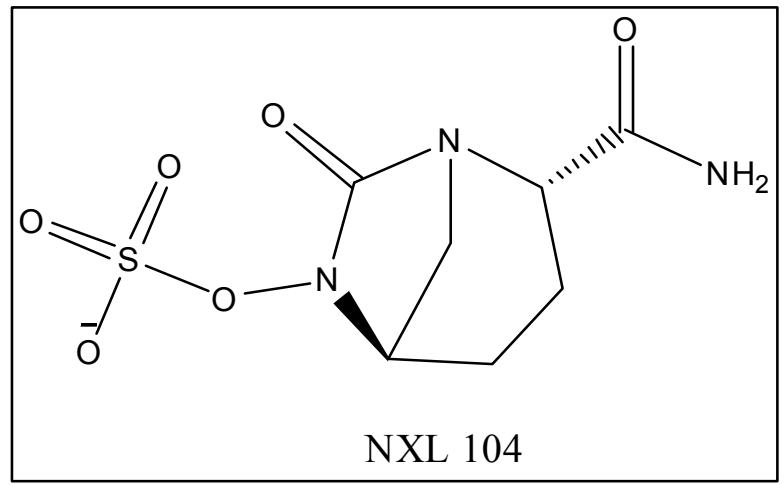

Figure 1.35: Structure of NXL 104 
$\beta$-lactamase inhibitor. These agents are used in combination so as to increase the cephalosporin's activity against most $\beta$-lactamase producing bacteria. This would be the first resumption of this established approach to protect a $\beta$-lactam antibiotic against resistance caused by $\beta$-lactamases since the approval of piperacillin/tazobactam in 1993 . This combination has been shown to be stable against class $A$ and class $C \beta$-lactamase, and is being tested for the treatment of complicated urinary tract infections.

The second agent in Phase 2 clinical trials is IC43. This is a recombinant subunit vaccine consisting of two outer membrane proteins of Pseudomonas aeruginosa. It is being tested for the treatment of ventilator-associated pneumonia. The final agent that is currently undergoing Phase 2 trials is KBPA101. This agent is a monoclonal antibody that targets Pseudomonas aeruginosa serotype O11. It is also associated with the codevelopment of a multivalent diagnostic test for rapid serotyping.

\section{Phase 1 Ongoing}

The first agent that is currently undergoing Phase 1 clinical trials is KB001. This is a humaneered monoclonal antibody fragment. It is an antivirulence antibody that targets PcrV protein of the Type III secretion system of Pseudomonas aeruginosa. It is being tested for the treatment of cystic fibrosis and ventilator-associated pneumonia. The next agent is ACHN-490 (Figure 1.36). It is an aminoglycoside that is active against

aminoglycoside-resistant gram-negative pathogens. The final agent is CB-182804. It is a lipopetide that shows activity against Escherichia coli, Acinetobacter, Pseudomonas aeruginosa, and Klebsiella.

\section{Pre-clinical}

There are a number of agents that are either currently in pre-clinical trials or have completed pre-clinical trials, but are not in Phase 1 trials. The first agent that has completed the pre-clinical trials is ceftaroline with NXL 104. This is another cephalosporin combined with a new $\beta$-lactamase inhibitor. This agent proves to be stable against class $\mathrm{A}$ and class $\mathrm{C} \beta$-lactamases. It is also shows efficacy against enterobacteria, Pseudomonas aeruginosa, and MRSA. The last agent that has completed clinical trials is POL 7080. POL7080 belongs to a novel class of antibiotics called protein epitope mimetics. This agent is specific for Pseudomonas aeruginosa.

The following agents are all currently involved in pre-clinical trials. The first is CXA-101 (Figure 1.37). This agent is a cephalosporin and is more stable against class $\mathrm{C}$ $\beta$-lactamases than ceftazidime. The next agent is BAL 30072 (Figure 1.38). It is a monobactam antibiotic. It is stable against class $C$ and class $B$ enzymes (metallo- $\beta$ lactamases). 


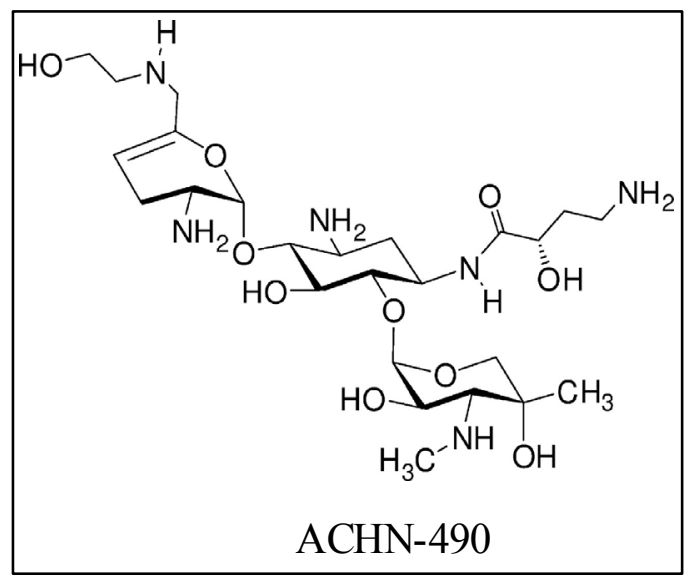

Figure 1.36: Structure of ACHN-490

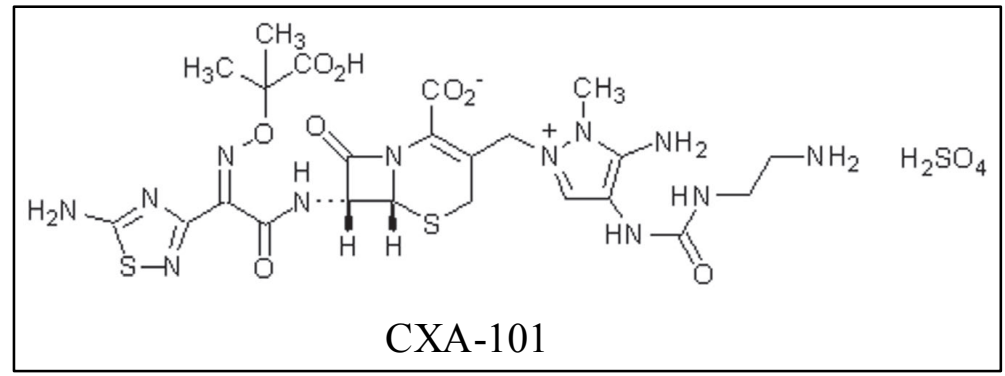

Figure 1.37: Structure of CXA-101

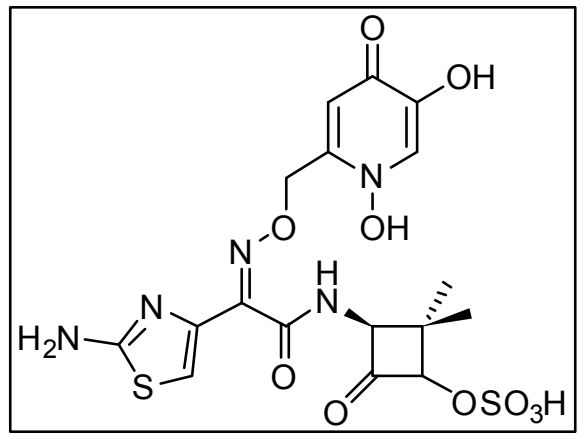

Figure 1.38: Structure of BAL 30072 


\section{Concluding Introductory Remarks}

The entire drug discovery process is mediated by the role that medicinal chemists play. Without the knowledge and guidance of medicinal chemists, the agents discussed in this chapter would, for the most part, not exist. Medicinal chemistry plays a pivotal in the process for drug development. Medicinal chemists can begin the discovery process by finding a hit compound. The hit compound can be identified in a number of ways; including computationally, through high-throughput screening, or chemical intuition developed over numerous years of training and study. From the hit compound, medicinal chemists can then lead that compound through the optimization process. During the optimization process, synthetic medicinal chemists utilize their training and knowledge to improve the potency, efficacy, and pharmaceutical profile of the hit compound into a lead compound. This lead compound can then begin evaluation for pre-clinical trials in hopes that it will enter clinical trials to become a marketable drug.

It is clear from the information presented in this chapter that the need to develop novel antibiotics is still strong. There has been a push to develop new agents for the treatment of gram-positive bacteria, due to the prevalence of MRSA, and that is now reflected in the antibiotic pipeline. There are several agents in advanced the advanced stages of approval for gram-positive infections. However, the real dilemma is present in the realm of gram-negative infections. There is an ever increasing prevalence of gramnegative bacterial resistance; this could be related to the push to develop new grampositive active agents while gram-negative infections were all but ignored. As of late, there has been a push to develop new gram-negative active agents. These agents are just beginning to filter into the antibacterial pipeline, and therefore have a long ways to go before they are available for human use. The time that is going to elapse between now and when these agents become available is going to be pivotal to see how bad the issue of gram-negative resistance becomes. The current antibacterial pipeline does show some promise for the future of antibacterial research, but it must people should not become lax. This field is always in need of novel research, and should not be neglected. 


\section{CHAPTER 2: NOVEL UREA DERIVATIVES AS ANTI-TUBERCULOSIS AGENTS}

\section{Introduction to Tuberculosis}

Mycobacterium tuberculosis is the causative agent of human tuberculosis (TB). This bacteria was first described in detail by Robert Koch in $1882 .{ }^{55,56}$ TB primarily manifests itself as a respiratory tract infection attacking the lungs, but it can also affect the central nervous system, lymphatic system, circulatory system, bones, joints, and even the skin. ${ }^{57}$ The respiratory manifestation of the disease can be easily spread via aerosol droplets that result from coughing, sneezing, speaking, or other forms of expulsion from the mouth and nose. ${ }^{58} \mathrm{~TB}$ is a deadly disease. It is estimated that one-third of the world's population (two billion people) is infected with the TB bacilli. Of the two billion people infected with the bacilli, approximately eight million will develop active tuberculosis and approximately 1.6 million people will die per annum. ${ }^{58-63}$

There are two stages of this disease: latent TB and active TB. ${ }^{64,65}$ In general, patients with the latent form of the disease are asymptomatic and not contagious. The opposite is true for patients with the active TB. Only about $5-10 \%$ of individuals with the latent form of TB will ever develop active TB. However, that statistic changes dramatically if the patient becomes immunocompromised, such as with human immunodeficiency virus (HIV). In such an instance, the rate increase to $10 \%$ per year. ${ }^{66}$ While TB is a very deadly disease, treatment options are available.

Treating Tuberculosis

Chemotherapy for TB started in the 1940s. In 1943, anti-TB research resulted in the discovery of active anti-TB agents, and strategies have been subsequently devised to treat $\mathrm{TB} .{ }^{58,67-70}$ Chemotherapeutic action is required once a patient develops active TB. There are two lines of agents used in the treatment of TB depending upon whether or not the bacteria have developed resistance to the first set of agents. The first-line therapy for TB consists of rifampin (RIF), isoniazid (INH), pyrazinamide (PZA), streptomycin (SM), and ethambutol (EMB) (Figure 2.1). The second-line agents, which are reserved for cases of resistance, retreatment, or intolerance to first-line drugs, include ethionamide, para-aminosalicyclic acid, cycloserine, capreomycin, and kanamycin (Figure 2.2). ${ }^{5}$ Due to the fact that TB has the ability to manifest itself in a latent state, and it is also a slow growing bacteria, the treatment time for a regimen of antibiotics is usually between 6-9 months to effectively rid the body of the bacteria. ${ }^{57}$ With the current antibiotics, regimens shorter than six months are not allowed due to the high rate of relapse. ${ }^{71}$ The reason the second-line agents are not used as first-line is due to the fact that although they are active against TB, they are usually not well tolerated having higher incidences of adverse side effects, and are less efficacious requiring even longer therapy to rid the body of the bacteria. ${ }^{5}$ 


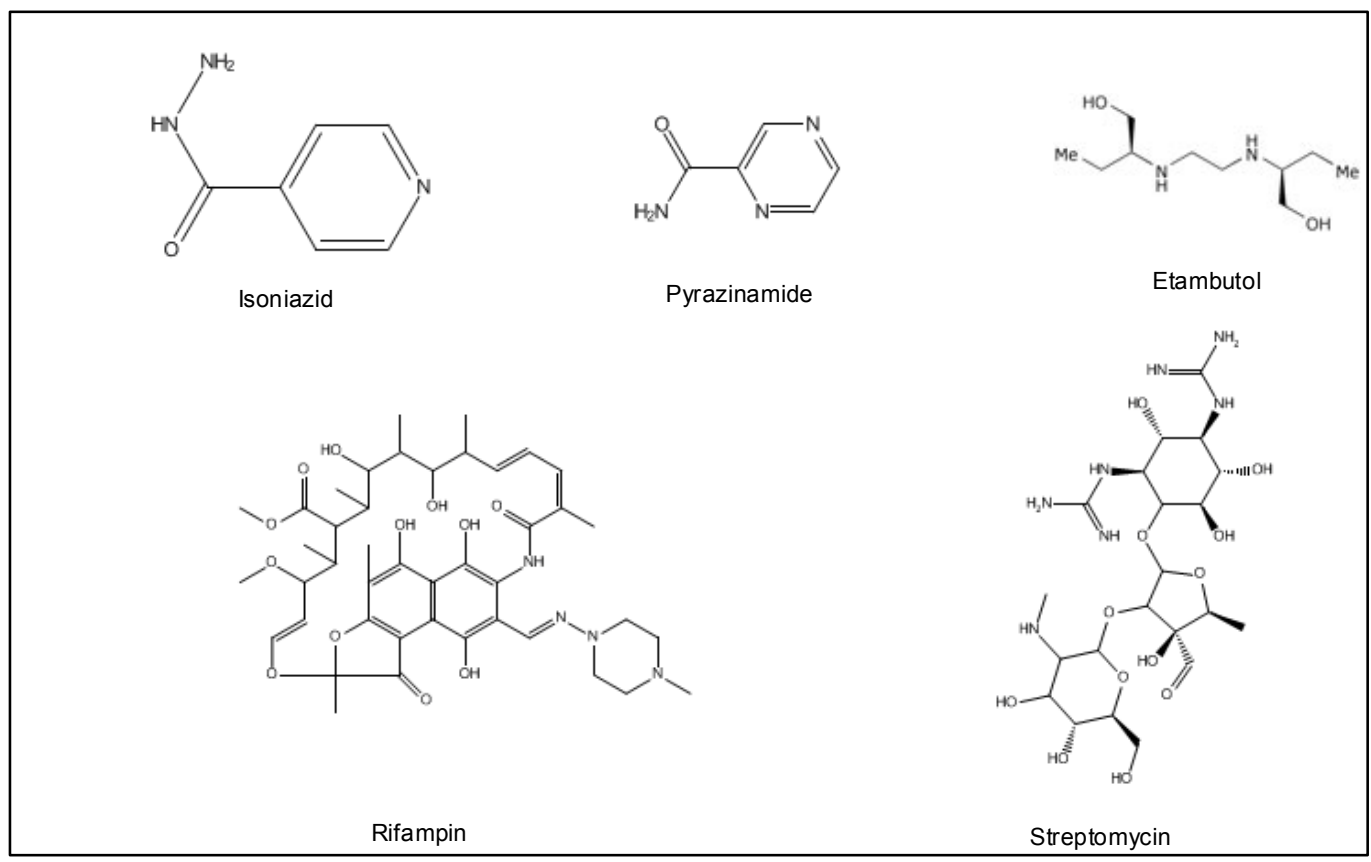

Figure 2.1: $\quad$ Structures of Anti-Tuberculosis Agents

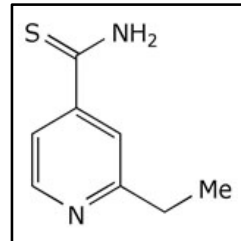

Ethionamide

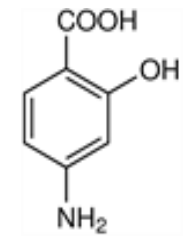

para-Aminosalicylic acid

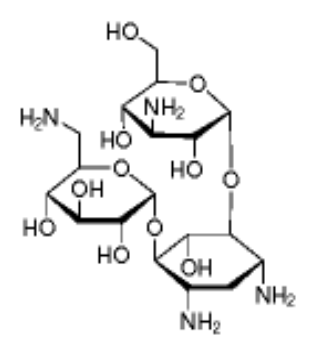

Kanamycin

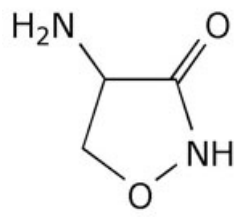

Cycloserine 


\section{Isoniazid}

The antibiotic isoniazid (INH) is an orally active synthetic agent that was discovered in the mid 1900s to be active against tuberculosis. However, INH is only active against the actively growing form of the bacteria. ${ }^{57} \mathrm{INH}$ exerts its antituberculosis activity by binding to one of the condensing enzymes (inhA) in the fatty acid biosynthesis pathway. ${ }^{72-75}$ A mutation within this gene was shown to confer resistance to $\mathrm{INH}$, thus suggesting that inhA is the target of this drug. ${ }^{76,77}$ It is a prodrug that must be enzymatically activated in the body. In the case of $\mathrm{INH}$, it is activated by the TB catalase-peroxidase enzyme (katG) to the activated radical acyl anion. ${ }^{7,79}$ This form of the drug reacts with nicotinamide adenine dinucleotide (NADH) to form a complex that binds tightly to inhA inhibiting the synthesis of mycolic acids in the mycobacterial cell wall. $^{72}$ It has been reported that NAD-adducts have a secondary effect on almost every aspect of mycobacterial metabolism. ${ }^{80}$

\section{Rifampin}

Rifampin is an orally active, highly effective semi-synthetic antibiotic. It shows bactericidal activity against all populations of mycobacteria. The introduction of rifampin to the standard treatment regimen reduced the duration of chemotherapy by half, from 18 to 9 months. ${ }^{57}$ RIF inhibits the $\beta$-subunit of RNA polymerase, thus preventing the transcription of DNA to RNA and the successive translation of proteins in mycobacteria. ${ }^{81}$ Resistance to RIF develops when a mutation occurs in the gene responsible for the $\beta$-subunit of the RNA polymerase (rpoB) causing the antibiotic to no longer be able to bind RNA polymerase. ${ }^{82}$

\section{Pyrazinamide}

Pyraziamide (PZA) is an orally active synthetic analog of nicotinamide. It exhibits slightly bactericidal activity on actively replicating bacteria, but overall is thought to act by a sterilizing effect. ${ }^{58}$ The activity of PZA is $\mathrm{pH}$ dependent. Good in vivo activity is seen at $\mathrm{pH} 5.5$, but it is nearly inactive at neutral $\mathrm{pH}^{5}{ }^{5} \mathrm{PZA}$ is also a prodrug that must be enzymatically activated by pyrazinamidases to convert it to its active from, pyrazinoic acid, which inhibits energy metabolism. ${ }^{83-85}$ The introduction of PZA into the treatment regimen reduced treatment time from 9 months to $6.5,86,87$

\section{Ethambutol}

Ethambutol (EMB) is synthetic amino alcohol. ${ }^{88-90}$ Ethambutol is a bacteriostatic agent that inhibits arabinogalactan biosynthesis, a primary component of the mycobacterial cell wall. ${ }^{91,92}$ It disrupts the cell wall of the mycobacteria allowing for other agents to better penetrate the bacilli and destroy it more effectively. EMB resistnace involves a gene over expression and mutations of arabinosyl transferase which is encoded by the $e m b B$ gene. ${ }^{92,93}$ 


\section{Streptomycin}

Streptomycin is an aminoglycoside antibiotic. ${ }^{58}$ It is bacteriostatic, and used in the treatment of drug resistant tuberculosis. ${ }^{57}$ Streptomycin acts by penetrating the inner membrane of Mycobacterium tuberculosis and binding to the 30S ribosomal subunit, thus inhibiting protein synthesis. ${ }^{94}$ This agent is associated with many toxic manifestations on the peripheral and central nervous system at higher doses, and hypersensitivity reactions, therefore it is not a drug of popular choice. ${ }^{58}$

\section{Need for Novel Anti-Tuberculosis Agents}

A number of once active anti-tuberculosis drugs are now inactive due to the ever increasing rise in drug resistant strains of tuberculosis. ${ }^{58}$ This is a frightening statistic in itself, but coupled with the fact that there have been no new first-line chemotherapeutic agents developed to combat TB in the last 35 years, it becomes staggering. ${ }^{9}$ While these agents may still be effective, there are still problems in treating TB, including poor patient compliance which leads to the development of more drug resistant strains. There is a lack in patient compliance due in large part to the fact that the current treatment regimen lasts 6-9 months. The length of the treatment is due to the difficulty in killing off the latent and slow-growing bacteria. Drug-resistant TB is a major public health issue in many developing countries around the world. ${ }^{59}$

The appearance of multi-drug resistant TB (MDR-TB) occurs when drugsusceptible TB is improperly or incompletely treated. According to the World Health Organization (WHO), MDR-TB is defined as a resistance to the two most effective firstline TB agents: rifampin and isoniazid. ${ }^{59}$ When a strain of TB becomes unresponsive to any fluoroquinolone and at least one of the three second-line agents (capreomycin, kanamycin, and amikacin), it becomes described at extensively drug-resistant TB (XDRTB). ${ }^{59}$ There are several ways in which a person can become infected with drug-resistant $\mathrm{TB}$, including not taking the prescribed course of drugs appropriately or becoming infected by an individual with a drug-resistant strain. ${ }^{65}$ As is evident by these facts, there is an ever growing need to develop novel agents for the treatment of tuberculosis. These new agents need to be potent, fast-acting, have an excellent pharmacokinetic/pharmacodynamic (PK/PD) profile, have a high therapeutic index, and preferably have a novel mechanism of action as to avoid cross-resistance with other agents.

\section{Targeting Epoxide Hydrolase}

Increasing drug resistance and poor activity of existing therapies towards the latent stage of Mycobacterium tuberculosis infection has produced a clear need to develop novel therapeutics to treat tuberculosis. ${ }^{95}$ Thus fast-acting drugs with novel mechanisms of action that are not cross resistant to existing drugs are being sought actively. To tackle this problem two primary screening strategies are being applied in 
tuberculosis drug discovery-target based high throughput screening and phenotypic minimum inhibitory concentration (MIC) based screening of whole cell bacteria.

Although target / enzyme based high throughput screening for new tuberculosis therapeutics has been widely adopted, this strategy has not produced many notable successes. This experience mirrors the success of other antibacterial drug discovery

programs. ${ }^{96}$ On the contrary, phenotypic direct MIC based screening of commercial and proprietary libraries has recently produced a number of interesting clinical candidates including the diaryl quinolone, TMC207, and benzothiazinone, BTZ043, ${ }^{97,98}$ for which the ultimate enzymatic target and antitubercular mode of action for these compounds was derived after potent inhibitors were identified.

We have adopted an analogous phenotypic screening approach to screen various available chemical libraries directly for anti-tuberculosis activity and then follow up hits that are shown to be selective with mode of action studies to produce novel validated anti-tubercular drug candidates. ${ }^{99}$ This study included the screening of a compound library from LeadScreen (Tripos) for anti-tuberculosis activity by microbroth dilution in Middlebrook 7H9 media. This screen identified urea derivative 1, which displayed an $\mathrm{MIC}$ of $0.3 \mu \mathrm{M}(0.01 \mu \mathrm{g} / \mathrm{ml})$ (Figure 2.3). Interestingly, the structure of the urea compound $\mathbf{1}$ is very similar to inhibitors of mammalian soluble epoxide hydrolase $(\mathrm{sEH})^{100}$ (Figure 2.4) and the recently reported inhibitors of the tuberculosis epoxide hydrolase $(\mathrm{EH})$ enzyme B. ${ }^{101}$

Initially it was thought that the tuberculosis genome contained six putative EH enzymes, but it is now suggested that the M. tuberculosis genome contains at least 30 members of the EH family. ${ }^{101}$ Consequently, these enzymes may represent good targets for tuberculosis drug discovery as they play essential roles in the detoxification of various substances in addition to lipid metabolism. Since $M$. tuberculosis contains several EHs, which are likely to be redundant, a target driven approach appears inferior to the phenotypic MIC for rapidly determining the initial therapeutic potential of EH inhibition. Currently, there are no reports on the whole cell anti-tubercular activity of EH inhibitors. In this study, the three sections of hit $\mathbf{1}$ were systematically modified to develop a detail anti-tubercular structure activity relationship for this series of compounds that represent analogs of EH inhibitors.

\section{Chemistry}

The optimization of compound $\mathbf{1}$ began by modifying each side of the urea moiety with a selection of substituents to probe the anti-tubercular structure activity relationship. These positions are shown as R (aryl) and R' (adamantyl). The synthesis of these derivatives was carried out by reacting the desired amine and with an isocyanate in dichloromethane in the presence of triethylamine (Scheme 2.1). Using this facile 


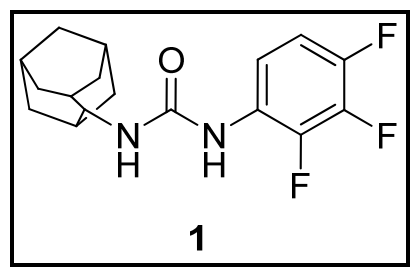

\section{Figure 2.3: $\quad$ Lead Compound 1}

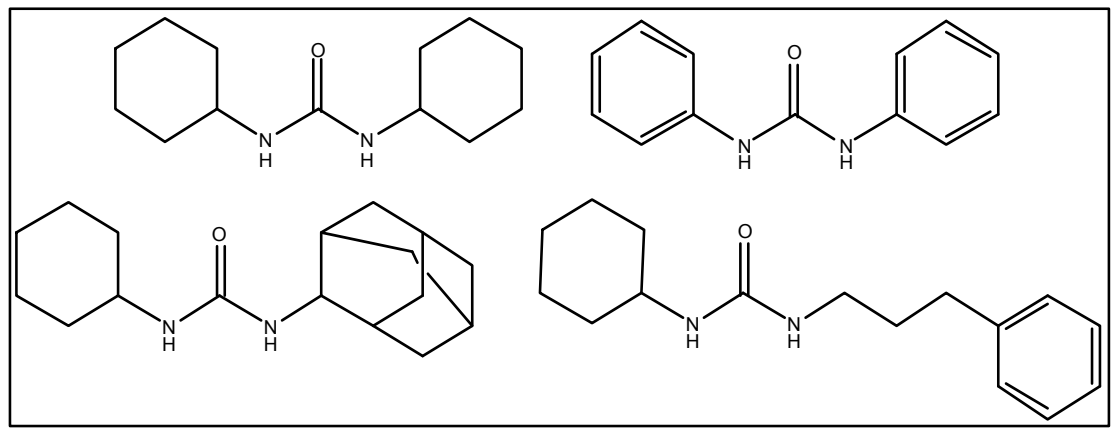

Figure 2.4: Inhibitors of Mammalian Soluble Epoxide Hydrolase

Scheme 2.1: Synthesis of First Urea Series

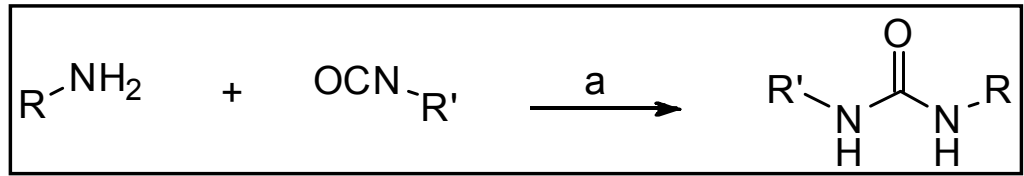

Reagents and Conditions: (a) triethylamine, dry dichloromethane, room temperature, overnight. 
chemistry, an array of compounds (1-30) was rapidly synthesized using parallel synthesis all in good yields $(>75 \%)$.

The second series of compounds was synthesized focusing on modifications of the urea moiety (Scheme 2.2A). The first compound targeted was the thiourea derivative 31 as there are already known thiourea drugs such as isoxyl and thiocarlide. ${ }^{102,103}$ As shown in Scheme 2.2A, this synthesis was identical to the urea synthesis with the exception that the isothiocyanate was used in place of the isocyanate to give $\mathbf{3 1}$ in good yield.

The synthesis of the carbamate derivative $\mathbf{3 2}$ is discussed next. This synthesis coupled the adamantyl alcohol with the phenyl isocyanate in order to form the desired product again in high yield (Scheme 2.2B). Further modification of the urea moiety is shown by the synthesis of the mono- and dimethylated derivatives 33 and 34 (Scheme 2.2C). The synthesis of the $\mathbf{3 3}$ started from 1, which was selectively deprotonated at the more acidic urea nitrogen adjacent to the phenyl ring with $n$-butyl lithium at low temperature. The anion was then reacted with iodomethane to form compound $\mathbf{3 3}$ in good yield. Di-N-methylated urea $\mathbf{3 4}$ was obtained in an analogous fashion using increased equivalents of $n$-butyl lithium and iodomethane.

The final series of compounds synthesized aimed to decrease the lipophilicity by the introduction of oxygen containing substituents, as poor solubility was noted in preliminary testing of the first two series of compounds. The first compound targeted was reference compound 36, a known inhibitor of human EH's which has been shown to be orally bioavailable. $\mathbf{3 6}$ was synthesized according to the published synthesis of $\mathrm{T}$. Kasagami et. al. (Scheme 2.3). ${ }^{104,105}$

Other oxygenated urea analogs 37-41 were synthesized according to Scheme 2.1. To complete the series compound 42, the urea derivate of the tuberculosis drug isoxyl, was synthesized (Scheme 2.4). 42 was synthesized by alkylating 4-nitrophenol with 1bromo-4-methylpentane to produce the O-alkylated intermediate. This nitro intermediate was then reduced by hydrogenolysis to produce the aniline intermediate. This compound was then reacted with triphosgene or thiophosgene to produce the 42 and 43 (Isoxyl) in acceptable yields.

\section{Results and Discussion}

Overall, the first series of urea compounds showed good activity primarily against M. tuberculosis (H37Rv) (Table 2.1). In this series, compounds 1, 3, 11, 20, 24 showed the best activity with an MIC value of $0.01 \mu \mathrm{g} / \mathrm{mL}$ that is comparable to the antituberculosis drug isoniazid $(0.01 \mu \mathrm{g} / \mathrm{mL})$. Some significant structure activity relationships (SAR) has emerged from this data. The one substituent has a strong preference for the bulky aliphatic ring system such as adamantly. Substituting adamantyl for a cyclohexyl 8 or cyclopentyl 9 considerably decreased the activity, while a cyclooctyl 7 ring system only minimally decreased the activity to a level comparable to 


\section{Scheme 2.2: Synthesis of Variations around Urea Moiety}

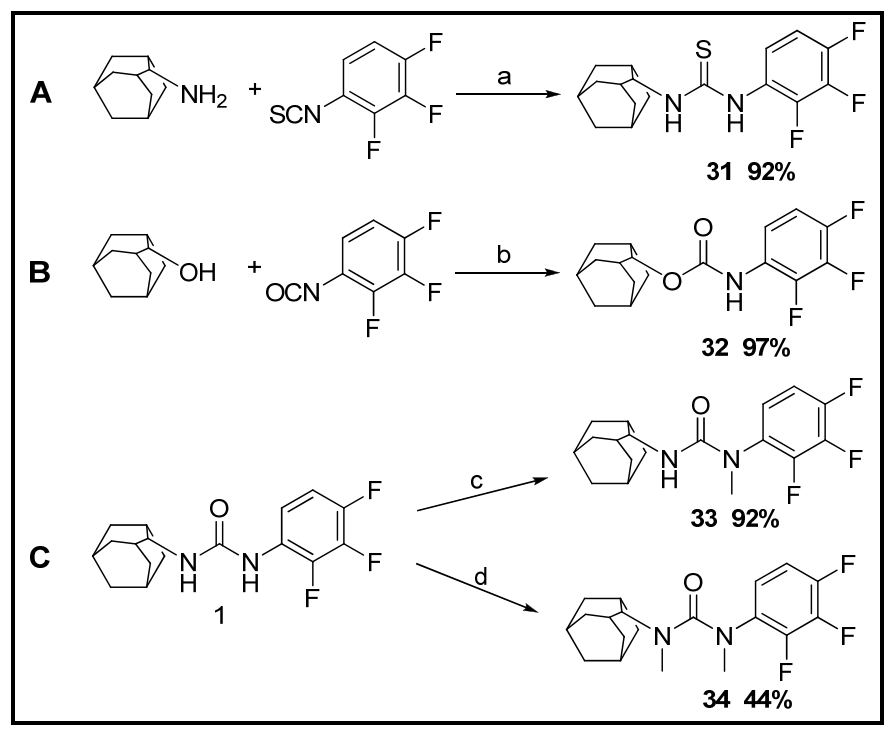

Reagents and Conditions: (a) triethylamine, dry dichloromethane, room temperature, overnight; (b) triethylamine, dry dichloromethane, room temperature, overnight; (c) (i) $n$ $\mathrm{BuLi}$, dry THF, $-78^{\circ} \mathrm{C}$; (ii) iodomethane, reflux, $24 \mathrm{hr}$; (d) (i) $n$-BuLi, dry THF, $-78^{\circ} \mathrm{C}$; (ii) iodomethane, reflux, $24 \mathrm{hr}$.

\section{Scheme 2.3: Synthesis of Compound 36}

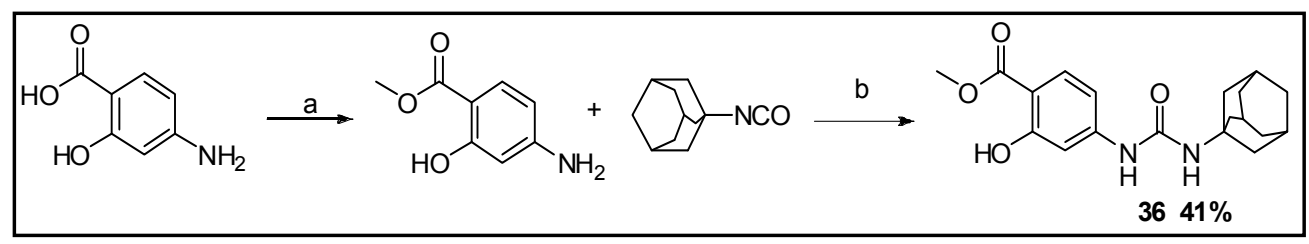

Reagents and Conditions: (a) conc. $\mathrm{H}_{2} \mathrm{SO}_{4}$, dry $\mathrm{MeOH}$, reflux, $12 \mathrm{hr}$; (b) dry dichloroethane, reflux, $4 \mathrm{~d}$. 
Scheme 2.4: Synthesis of Compounds 42 and 43

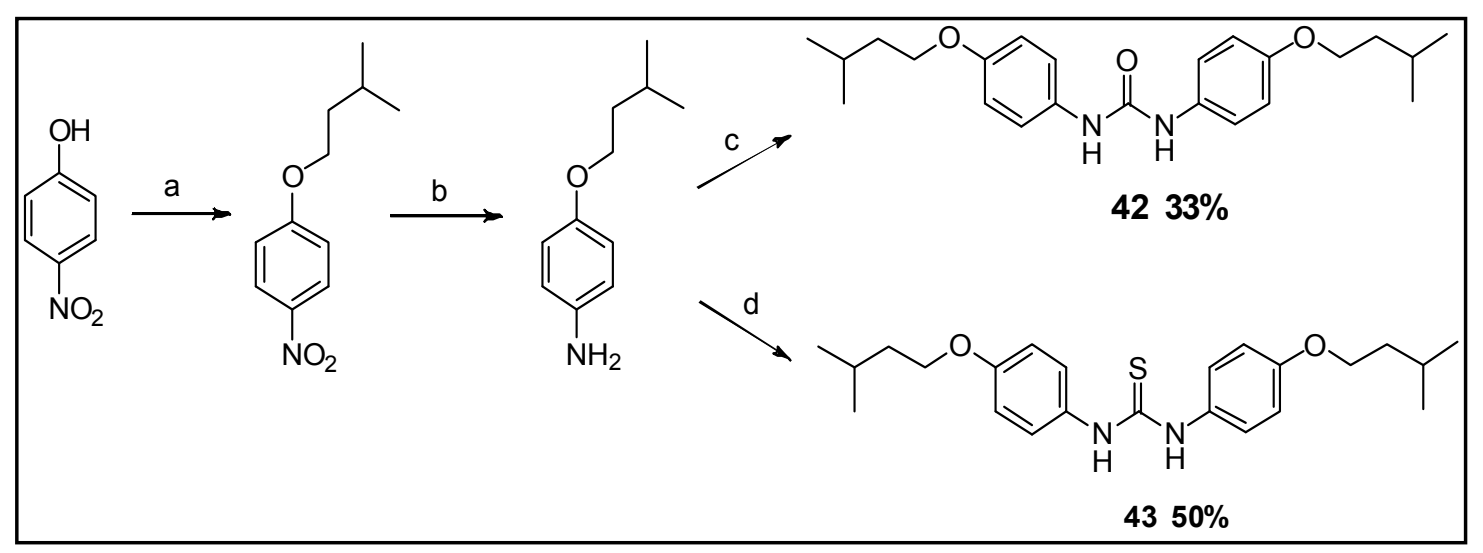

Reagents and Conditions: (a) 1-bromo-4-methylpentane, $\mathrm{NaOH}, \mathrm{DMF}, 65^{\circ} \mathrm{C}$, overnight; (b) $\mathrm{Pd} / \mathrm{C}, \mathrm{H}_{2}$, ethanol, overnight; (c) triphosgene, triethylamine, DCM, room temperature, overnight; (d) thiophosgene, triethylamine, DCM, room temperature, overnight. 
Table 2.1: In Vitro Antibacterial Activity of First Urea Series

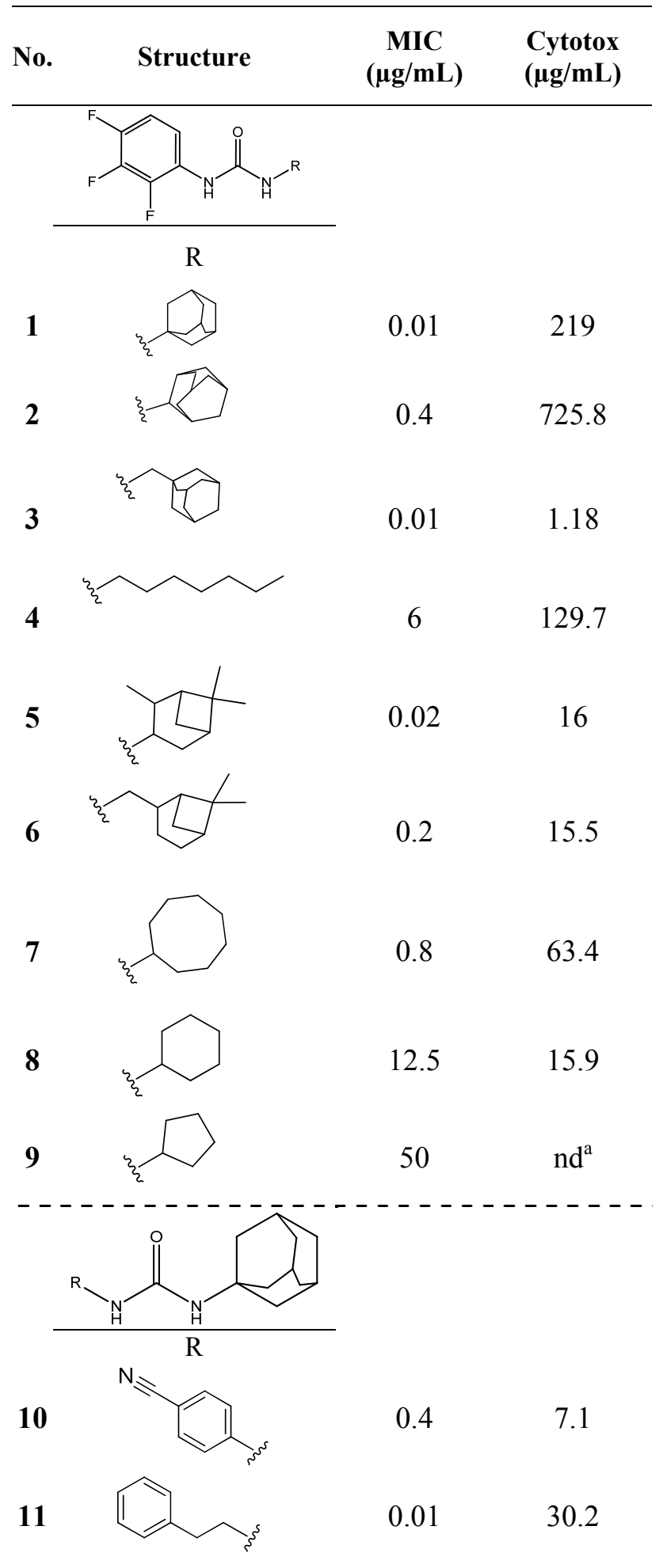


Table 2.1: Continued

Cytotox
$(\mu \mathrm{g} / \mathbf{m L})$


Table 2.1: Continued

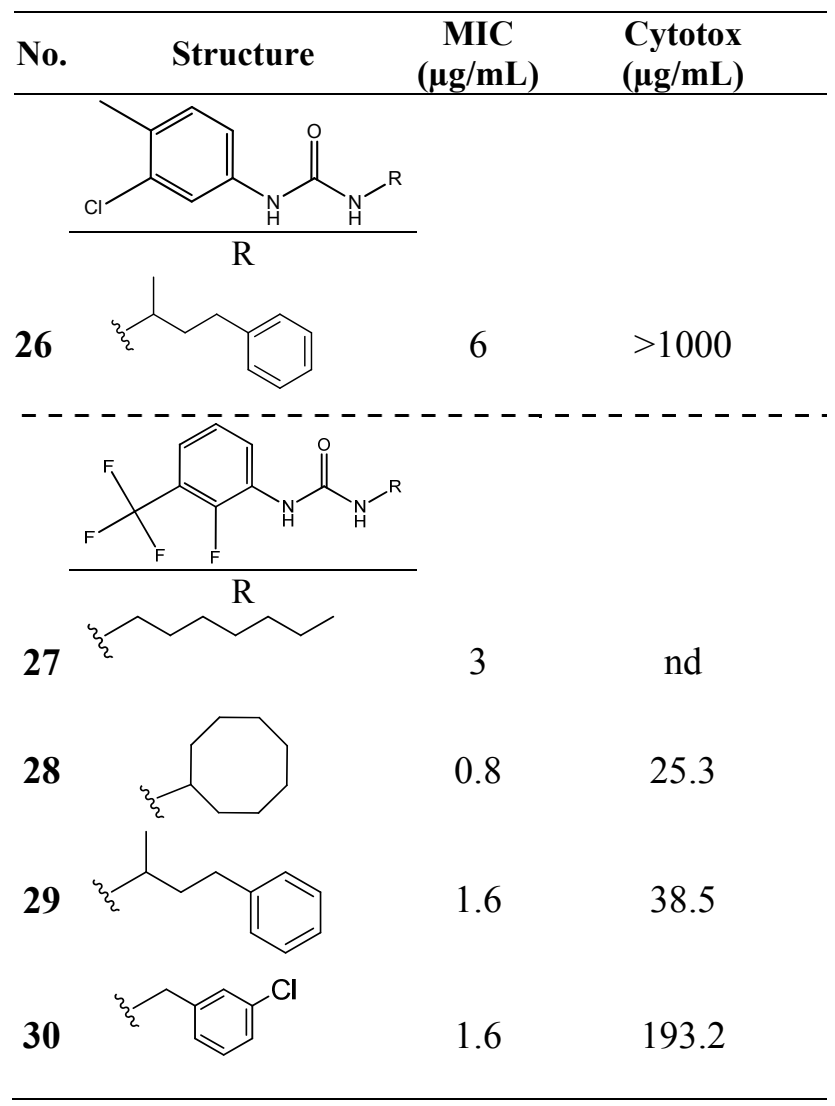

${ }^{\mathrm{a}} \mathrm{nd}=$ not determined 
the drug ethambutol $(0.8 \mu \mathrm{g} / \mathrm{mL})$. Substitution in the aryl ring at the meta and/or para positions (Compounds 10-14) were more tolerated with those substitutions not having a major impact on the anti-tuberculosis activity. In the group of compounds which contain the trifluorophenyl moiety (Compounds 1-9), the adamantyl compounds $\mathbf{1}$ and $\mathbf{3}$ exhibit the best activity with potent MIC values of $0.01 \mu \mathrm{g} / \mathrm{mL}$.

It can be seen that within this series the bulky hydrophobic adamantyl group is preferred over a straight-chain alky group $\mathbf{4}$ or even a simple cyclic alkyl group $\mathbf{8}$ and $\mathbf{9}$ which lack the bulk of the adamantyl group. With regard to compounds that only contain aliphatic groups (Compounds 15-21), it can be seen that the best MIC value is displayed by the most hydrophobic compound with the longest alkyl chain 20. When comparing the compounds with the 3-chloro-4-methylphenyl substitution (Compounds 22-26), it can be seen that compound with a bulky alkyl rings on the opposite side (adamantyl and cyclooctyl) produce the most active compounds (22 and 24). This trend continues in the compounds in the 2-fluoro-3-(trifluoromethyl)phenyl arylurea series 27-30.

The MIC data for the second series of compounds in which the central urea moiety was modified is shown below (Table 2.2). In this series, it is clearly seen that the unmodified urea moiety is preferred for best anti-tuberculosis activity. Introduction of a thiourea 31 produces a decrease in activity. Replacing the urea with a carbamate 32 produces a 10-fold larger decrease in potency. Mono N-methylation of the urea $\mathbf{3 3}$ shows similar decrease in activity and di-N-methlyation $\mathbf{3 4}$ produces an even greater decrease in activity.

The MIC data for the third series of oxygenated ureas is shown below (Table 2.3). Compounds $\mathbf{3 5}$ and $\mathbf{3 6}$ showed good antitubercular activity while the remaining compounds 37-41 had much poorer activity. It is of interest to note that $\mathbf{3 5}$ and $\mathbf{3 6}$ were the only two in this series which contained the preferred SAR arrangement of having a bulky aliphatic ring on one side of the molecule and having an aromatic ring on the other. When comparing compounds 37 and $\mathbf{3 8}$ to aliphatic analog 28, it can be seen that placing the oxygen in the alkyl chain dramatically decreases antitubercular activity. Compound 42, the urea analog of thiourea tuberculosis drug thiocarlide, was found to be inactive. This is in contrast to the comparison of compounds $\mathbf{1}$ and 31, where it was shown that replacing the urea moiety with a thiourea decreased the activity but 31 still had some antitubercular activity demonstrating the contribution of the adamantyl and phenyl groups to the overall activity. It can mean that thiocarlde acts on a different target than the compounds selected here.

\section{Conclusions}

In this study, clear structure activity relationships (SAR) for anti-tubercular activity of urea-based EH inhibitors has emerged with the best compounds containing a 1-cylcoalkyl-3-phenyl disubstituted urea structure. The 1-3 disubstituted urea moiety was shown to be most active over other urea substitution patterns and urea bioisosteres. For 
Table 2.2: In Vitro Antibacterial Activity of Compounds with Varying Urea Moieties

\begin{tabular}{|c|c|c|c|c|}
\hline \multirow[t]{2}{*}{ No. } & & & $F$ & \multirow[t]{2}{*}{$\begin{array}{c}\text { M. tb } \\
\text { MIC }(\mu \mathrm{g} / \mathrm{mL})\end{array}$} \\
\hline & $\mathbf{X}$ & $\mathbf{Y}$ & $\mathbf{Z}$ & \\
\hline 1 & $\mathrm{NH}$ & $\mathrm{O}$ & $\mathrm{NH}$ & 0.01 \\
\hline 31 & $\mathrm{NH}$ & $\mathrm{S}$ & $\mathrm{NH}$ & 0.8 \\
\hline 32 & $\mathrm{O}$ & $\mathrm{O}$ & $\mathrm{NH}$ & 6 \\
\hline 33 & $\mathrm{NH}$ & $\mathrm{O}$ & $\mathrm{NMe}$ & 6 \\
\hline 34 & $\mathrm{NMe}$ & $\mathrm{O}$ & $\mathrm{NMe}$ & 12 \\
\hline
\end{tabular}


Table 2.3: In Vitro Antibacterial Activity of Miscellaneous Urea Compounds

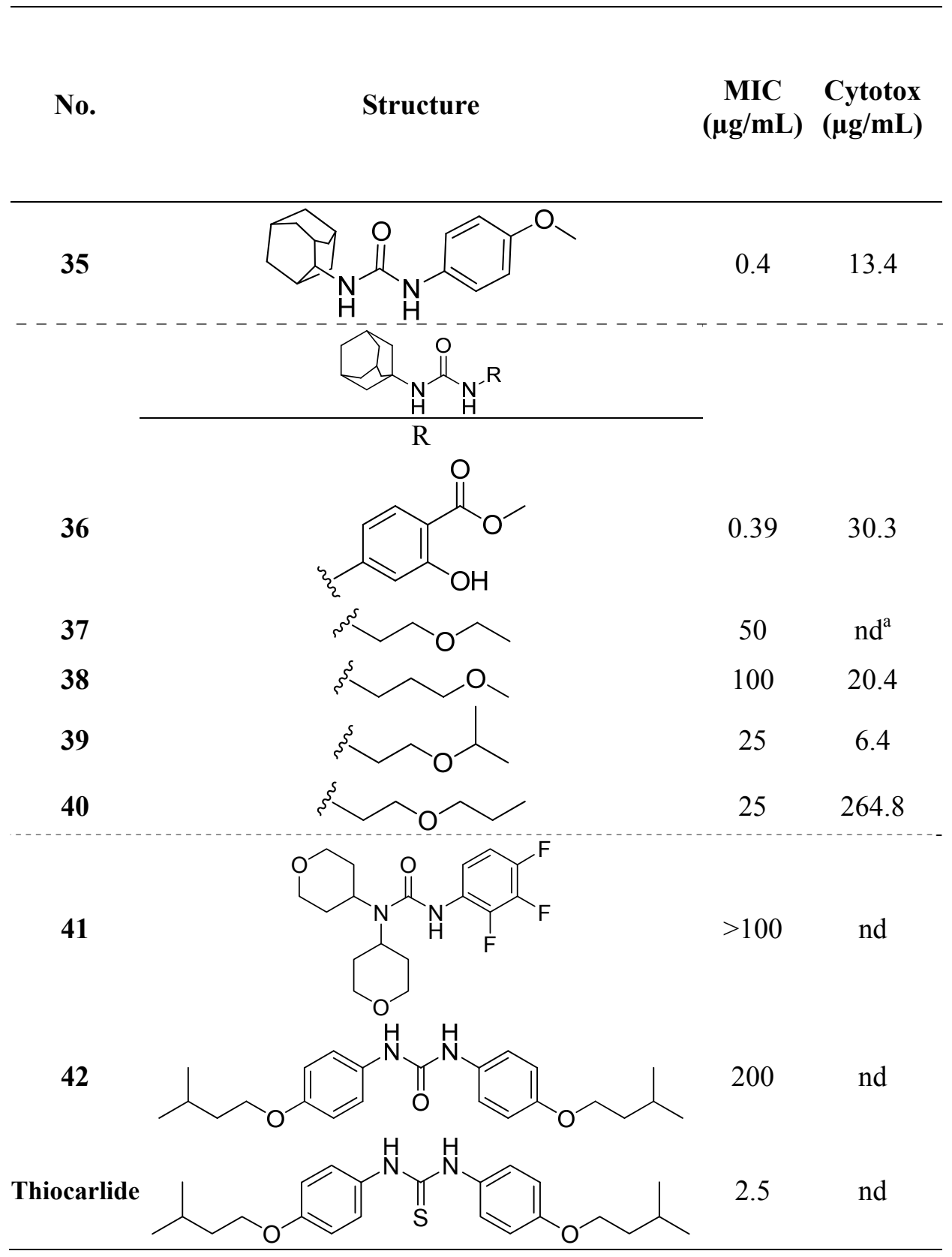

${ }^{\mathrm{a}}$ nd $=$ not determined 
the cycloalkyl ring subsituent, a strong preference for bulkyl groups such as adamantyl was preferred for anti-tubercular activity.

This is consistent with previous findings by Biswal et al., ${ }^{101}$ which indicates the importance of the adamantyl substituent in inhibiting $M$. tuberculosis EH enzyme B. Therefore, bulky groups such as adamantyl appear relevant for both enzyme and whole cell activities. This is noteworthy as other adamantyl analogs have been shown to have good anti-tubercular activity; most notably the clinical candidate adamantyl diamine SQ109 and admanatyl amides discovered through high throughput screening by the National Institutes of Health $(\mathrm{NIH})$ sponsored Tuberculosis Antimicrobial Acquisition and Coordinating Facility (TAACF) program. ${ }^{91,106,107}$ Substitutions to the phenyl ring were well tolerated; suggesting further analogs of this position may be worthwhile.

This SAR provides support that $\alpha / \beta$-hydrolase fold EHs may be actual targets of ureas in $M$. $t b$ due to structural similarities of these compounds to human sEH inhibitors. Evidence for a specific mode of action is bolstered by a lack of correlation between lipophilicity and MIC against $M$. $t b$, suggesting that activity was not due to membrane disruption. This is further supported by several compounds exhibiting good activity against $M$. smegmatis and the general lack of activity of most analogs against other grampositive and -negative bacterial pathogens including Staphylococcus aureus, Bacillus anthracis, Esherichia coli, Pseudomonas aeruginosa and Klebsiella pneumoniae. Both of these affects will be more closely analyzed in upcoming studies. In general all ureabased compounds with potent MICs that were comparable to isoniazid and ethambutol (0.01-1.6 $\mu \mathrm{g} / \mathrm{mL})$, showed good therapeutic selectivity for M. tuberculosis with selectivity indices of 16.5->21,900. Importantly, this indicates that selective inhibitors of the mycobacterial EHs may be obtained. Increasing solubility, metabolic stability and selectivity away from inhibition of human EHs are currently the principal design drivers that are being used to further optimize this series.

Currently, computer-based structure docking experiments are being conducted my members of Dr. Richard Lee's laboratory. These findings will be used to further guide the future directions of this project. Initial studies are being performed in an effort to establish a model which can effectively predict that activity of potential inhibitors before they are synthesized in the laboratory. This computer model provides details of how the inhibitors bind into the active site of the epoxide hydrolase enzyme found in Mycobacterium tuberculosis (Figure 2.5). This figure depicts the modeled interactions of compound 1 (ball and stick form with yellow carbons) within the active site of Mycobacterium tuberculosis epoxide hydrolase B (EphB) with the catalytic residues (tube form with grey carbons). Panel A shows the $90^{\circ}$ left side view of the hydrophobic pocket where the adamantyl functionality resides. Panel B shows the front view of the hydrogen bonding network with the catalytic residues Tyrosine 164, Tyrosine 272, and Aspartic Acid 104 to the urea moiety of compound 1. Panel $\mathrm{C}$ displays the $90^{\circ}$ right side view and key interactions of the aromatic binding pocket. 


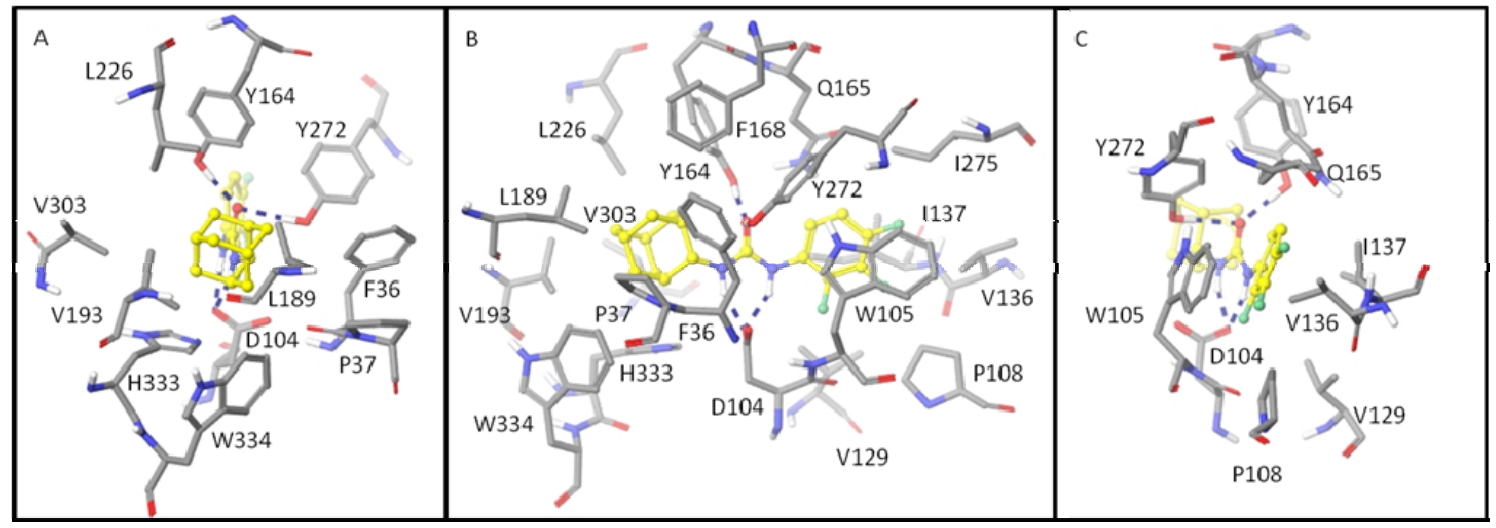

Figure 2.5: Hydrogen Bonding Network 


\section{Experimental Section}

Chemistry

All anhydrous solvents and starting materials were purchased from Aldrich Chemical Co. (Milwaukee, WI). All reagent grade solvents used from chromatography were purchased from Fisher Scientific (Suwanee, GA) and flash column chromatography silica cartridges were obtained from Biotage Inc. (Lake Forest, VA). The reactions were monitored by thin-layer chromatography (TLC) on pre-coated Merch $60 \mathrm{~F}_{254}$ silica gel plates and visualized using ultraviolet (UV) light $(254 \mathrm{~nm})$. A Biotage FLASH column chromatography system was used to purify mixtures. All ${ }^{1} \mathrm{H}$ nuclear magnetic resonance (NMR) spectra were recorded on a Varian INOVA-500 spectrometer. Chemical shifts $(\delta)$ are reported in parts per million relative to the residual solvent peak or internal standard (tetramethylsilane), and coupling constants $(J)$ are reported in hertz $(\mathrm{Hz})$. Mass spectra were recorded on a Bruker Esquire liquid-chromatography mass-spectrometer using electrospray ionization. Purity of the products was confirmed before testing by analytical reverse phase-high performace liquid chromatography on a Shimadzu high-performance liquid-chromatography system, and all final compounds had a purity of $95 \%$ or greater as determined by RP-HPLC. Gradient Conditions: solvent A (0.1\% Trifluoroacetic Acid (TFA) in water) and solvent B (acetonitrile): 0-2.00 min 100\& A, 2.00-7.00 min 0-100\% B (linear gradient), 7.00-8.00 min 100\% B, UV detection at $254 \mathrm{~nm}$. Melting points were obtained on the OptiMelt MPA100 Automated Melting Point System.

General Method for the Synthesis of Urea Compounds

In a round bottom flask equipped with a stir bar, $1.2 \mathrm{mmol}$ of the appropriate amine was added to $10 \mathrm{~mL}$ of anhydrous dichloromethane. To this solution, $1.0 \mathrm{mmol}$ of the appropriate isocyanate followed by $3.6 \mathrm{mmol}$ of triethylamine was added. The reaction was stirred at room temperature overnight. The solvent was removed by rotary evaporation. The resulting residue was purified by flash chromatography using a petroleum ether to ethyl acetate gradient to elute the final compound.

1-(2-adamantyl)-3-(2,3,4-trifluorophenyl)urea (1). ${ }^{1} \mathrm{H}$ NMR (DMSO- $\left.d_{6}\right): \delta 1.58(2 \mathrm{H}$, d, $J=12 \mathrm{~Hz}), 1.80(12 \mathrm{H}, \mathrm{m}), 3.78(1 \mathrm{H}, \mathrm{d}, J=8.0 \mathrm{~Hz}), 6.96(1 \mathrm{H}, \mathrm{d}, J=8.0 \mathrm{~Hz}), 7.20(1 \mathrm{H}$, q), $7.96(1 \mathrm{H}, \mathrm{m}), 8.51(1 \mathrm{H}, \mathrm{s})$. RP-HPLC: $t_{R}=7.18 \mathrm{~min}$. ESI-MS $m / z: 347.1[\mathrm{M}+\mathrm{Na}]^{+}$. Mp: $229-230^{\circ} \mathrm{C}$.

1-(1-adamantyl)-3-(2,3,4-trifluorophenyl)urea (2). ${ }^{1} \mathrm{H}$ NMR (DMSO- $\left.d_{6}\right): \delta 1.63(6 \mathrm{H}$, s), $1.93(6 \mathrm{H}, \mathrm{s}), 2.03(3 \mathrm{H}, \mathrm{s}), 6.44(1 \mathrm{H}, \mathrm{s}), 7.16(1 \mathrm{H}, \mathrm{q}, J=10.0 \mathrm{~Hz}), 7.88(1 \mathrm{H}, \mathrm{m}), 8.26$ $(1 \mathrm{H}, \mathrm{s})$. RP-HPLC: $t_{R}=7.29 \mathrm{~min}$. ESI-MS $m / z: 347.1[\mathrm{M}+\mathrm{Na}]^{+} . \mathrm{Mp}: 216-219{ }^{\circ} \mathrm{C}$.

1-(1-(1-adamantyl)methyl)-3-(2,3,4-trifluorophenyl)urea (3). ${ }^{1} \mathrm{H}$ NMR (DMSO- $\left.d_{6}\right)$ : $\delta$ $1.55(12 \mathrm{H}, \mathrm{m}), 1.94(3 \mathrm{H}, \mathrm{m}), 2.81(2 \mathrm{H}, \mathrm{d}, J=6.0 \mathrm{~Hz}), 6.60(1 \mathrm{H}, \mathrm{t}, J=5.5 \mathrm{~Hz}), 7.19(1 \mathrm{H}$, 
q, $J=9.5 \mathrm{~Hz}), 7.92(1 \mathrm{H}, \mathrm{m}), 8.44(1 \mathrm{H}, \mathrm{s})$. RP-HPLC: $t_{R}=7.08 \mathrm{~min}$. ESI-MS $m / z: 361.3$ $[\mathrm{M}+\mathrm{Na}]^{+}$. Mp: $171-173^{\circ} \mathrm{C}$.

1-heptyl-3-(2,3,4-trifluorophenyl)urea (4). ${ }^{1} \mathrm{H}$ NMR (DMSO- $\left.d_{6}\right): \delta 0.87(3 \mathrm{H}, \mathrm{t}, J=6.5$ $\mathrm{Hz}), 1.24(8 \mathrm{H}, \mathrm{s}), 1.42(2 \mathrm{H}, \mathrm{m}), 3.08(2 \mathrm{H}, \mathrm{q}, J=6.5 \mathrm{~Hz}), 6.57(1 \mathrm{H}, \mathrm{t}, J=5.0 \mathrm{~Hz}), 7.19$ $(1 \mathrm{H}, \mathrm{q}, J=9.0 \mathrm{~Hz}), 7.84(1 \mathrm{H}, \mathrm{m}), 8.40(1 \mathrm{H}, \mathrm{s})$. RP-HPLC: $t_{R}=7.04 \mathrm{~min}$. ESI-MS $m / z$ : $311.1[\mathrm{M}+\mathrm{Na}]^{+} . \mathrm{Mp}: 96-98^{\circ} \mathrm{C}$.

1-(2,3,4-trifluorophenyl)-3-(2,6,6-trimethylbicyclo[3.1.1] heptan-3-yl)urea (5). ${ }^{1} \mathrm{H}$ NMR (DMSO- $\left.d_{6}\right): \delta 0.90(1 \mathrm{H}, \mathrm{d}, J=9.5 \mathrm{~Hz}), 1.00(3 \mathrm{H}, \mathrm{s}), 1.06(3 \mathrm{H}, \mathrm{d}, J=7.0 \mathrm{~Hz}), 1.20$ $(3 \mathrm{H}, \mathrm{s}), 1.52(1 \mathrm{H}, \mathrm{m}), 1.79(2 \mathrm{H}, \mathrm{m}), 1.91(1 \mathrm{H}, \mathrm{m}), 2.44(2 \mathrm{H}, \mathrm{m}), 3.97(1 \mathrm{H}$, quintuplet, $J=$ $8.0 \mathrm{~Hz}), 6.70(1 \mathrm{H}, \mathrm{d}, J=8.0 \mathrm{~Hz}), 7.18(1 \mathrm{H}, \mathrm{q}, J=9.5 \mathrm{~Hz}), 7.88(1 \mathrm{H}, \mathrm{m}), 8.26(1 \mathrm{H}, \mathrm{s})$. RP-HPLC: $t_{R}=7.26 \mathrm{~min}$. ESI-MS $m / z: 349.1[\mathrm{M}+\mathrm{Na}]^{+}$. Mp: $156-159{ }^{\circ} \mathrm{C}$.

1-((6,6-dimethylbicyclo[3.1.1] heptan-2-yl)methyl)-3-(2,3,4-trifluorophenyl)urea (6). ${ }^{1} \mathrm{H}$ NMR (DMSO- $\left.d_{6}\right): \delta 0.86(1 \mathrm{H}, \mathrm{d}, J=9.5 \mathrm{~Hz}), 1.00(3 \mathrm{H}, \mathrm{s}), 1.17(3 \mathrm{H}, \mathrm{s}), 1.44(1 \mathrm{H}, \mathrm{m})$, $1.86(5 \mathrm{H}, \mathrm{m}), 2.10(1 \mathrm{H}, \mathrm{m}), 2.33(1 \mathrm{H}, \mathrm{m}), 3.08(2 \mathrm{H}, \mathrm{m}), 6.62(1 \mathrm{H}, \mathrm{t}, J=5.5 \mathrm{~Hz}), 7.17$ $(1 \mathrm{H}, \mathrm{q}, J=10.0 \mathrm{~Hz}), 7.86(1 \mathrm{H}, \mathrm{m}), 8.38(1 \mathrm{H}, \mathrm{s})$. RP-HPLC: $t_{R}=7.30 \mathrm{~min}$. ESI-MS $\mathrm{m} / z$ : $349.1[\mathrm{M}+\mathrm{Na}]^{+}$. Mp: $105-107^{\circ} \mathrm{C}$.

1-cyclooctyl-3-(2,3,4-trifluorophenyl)urea (7). ${ }^{1} \mathrm{H}$ NMR (DMSO- $\left.d_{6}\right): \delta 1.55(13 \mathrm{H}, \mathrm{m})$, $1.76(2 \mathrm{H}, \mathrm{t}, J=9.5 \mathrm{~Hz}), 6.63(1 \mathrm{H}, \mathrm{d}, J=8.0 \mathrm{~Hz}), 7.18(1 \mathrm{H}, \mathrm{q}, J=9.5 \mathrm{~Hz}), 7.89(1 \mathrm{H}, \mathrm{m})$, $8.31(1 \mathrm{H}, \mathrm{s})$. RP-HPLC: $t_{R}=6.98 \mathrm{~min}$. ESI-MS $m / z: 323.1[\mathrm{M}+\mathrm{Na}]^{+}$. Mp: $160-163{ }^{\circ} \mathrm{C}$.

1-cyclohexyl-3-(2,3,4-trifluorophenyl)urea (8). ${ }^{1} \mathrm{H}$ NMR (DMSO- $\left.d_{6}\right): \delta 1.19(3 \mathrm{H}, \mathrm{m})$, $1.32(2 \mathrm{H}, \mathrm{m}), 1.53(1 \mathrm{H}, \mathrm{m}), 1.65(2 \mathrm{H}, \mathrm{m}), 1.80(2 \mathrm{H}, \mathrm{m}), 3.48(3 \mathrm{H}, \mathrm{m}), 6.60(1 \mathrm{H}, \mathrm{d}, J=$ $9.0 \mathrm{~Hz}), 7.20(1 \mathrm{H}, \mathrm{q}, J=10 \mathrm{~Hz}), 7.90(1 \mathrm{H}, \mathrm{m}), 8.33(1 \mathrm{H}, \mathrm{s})$. RP-HPLC: $t_{R}=6.39 \mathrm{~min}$. ESI-MS $m / z: 295.0[\mathrm{M}+\mathrm{Na}]^{+}$. Mp: $188-191{ }^{\circ} \mathrm{C}$.

1-cyclopentyl-3-(2,3,4-trifluorophenyl)urea (9). ${ }^{1} \mathrm{H}$ NMR (DMSO- $\left.d_{6}\right): \delta 1.37(2 \mathrm{H}, \mathrm{m})$, $1.59(4 \mathrm{H}, \mathrm{m}), 1.84(2 \mathrm{H}, \mathrm{m}), 3.94(1 \mathrm{H}, \mathrm{q}, J=6.5 \mathrm{~Hz}), 6.66(1 \mathrm{H}, \mathrm{d}, J=7.5 \mathrm{~Hz}), 7.19(1 \mathrm{H}$, $\mathrm{q}, J=9.5 \mathrm{~Hz}), 7.90(1 \mathrm{H}, \mathrm{m}), 8.27(1 \mathrm{H}, \mathrm{s})$. RP-HPLC: $t_{R}=6.14 \mathrm{~min}$. ESI-MS $\mathrm{m} / z: 281.0$ $[\mathrm{M}+\mathrm{Na}]^{+}$. Mp: $184-186^{\circ} \mathrm{C}$.

1-(2-adamantyl)-3-(4-cyanophenyl)urea (10). ${ }^{1} \mathrm{H}$ NMR (DMSO- $\left.d_{6}\right): \delta 1.58(2 \mathrm{H}, \mathrm{d}, J=$ $12.0 \mathrm{~Hz}), 1.79(12 \mathrm{H}, \mathrm{m}), 3.78(1 \mathrm{H}, \mathrm{d}, J=7.5 \mathrm{~Hz}), 6.67(1 \mathrm{H}, \mathrm{d}, J=7.5 \mathrm{~Hz}), 7.55(2 \mathrm{H}, \mathrm{d}, J$ $=8.5 \mathrm{~Hz}), 7.67(2 \mathrm{H}, \mathrm{d}, J=8.5 \mathrm{~Hz}), 8.92(1 \mathrm{H}, \mathrm{s})$. RP-HPLC: $t_{R}=6.83 \mathrm{~min}$. ESI-MS $m / z$ : $296.1[\mathrm{M}+\mathrm{H}]^{+}$. Mp: $217-219^{\circ} \mathrm{C}$.

1-(2-adamantyl)-3-phenethylurea (11). ${ }^{1} \mathrm{H}$ NMR (DMSO- $\left.d_{6}\right): \delta 1.66(14 \mathrm{H}, \mathrm{m}), 2.68$ $(2 \mathrm{H}, \mathrm{t}, J=7.0 \mathrm{~Hz}), 3.24(2 \mathrm{H}, \mathrm{q}, J=7.0 \mathrm{~Hz}), 3.67(1 \mathrm{H}, \mathrm{d}, J=8.0 \mathrm{~Hz}), 5.82(1 \mathrm{H}, \mathrm{t}, J=5.5$ $\mathrm{Hz}), 6.11(1 \mathrm{H}, \mathrm{d}, J=8.5 \mathrm{~Hz}), 7.21(3 \mathrm{H}, \mathrm{d}, J=6.0 \mathrm{~Hz}), 7.30(2 \mathrm{H}, \mathrm{t}, J=7.5 \mathrm{~Hz}) . \mathrm{RP}-$ HPLC: $t_{R}=6.82 \mathrm{~min}$. ESI-MS $m / z: 299.2[\mathrm{M}+\mathrm{H}]^{+}$. Mp: $115-117^{\circ} \mathrm{C}$. 
1-(3-acetylphenyl)-3-(2-adamantyl)urea (12). ${ }^{1} \mathrm{H}$ NMR (DMSO- $\left.d_{6}\right): \delta 1.57(2 \mathrm{H}, \mathrm{d}, J=$ $12.0 \mathrm{~Hz}), 1.80(13 \mathrm{H}, \mathrm{m}), 2.55(3 \mathrm{H}, \mathrm{s}), 3.79(1 \mathrm{H}, \mathrm{d}, J=7.5 \mathrm{~Hz}), 6.50(1 \mathrm{H}, \mathrm{d}, J=7.5 \mathrm{~Hz})$, $7.38(1 \mathrm{H}, \mathrm{t}, J=8.0 \mathrm{~Hz}), 7.50(1 \mathrm{H}, \mathrm{d}, J=8.0 \mathrm{~Hz}), 7.58(1 \mathrm{H}, \mathrm{d}, J=8.0 \mathrm{~Hz}), 8.00(1 \mathrm{H}, \mathrm{s})$. RP-HPLC: $t_{R}=6.63 \mathrm{~min}$. ESI-MS $m / z: 335.2[\mathrm{M}+\mathrm{Na}]^{+}$. Mp: $213-215{ }^{\circ} \mathrm{C}$.

1-(2-adamantyl)-3-benzylurea (13). ${ }^{1} \mathrm{H}$ NMR (DMSO- $\left.d_{6}\right): \delta 1.52(2 \mathrm{H}, \mathrm{d}, J=12.5 \mathrm{~Hz})$, $1.78(12 \mathrm{H}, \mathrm{m}), 3.70(1 \mathrm{H}, \mathrm{d}, J=8.0 \mathrm{~Hz}), 4.21(2 \mathrm{H}, \mathrm{d}, J=6.0 \mathrm{~Hz}), 6.18(1 \mathrm{H}, \mathrm{d}, J=8.0$ $\mathrm{Hz}), 6.27(1 \mathrm{H}, \mathrm{t}, J=6.0 \mathrm{~Hz}), 7.24(3 \mathrm{H}, \mathrm{q}, J=7.5 \mathrm{~Hz}), 7.33(2 \mathrm{H}, \mathrm{t}, J=7.5 \mathrm{~Hz})$. RPHPLC: $t_{R}=6.37 \mathrm{~min}$. ESI-MS $m / z: 285.2[\mathrm{M}+\mathrm{H}]^{+}$. Mp: $205-207{ }^{\circ} \mathrm{C}$.

1-(2-adamantyl)-3-(3-chloro-2-methylphenyl)urea (14). ${ }^{1} \mathrm{H}$ NMR (DMSO- $\left.d_{6}\right): \delta 1.58$ $(2 \mathrm{H}, \mathrm{d}, J=12.5 \mathrm{~Hz}), 1.77(10 \mathrm{H}, \mathrm{m}), 1.91(2 \mathrm{H}, \mathrm{d}, J=12.5 \mathrm{~Hz}), 2.26(3 \mathrm{H}, \mathrm{s}), 3.79(1 \mathrm{H}, \mathrm{d}$, $J=7.5 \mathrm{~Hz}), 6.91(1 \mathrm{H}, \mathrm{d}, J=8.0 \mathrm{~Hz}), 7.03(1 \mathrm{H}, \mathrm{d}, J=7.5 \mathrm{~Hz}), 7.10(1 \mathrm{H}, \mathrm{t}, J=8.0 \mathrm{~Hz})$, $7.87(2 \mathrm{H}, \mathrm{m})$. RP-HPLC: $t_{R}=6.98 \mathrm{~min}$. ESI-MS $m / z: 341.1[\mathrm{M}+\mathrm{Na}]^{+}$. Mp: $254-257{ }^{\circ} \mathrm{C}$.

1-(2-adamantyl)-3-isopropylurea (15). ${ }^{1} \mathrm{H}$ NMR (DMSO- $\left.d_{6}\right): \delta 1.02(6 \mathrm{H}, \mathrm{d}, J=6.5$ $\mathrm{Hz}), 1.50(2 \mathrm{H}, \mathrm{d}, J=12.5 \mathrm{~Hz}), 1.75(12 \mathrm{H}, \mathrm{m}), 3.64(2 \mathrm{H}, \mathrm{m}), 5.66(1 \mathrm{H}, \mathrm{d}, J=7.5 \mathrm{~Hz})$, $5.95(1 \mathrm{H}, \mathrm{d}, J=8.0 \mathrm{~Hz})$. ESI-MS $m / z: 237.1[\mathrm{M}+\mathrm{H}]^{+}$. Mp: $240-242{ }^{\circ} \mathrm{C}$.

1-(2-adamantyl)-3-tert-butylurea (16). ${ }^{1} \mathrm{H}$ NMR (DMSO- $\left.d_{6}\right): \delta 1.22(9 \mathrm{H}, \mathrm{s}), 1.50(2 \mathrm{H}$, $\mathrm{d}, J=12.0 \mathrm{~Hz}), 1.75(12 \mathrm{H}, \mathrm{m}), 3.64(1 \mathrm{H}, \mathrm{d}, J=8.0 \mathrm{~Hz}), 5.70(1 \mathrm{H}, \mathrm{s}), 5.95(1 \mathrm{H}, \mathrm{d}, J=8.5$ $\mathrm{Hz})$. ESI-MS $m / z: 273.1[\mathrm{M}+\mathrm{Na}]^{+}$. Mp: $>300{ }^{\circ} \mathrm{C}$.

1-(2-adamantyl)-3-propylurea (17). ${ }^{1} \mathrm{H}$ NMR (DMSO- $\left.d_{6}\right): \delta 0.84(3 \mathrm{H}, \mathrm{t}, J=7.0 \mathrm{~Hz})$, $1.37(2 \mathrm{H}$, sextuplet, $J=7.5 \mathrm{~Hz}), 1.51(2 \mathrm{H}, \mathrm{d}, J=12.5 \mathrm{~Hz}), 1.76(12 \mathrm{H}, \mathrm{m}), 2.94(2 \mathrm{H}, \mathrm{q}, J$ $=7.0 \mathrm{~Hz}), 3.66(1 \mathrm{H}, \mathrm{d}, J=8.0 \mathrm{~Hz}), 5.81(1 \mathrm{H}, \mathrm{t}, J=5.5 \mathrm{~Hz}), 6.02(1 \mathrm{H}, \mathrm{d}, J=8.0 \mathrm{~Hz})$. ESI-MS $m / z: 237.1[\mathrm{M}+\mathrm{H}]^{+}$. Mp: $194-196{ }^{\circ} \mathrm{C}$.

1-(2-adamantyl)-3-cyclohexylurea (18). ${ }^{1} \mathrm{H}$ NMR (DMSO- $\left.d_{6}\right): \delta 1.17(5 \mathrm{H}, \mathrm{m}), 1.51$ $(3 \mathrm{H}, \mathrm{d}, J=12.0 \mathrm{~Hz}), 1.72(17 \mathrm{H}, \mathrm{m}), 3.65(1 \mathrm{H}, \mathrm{d}, J=7.5 \mathrm{~Hz}), 5.75(1 \mathrm{H}, \mathrm{d}, J=8.0 \mathrm{~Hz})$, $5.98(1 \mathrm{H}, \mathrm{d}, J=8.5 \mathrm{~Hz})$. ESI-MS $m / z: 299.3[\mathrm{M}+\mathrm{Na}]^{+}$. Mp: $>300{ }^{\circ} \mathrm{C}$.

1-(2-adamantyl)-3-pentylurea (19). ${ }^{1} \mathrm{H} \mathrm{NMR}\left(\mathrm{CDCl}_{3}\right): \delta 0.93(3 \mathrm{H}, \mathrm{t}, J=6.5 \mathrm{~Hz}), 1.35$ $(4 \mathrm{H}, \mathrm{m}), 1.53(2 \mathrm{H}$, quintet, $J=7.5 \mathrm{~Hz}), 1.62(2 \mathrm{H}, \mathrm{s}), 1.76(2 \mathrm{H}, \mathrm{s}), 1.80(1 \mathrm{H}, \mathrm{s}), 1.86(7 \mathrm{H}$, $\mathrm{t}, J=11.0 \mathrm{~Hz}), 1.93(2 \mathrm{H}, \mathrm{s}), 3.19(2 \mathrm{H}, \mathrm{q}, J=7.0 \mathrm{~Hz}), 3.81(1 \mathrm{H}, \mathrm{s}), 4.26(1 \mathrm{H}, \mathrm{s}), 4.64(1 \mathrm{H}$, s). ESI-MS $m / z: 287.1[\mathrm{M}+\mathrm{Na}]^{+}$. Mp: $151-153{ }^{\circ} \mathrm{C}$.

1-(2-adamantyl)-3-hexylurea (20). ${ }^{1} \mathrm{H}$ NMR (DMSO- $\left.d_{6}\right): \delta 0.87(3 \mathrm{H}, \mathrm{t}, J=6.5 \mathrm{~Hz})$, $1.31(8 \mathrm{H}, \mathrm{m}), 1.50(2 \mathrm{H}, \mathrm{d}, J=12.5 \mathrm{~Hz}), 1.76(12 \mathrm{H}, \mathrm{m}), 2.97(2 \mathrm{H}, \mathrm{q}, J=6.5 \mathrm{~Hz}), 3.65$ $(1 \mathrm{H}, \mathrm{d}, J=8.0 \mathrm{~Hz}), 5.78(1 \mathrm{H}, \mathrm{t}, J=5.5 \mathrm{~Hz}), 6.01(1 \mathrm{H}, \mathrm{d}, J=8.5 \mathrm{~Hz})$. ESI-MS $m / z: 279.3$ $[\mathrm{M}+\mathrm{H}]^{+}$. Mp: $95-98{ }^{\circ} \mathrm{C}$.

1-(2-adamantyl)-3-heptylurea (21). ${ }^{1} \mathrm{H}$ NMR $\left(\mathrm{CDCl}_{3}\right): \delta 0.90(3 \mathrm{H}, \mathrm{t}, J=6.0 \mathrm{~Hz}), 1.31$ $(8 \mathrm{H}, \mathrm{m}), 1.52(2 \mathrm{H}, \mathrm{t}, J=6.5 \mathrm{~Hz}), 1.66(2 \mathrm{H}, \mathrm{m}), 1.75(2 \mathrm{H}, \mathrm{s}), 1.77(1 \mathrm{H}, \mathrm{s}), 1.86(7 \mathrm{H}, \mathrm{t}, J=$ 
$11.0 \mathrm{~Hz}), 1.93(2 \mathrm{H}, \mathrm{s}), 3.18(2 \mathrm{H}, \mathrm{q}, J=6.5 \mathrm{~Hz}), 3.81(1 \mathrm{H}, \mathrm{s}), 4.34(1 \mathrm{H}, \mathrm{s}), 4.70(1 \mathrm{H}, \mathrm{s})$. ESI-MS $m / z: 315.1[\mathrm{M}+\mathrm{Na}]^{+}$. Mp: $83-86{ }^{\circ} \mathrm{C}$.

1-(1-(1-adamantyl)methyl)-3-(3-chloro-4-methylphenyl)urea (22). ${ }^{1} \mathrm{H}$ NMR (DMSO$\left.d_{6}\right): \delta 1.45(5 \mathrm{H}, \mathrm{s}), 1.64(7 \mathrm{H}, \mathrm{m}), 1.95(3 \mathrm{H}, \mathrm{s}), 2.23(3 \mathrm{H}, \mathrm{s}), 2.79(2 \mathrm{H}, \mathrm{d}, J=6.0 \mathrm{~Hz}), 6.14$ $(1 \mathrm{H}, \mathrm{m}), 7.06(1 \mathrm{H}, \mathrm{m}), 7.17(1 \mathrm{H}, \mathrm{d}, J=8.0 \mathrm{~Hz}), 7.66(1 \mathrm{H}, \mathrm{m}), 8.46(1 \mathrm{H}, \mathrm{s})$. RP-HPLC: $t_{R}$ $=7.24$ min. ESI-MS $m / z: 355.3[\mathrm{M}+\mathrm{Na}]^{+} . \mathrm{Mp}: 183-185^{\circ} \mathrm{C}$.

1-(3-chloro-4-methylphenyl)-3-heptylurea (23). ${ }^{1} \mathrm{H}$ NMR $\left(\mathrm{CD}_{3} \mathrm{OD}\right): \delta 0.93(3 \mathrm{H}, \mathrm{m})$, $1.35(8 \mathrm{H}, \mathrm{m}), 1.54(2 \mathrm{H}, \mathrm{m}), 2.30(3 \mathrm{H}, \mathrm{s}), 3.19(2 \mathrm{H}, \mathrm{t}, J=6.5 \mathrm{~Hz}), 7.13(2 \mathrm{H}, \mathrm{m}), 7.53(1 \mathrm{H}$, s). RP-HPLC: $t_{R}=6.99 \mathrm{~min}$. ESI-MS $m / z: 305.1[\mathrm{M}+\mathrm{Na}]^{+}$. Mp: $99-101{ }^{\circ} \mathrm{C}$.

1-(3-chloro-4-methylphenyl)-3-(3-fluorobenzyl)urea (24). ${ }^{1} \mathrm{H} \mathrm{NMR}\left(\mathrm{CD}_{3} \mathrm{OD}\right): \delta 2.30$ $(3 \mathrm{H}, \mathrm{s}), 4.40(2 \mathrm{H}, \mathrm{s}), 7.00(1 \mathrm{H}, \mathrm{t}, J=8.5 \mathrm{~Hz}), 7.08(1 \mathrm{H}, \mathrm{d}, J=10.0 \mathrm{~Hz}), 7.15(3 \mathrm{H}, \mathrm{m})$, $7.35(1 \mathrm{H}, \mathrm{q}, J=6.5 \mathrm{~Hz}), 7.54(1 \mathrm{H}, \mathrm{s})$. RP-HPLC: $t_{R}=6.38 \mathrm{~min}$. ESI-MS $m / z: 315.1[\mathrm{M}+$ $\mathrm{Na}]^{+}$. Mp: $146-148{ }^{\circ} \mathrm{C}$.

1-(3-chloro-4-methylphenyl)-3-cyclooctylurea (25). ${ }^{1} \mathrm{H}$ NMR (DMSO- $\left.d_{6}\right): \delta 1.63(14 \mathrm{H}$, m), $2.23(3 \mathrm{H}, \mathrm{s}), 3.68(1 \mathrm{H}, \mathrm{m}), 6.13(1 \mathrm{H}, \mathrm{d}, J=8.0 \mathrm{~Hz}), 7.05(1 \mathrm{H}, \mathrm{d}, J=8.0 \mathrm{~Hz}), 7.16$ $(1 \mathrm{H}, \mathrm{d}, J=8.0 \mathrm{~Hz}), 7.65(1 \mathrm{H}, \mathrm{s}), 8.35(1 \mathrm{H}, \mathrm{s}) . \mathrm{RP}-\mathrm{HPLC}: t_{R}=6.90 \mathrm{~min}$. ESI-MS $\mathrm{m} / \mathrm{z}$ : $317.2[\mathrm{M}+\mathrm{Na}]^{+} . \mathrm{Mp}: 179-182^{\circ} \mathrm{C}$.

1-(3-chloro-4-methylphenyl)-3-(4-phenylbutan-2-yl)urea (26). ${ }^{1} \mathrm{H}$ NMR $\left(\mathrm{CD}_{3} \mathrm{OD}\right): \delta$ $1.20(3 \mathrm{H}, \mathrm{d}, J=6.5 \mathrm{~Hz}), 1.77(2 \mathrm{H}, \mathrm{q}, J=7.0 \mathrm{~Hz}), 2.29(3 \mathrm{H}, \mathrm{s}), 2.69(2 \mathrm{H}, \mathrm{m}), 3.82(1 \mathrm{H}$, m), $7.19(7 \mathrm{H}, \mathrm{m}), 7.54(1 \mathrm{H}, \mathrm{s})$. RP-HPLC: $t_{R}=6.75 \mathrm{~min}$. ESI-MS $m / z: 339.1[\mathrm{M}+\mathrm{Na}]^{+}$. Mp: $111-113{ }^{\circ} \mathrm{C}$.

1-(2-fluoro-3-(trifluoromethyl)phenyl)-3-heptylurea (27). ${ }^{1} \mathrm{H}$ NMR (DMSO- $\left.d_{6}\right): \delta$ $0.86(3 \mathrm{H}, \mathrm{t}, J=6.5 \mathrm{~Hz}), 1.27(8 \mathrm{H}, \mathrm{m}), 1.43(2 \mathrm{H}, \mathrm{t}, J=6.5 \mathrm{~Hz}), 3.10(2 \mathrm{H}, \mathrm{q}, J=6.5 \mathrm{~Hz})$, $6.67(1 \mathrm{H}, \mathrm{t}, J=5.5 \mathrm{~Hz}), 7.28(2 \mathrm{H}, \mathrm{m}), 8.42(1 \mathrm{H}, \mathrm{t}, J=7.0 \mathrm{~Hz}), 8.55(1 \mathrm{H}, \mathrm{s})$. RP-HPLC: $t_{R}$ $=7.39 \mathrm{~min}$. ESI-MS m/z: $343.1[\mathrm{M}+\mathrm{Na}]^{+}$. Mp: $77-79{ }^{\circ} \mathrm{C}$.

1-cyclooctyl-3-(2-fluoro-3-(trifluoromethyl)phenyl)urea (28). ${ }^{1} \mathrm{H}$ NMR $\left(\mathrm{CDCl}_{3}\right): \delta$ $1.67(14 \mathrm{H}, \mathrm{m}), 1.90(2 \mathrm{H}, \mathrm{m}), 3.86(1 \mathrm{H}, \mathrm{m}), 7.25(2 \mathrm{H}, \mathrm{d}), 8.36(1 \mathrm{H}, \mathrm{m})$. RP-HPLC: $t_{R}=$ 7.32 min. ESI-MS $m / z: 355.1[\mathrm{M}+\mathrm{Na}]^{+}$. Mp: $127-129^{\circ} \mathrm{C}$.

1-(2-fluoro-3-(trifluoromethyl)phenyl)-3-(4-phenylbutan-2-yl)urea (29). ${ }^{1} \mathrm{H}$ NMR $\left(\mathrm{DMSO}-d_{6}\right): \delta 1.13(3 \mathrm{H}, \mathrm{d}, J=6.5 \mathrm{~Hz}), 1.71(2 \mathrm{H}, \mathrm{d}, J=7.0 \mathrm{~Hz}), 2.62(2 \mathrm{H}, \mathrm{d}, J=7.5 \mathrm{~Hz})$, $3.70(1 \mathrm{H}, \mathrm{m}), 6.68(1 \mathrm{H}, \mathrm{d}, J=7.0 \mathrm{~Hz}), 7.22(7 \mathrm{H}, \mathrm{m}), 8.47(2 \mathrm{H}, \mathrm{m})$. RP-HPLC: $t_{R}=7.12$ $\min$. ESI-MS $m / z: 377.0[\mathrm{M}+\mathrm{Na}]^{+}$. Mp: $145-148^{\circ} \mathrm{C}$.

1-(3-chlorobenzyl)-3-(2-fluoro-3-(trifluoromethyl)phenyl)urea (30). ${ }^{1} \mathrm{H}$ NMR $\left(\mathrm{DMSO}-d_{6}\right): \delta 4.35(2 \mathrm{H}, \mathrm{d}, J=6.0 \mathrm{~Hz}), 7.22(1 \mathrm{H}, \mathrm{t}, J=5.5 \mathrm{~Hz}), 7.32(4 \mathrm{H}, \mathrm{m}), 7.39(2 \mathrm{H}$, $\mathrm{m}), 8.43(1 \mathrm{H}, \mathrm{m}), 8.76(1 \mathrm{H}, \mathrm{s})$. RP-HPLC: $t_{R}=6.87 \mathrm{~min}$. ESI-MS $m / z: 369.0[\mathrm{M}+\mathrm{Na}]^{+}$. Mp: $152-153^{\circ} \mathrm{C}$. 
1-(2-adamantyl)-3-(2,3,4-trifluorophenyl)thiourea (31). In a round bottom flask equipped with a stir bar, 2-adamantanamine $(0.238 \mathrm{~g}, 1.27 \mathrm{mmol})$ was dissolved in 10 $\mathrm{mL}$ of anhydrous dichloromethane. To this solution, 2,3,4-trifluorophenyl isothiocyanate $(0.14 \mathrm{~mL}, 1.06 \mathrm{mmol})$ followed by triethylamine $(0.53 \mathrm{~mL}, 3.80 \mathrm{mmol})$ was added. The reaction was stirred at room temperature overnight. The solvent was removed by rotary evaporation. The resulting residue was purified by flash chromatography using a petroleum ether to ethyl acetate gradient to elute the final compound $(0.330 \mathrm{~g}, 92 \%) .{ }^{1} \mathrm{H}$ NMR (DMSO- $\left.d_{6}\right): \delta 1.62(2 \mathrm{H}, \mathrm{d}, J=12.0 \mathrm{~Hz}), 1.81(10 \mathrm{H}, \mathrm{m}), 2.01(2 \mathrm{H}, \mathrm{s}), 4.33(1 \mathrm{H}, \mathrm{s})$, $7.27(1 \mathrm{H}, \mathrm{q}, J=9.5 \mathrm{~Hz}), 7.66(1 \mathrm{H}, \mathrm{s}), 8.19(1 \mathrm{H}, \mathrm{s}), 9.30(1 \mathrm{H}, \mathrm{s})$. RP-HPLC: $t_{R}=7.10$ $\min$. ESI-MS $m / z: 363.1[\mathrm{M}+\mathrm{Na}]^{+}$. Mp: $176-179^{\circ} \mathrm{C}$.

2-adamantyl 2,3,4-trifluorophenylcarbamate (32). In a round bottom flask equipped with a stir bar, 2-adamantanol $(0.422 \mathrm{~g}, 2.77 \mathrm{mmol})$ was dissolved in $10 \mathrm{~mL}$ of anhydrous dichloromethane. To this solution, 2,3,4-trifluorophenyl isocyanate $(2.79 \mathrm{~mL}, 2.31 \mathrm{mmol})$ followed by triethylamine $(1.15 \mathrm{~mL}, 8.32 \mathrm{mmol})$ was added. The reaction was stirred at room temperature overnight. The solvent was removed by rotary evaporation. The resulting residue was purified by flash chromatography using a petroleum ether to ethyl acetate gradient to elute the final compound $(0.727 \mathrm{~g}, 97 \%)$. ${ }^{1} \mathrm{H}$ NMR (DMSO- $\left.d_{6}\right): \delta$ $1.54(2 \mathrm{H}, \mathrm{d}, J=11.7 \mathrm{~Hz}), 1.78(10 \mathrm{H}, \mathrm{m}), 2.00(1 \mathrm{H}, \mathrm{s}), 4.78(1 \mathrm{H}, \mathrm{s}), 7.28(1 \mathrm{H}, \mathrm{q}, J=9.6$ $\mathrm{Hz}), 7.45(1 \mathrm{H}, \mathrm{m}), 9.46(1 \mathrm{H}, \mathrm{s})$. RP-HPLC: $t_{R}=7.40 \mathrm{~min}$. ESI-MS $m / z: 348.1[\mathrm{M}+\mathrm{Na}]^{+}$. Mp: $114-116^{\circ} \mathrm{C}$.

1-(2-adamantyl)-3-methyl-3-(2,3,4-trifluorophenyl)urea (33). To a round bottom flask containing $1(0.20 \mathrm{~g}, 0.617 \mathrm{mmol})$, anhydrous THF $(10 \mathrm{~mL})$ was added under argon. The solution was then cooled to $-78^{\circ} \mathrm{C}$. To the cold solution, $n$-butyl lithium $(0.385 \mathrm{~mL}$, $0.617 \mathrm{mmol}$ ) was added drop wise and allowed to stir at $-78^{\circ} \mathrm{C}$ for $10 \mathrm{~min}$. To this solution, iodomethane $(0.038 \mathrm{~mL}, 0.617 \mathrm{mmol})$ was added drop wise at $-78^{\circ} \mathrm{C}$. The solution was then allowed to warm to room temperature and then refluxed for $24 \mathrm{hrs}$. The solvent was then removed by rotary evaporation. The resulting residue was purified by flash chromatography using a petroleum ether to ethyl acetate gradient to elute the final compound as an oil $(0.192 \mathrm{~g}, 92 \%) .{ }^{1} \mathrm{H}$ NMR (DMSO- $\left.d_{6}\right): \delta 1.45(2 \mathrm{H}, \mathrm{d}, J=12.0$ $\mathrm{Hz}), 1.73(10 \mathrm{H}, \mathrm{m}), 1.86(2 \mathrm{H}, \mathrm{s}), 3.14(3 \mathrm{H}, \mathrm{s}), 370(1 \mathrm{H}, \mathrm{s}), 5.62(1 \mathrm{H}, \mathrm{d}, J=5.5 \mathrm{~Hz}), 7.26$ $(1 \mathrm{H}, \mathrm{m}), 7.34(1 \mathrm{H}, \mathrm{q}, J=9.0 \mathrm{~Hz})$. RP-HPLC: $t_{R}=7.10 \mathrm{~min}$. ESI-MS m/z: $361.2[\mathrm{M}+$ $\mathrm{Na}]^{+}$.

1-(2-adamantyl)-1,3-dimethyl-3-(2,3,4-trifluorophenyl)urea (34). To a round bottom flask containing $1(0.40 \mathrm{~g}, 1.23 \mathrm{mmol})$, anhydrous THF $(25 \mathrm{~mL})$ was added under argon. The solution was then cooled to $-78^{\circ} \mathrm{C}$. To the cold solution, $n$-butyl lithium $(1.54 \mathrm{~mL}$, $2.47 \mathrm{mmol}$ ) was added drop wise and allowed to stir at $-78^{\circ} \mathrm{C}$ for $10 \mathrm{~min}$. To this solution, iodomethane $(0.154 \mathrm{~mL}, 2.47 \mathrm{mmol})$ was added drop wise at $-78^{\circ} \mathrm{C}$. The solution was then allowed to warm to room temperature and then refluxed for $24 \mathrm{hrs}$. The solvent was then removed by rotary evaporation. The resulting residue was purified by flash chromatography using a petroleum ether to ethyl acetate gradient to elute the final compound ( $0.190 \mathrm{~g}, 44 \%)$. ${ }^{1} \mathrm{H}$ NMR (DMSO- $\left.d_{6}\right): \delta 1.51(2 \mathrm{H}, \mathrm{d}, J=12.5 \mathrm{~Hz}), 1.74$ 
$(10 \mathrm{H}, \mathrm{m}), 2.18(2 \mathrm{H}, \mathrm{s}), 2.66(3 \mathrm{H}, \mathrm{s}), 3.11(3 \mathrm{H}, \mathrm{s}), 3.61(1 \mathrm{H}, \mathrm{s}), 7.23(1 \mathrm{H}, \mathrm{m}), 7.38(1 \mathrm{H}, \mathrm{q}$, $J=9.5 \mathrm{~Hz})$. RP-HPLC: $t_{R}=7.42 \mathrm{~min}$. ESI-MS $m / z: 375.1[\mathrm{M}+\mathrm{Na}]^{+}$. Mp: $71-74{ }^{\circ} \mathrm{C}$.

1-(2-adamantyl)-3-(4-methoxyphenyl)urea (35). ${ }^{1} \mathrm{H}$ NMR (DMSO- $\left.d_{6}\right): \delta 1.57(2 \mathrm{H}, \mathrm{d}, J$ $=12.5 \mathrm{~Hz}), 1.79(12 \mathrm{H}, \mathrm{m}), 3.70(3 \mathrm{H}, \mathrm{s}), 3.76(1 \mathrm{H}, \mathrm{d}, J=8.0 \mathrm{~Hz}), 6.34(1 \mathrm{H}, \mathrm{d}, J=8.0$ $\mathrm{Hz}), 6.82(2 \mathrm{H}, \mathrm{d}, J=8.5 \mathrm{~Hz}), 7.28(2 \mathrm{H}, \mathrm{d}, J=9.0 \mathrm{~Hz}), 8.20(1 \mathrm{H}, \mathrm{s})$. RP-HPLC: $t_{R}=6.62$ $\min$. ESI-MS $m / z: 301.2[\mathrm{M}+\mathrm{H}]^{+}$. Mp: $125-128^{\circ} \mathrm{C}$.

Methyl 4-(3-(1-adamantyl)ureido)-2-hydroxybenzoate (36). In a round bottom flask equipped with a stir bar, 4-amino-2-hydroxy benzoic acid $(5.0 \mathrm{~g}, 32.67 \mathrm{mmol})$ was dissolved in $50 \mathrm{~mL}$ of anhydrous methanol. To this solution concentrated sulfuric acid (7 $\mathrm{mL}$ ) was added. This solution was allowed to reflux overnight. The solution was allowed to cool to room temperature and then sodium bicarbonate was stirred with the solution until gas evolution ceased. The sodium bicarbonate was then filtered off and the solution concentrated by rotary evaporation. The methyl ester was purified by flash chromatography using a hexane to ethyl acetate gradient to elute the purified product (3.0 $\mathrm{g}, 55 \%)$. The methyl ester $(1.204 \mathrm{~g}, 7.2 \mathrm{mmol})$ was then taken back up in anhydrous dichloroethane $(10 \mathrm{~mL})$ and 1-adamantyl isocyanate $(1.064 \mathrm{~g}, 6.0 \mathrm{mmol})$ added. The solution was refluxed for 4 days. Pure Lee 1392 (0.85 g, 41\%) was obtained by using flash chromatography with a hexane to ethyl acetate gradient. ${ }^{1} \mathrm{H} \mathrm{NMR}\left(\mathrm{CDCl}_{3}\right): \delta 1.68$ $(6 \mathrm{H}, \mathrm{s}), 2.05(9 \mathrm{H}, \mathrm{m}), 3.90(3 \mathrm{H}, \mathrm{s}), 4.73(1 \mathrm{H}, \mathrm{s}), 6.62(1 \mathrm{H}, \mathrm{s}), 6.83(1 \mathrm{H}, \mathrm{s}), 6.98(1 \mathrm{H}, \mathrm{d}, J$ $=9 \mathrm{~Hz}), 7.70(1 \mathrm{H}, \mathrm{d}, J=8.5 \mathrm{~Hz}), 10.83(1 \mathrm{H}, \mathrm{s})$. RP-HPLC: $t_{R}=6.82 \mathrm{~min}$. ESI-MS $\mathrm{m} / \mathrm{z}$ : $367.1[\mathrm{M}+\mathrm{Na}]^{+}$. Mp: $207-210{ }^{\circ} \mathrm{C}$.

1-(1-adamantyl)-3-(2-ethoxyethyl)urea (37). ${ }^{1} \mathrm{H} \mathrm{NMR}\left(\mathrm{CDCl}_{3}\right): \delta 1.23(3 \mathrm{H}, \mathrm{t}, J=7.0$ $\mathrm{Hz}), 1.69(6 \mathrm{H}, \mathrm{s}), 1.98(6 \mathrm{H}, \mathrm{s}), 2.09(3 \mathrm{H}, \mathrm{s}), 3.33(2 \mathrm{H}, \mathrm{q}, J=5.0 \mathrm{~Hz}), 3.52(4 \mathrm{H}, \mathrm{m}), 4.41$ $(1 \mathrm{H}, \mathrm{s}), 4.56(1 \mathrm{H}, \mathrm{s})$. ESI-MS $m / z: 289.1[\mathrm{M}+\mathrm{Na}]^{+} . \mathrm{Mp}: 116-118^{\circ} \mathrm{C}$.

1-(1-adamantyl)-3-(3-methoxypropyl)urea (38). ${ }^{1} \mathrm{H} \mathrm{NMR}\left(\mathrm{CDCl}_{3}\right): \delta 1.69(6 \mathrm{H}, \mathrm{s}), 1.77$ $(2 \mathrm{H}$, quintet, $J=6.0 \mathrm{~Hz}), 1.98(6 \mathrm{H}, \mathrm{s}), 2.09(3 \mathrm{H}, \mathrm{s}), 3.25(2 \mathrm{H}, \mathrm{q}, J=6.0 \mathrm{~Hz}), 3.36(3 \mathrm{H}, \mathrm{s})$, $3.49(2 \mathrm{H}, \mathrm{t}, J=5.5 \mathrm{~Hz})$. ESI-MS $m / z: 289.3[\mathrm{M}+\mathrm{Na}]^{+}$. Mp: $135-137^{\circ} \mathrm{C}$.

1-(1-adamantyl)-3-(2-isopropoxyethyl)urea (39). ${ }^{1} \mathrm{H} \mathrm{NMR}\left(\mathrm{CDCl}_{3}\right): \delta 1.18(6 \mathrm{H}, \mathrm{d}, J=$ $6.0 \mathrm{~Hz}), 1.68(6 \mathrm{H}, \mathrm{s}), 1.98(6 \mathrm{H}, \mathrm{s}), 2.08(3 \mathrm{H}, \mathrm{s}), 3.30(2 \mathrm{H}, \mathrm{q}, J=5.5 \mathrm{~Hz}), 3.50(2 \mathrm{H}, \mathrm{t}, J=$ $5 \mathrm{~Hz}), 3.61(1 \mathrm{H}, \mathrm{m}), 4.50(1 \mathrm{H}, \mathrm{s}), 4.61(1 \mathrm{H}, \mathrm{s})$. ESI-MS m/z: $281.5[\mathrm{M}+\mathrm{H}]^{+}$. Mp: $92-95$ ${ }^{\circ} \mathrm{C}$.

1-(1-adamantyl)-3-(2-propoxyethyl)urea (40). ${ }^{1} \mathrm{H} \mathrm{NMR}\left(\mathrm{CDCl}_{3}\right): \delta 0.95(3 \mathrm{H}, \mathrm{t}, J=7.5$ $\mathrm{Hz}), 1.62(2 \mathrm{H}, \mathrm{m}), 1.69(6 \mathrm{H}, \mathrm{s}), 1.98(6 \mathrm{H}, \mathrm{s}), 2.09(3 \mathrm{H}, \mathrm{s}), 3.33(2 \mathrm{H}, \mathrm{q}, J=5.0 \mathrm{~Hz}), 3.42$ $(2 \mathrm{H}, \mathrm{t}, J=6.5 \mathrm{~Hz}), 3.50(2 \mathrm{H}, \mathrm{t}, J=5.0 \mathrm{~Hz}), 4.39(1 \mathrm{H}, \mathrm{s}), 4.54(1 \mathrm{H}, \mathrm{s})$. ESI-MS $m / z$ : $303.1[\mathrm{M}+\mathrm{Na}]^{+} . \mathrm{Mp}: 87-90{ }^{\circ} \mathrm{C}$.

1,1-bis(tetrahydro-2H-pyran-4-yl)-3-(2,3,4-trifluorophenyl)urea (41). ${ }^{1} \mathrm{H} \mathrm{NMR}$ $\left(\mathrm{CDCl}_{3}\right): \delta 1.69(4 \mathrm{H}, \mathrm{d}, J=10.5 \mathrm{~Hz}), 2.17(4 \mathrm{H}, \mathrm{m}), 3.50(4 \mathrm{H}, \mathrm{t}, J=11 \mathrm{~Hz}), 3.89(2 \mathrm{H}, \mathrm{m})$, 
$4.10(4 \mathrm{H}, \mathrm{m}), 6.45(1 \mathrm{H}, \mathrm{s}), 6.96(1 \mathrm{H}, \mathrm{q}, J=9.5 \mathrm{~Hz}), 7.78(1 \mathrm{H}, \mathrm{m})$. RP-HPLC: $t_{R}=5.58$ min. ESI-MS $m / z: 359.3[\mathrm{M}+\mathrm{H}]^{+}$. Mp: $191-193{ }^{\circ} \mathrm{C}$.

1,3-bis(4-(isopentyloxy)phenyl)urea (42). To a round-bottom flask, 4-nitrophenol (2.0 g, $14.37 \mathrm{mmol})$ and sodium hydroxide $(1.73 \mathrm{~g}, 43.13 \mathrm{mmol})$, was dissolved in N,Ndimethylformamide $(50 \mathrm{~mL})$. The solution was stirred at room temperature for $15 \mathrm{~min}$. After stirring, 1-bromo-4-methylpentane $(5.39 \mathrm{~mL}, 43.43 \mathrm{mmol})$ was added to the solution and refluxed for $3 \mathrm{~h}$. The resulting solution was washed with $0.7 \mathrm{~N} \mathrm{HCl}(3 \times 20$ $\mathrm{mL})$ then extracted with diethyl ether $(3 \times 20 \mathrm{~mL})$. The combined organic fractions were then washed with brine $(3 \times 20 \mathrm{~mL})$ and dried over magnesium sulfate. The solution was then filtered and the solvent by using rotary evaporation. The crude mixture was then purified by flash chromatography using a petroleum ether to ethyl acetate gradient to obtain pure intermediate $(2.69 \mathrm{~g}, 90 \%)$. The intermediate nitro compound was then converted to an aniline by hydrogenation using $\mathrm{Pd} / \mathrm{C}$ catalyst overnight. The aniline was used in the next step without further purification $(1.85 \mathrm{~g}, 80 \%)$. In a round bottom flask, the aniline $(1.27 \mathrm{~g}, 7.08 \mathrm{mmol})$ was dissolved in dichloromethane and then triethylamine $(1.97 \mathrm{~mL}, 14.16 \mathrm{mmol})$ was added and the solution was allowed to stir at room temperature for $15 \mathrm{~min}$. In a separate round bottom flask, triphosgene $(0.70 \mathrm{~g}, 2.36$ mmol) was dissolved in dichloromethane. Then the solution of the aniline was slowly added into the solution of thiophosgene under argon and allowed to stir overnight at room temperature. The product $(0.301 \mathrm{~g}, 33 \%)$ crashed out of solution and was filtered off and washed with dichloromethane. ${ }^{1} \mathrm{H}$ NMR $\left(\mathrm{DMSO}-d_{6}\right): \delta 0.93(12 \mathrm{H}, \mathrm{d}, J=6.5 \mathrm{~Hz}), 1.59$ $(4 \mathrm{H}, \mathrm{q}, J=6.5 \mathrm{~Hz}), 1.77(2 \mathrm{H}, \mathrm{m}), 3.94(4 \mathrm{H}, \mathrm{t}, J=6.5 \mathrm{~Hz}), 6.85(4 \mathrm{H}, \mathrm{d}, J=9.0 \mathrm{~Hz}), 7.31$ $(4 \mathrm{H}, \mathrm{d}, J=9.0 \mathrm{~Hz}), 8.35(2 \mathrm{H}, \mathrm{s})$. RP-HPLC: $t_{R}=7.44 \mathrm{~min}$. ESI-MS $m / z: 407.3[\mathrm{M}+$ $\mathrm{Na}]^{+} . \mathrm{Mp}: 173-175^{\circ} \mathrm{C}$.

1,3-bis(4-(isopentyloxy)phenyl)thiourea (43). To a round-bottom flask, 4-nitrophenol $(2.0 \mathrm{~g}, 14.37 \mathrm{mmol})$ and sodium hydroxide $(1.73 \mathrm{~g}, 43.13 \mathrm{mmol})$, was dissolved in N,Ndimethylformamide $(50 \mathrm{~mL})$. The solution was stirred at room temperature for $15 \mathrm{~min}$. After stirring, 1-bromo-4-methylpentane $(5.39 \mathrm{~mL}, 43.43 \mathrm{mmol})$ was added to the solution and refluxed for $3 \mathrm{~h}$. The resulting solution was washed with $0.7 \mathrm{~N} \mathrm{HCl}(3 \times 20$ $\mathrm{mL})$ then extracted with diethyl ether $(3 \times 20 \mathrm{~mL})$. The combined organic fractions were then washed with brine $(3 \times 20 \mathrm{~mL})$ and dried over magnesium sulfate. The solution was then filtered and the solvent by using rotary evaporation. The crude mixture was then purified by flash chromatography using a petroleum ether to ethyl acetate gradient to obtain pure intermediate $(2.69 \mathrm{~g}, 90 \%)$. The intermediate nitro compound was then converted to an aniline by hydrogenation using $\mathrm{Pd} / \mathrm{C}$ catalyst overnight. The aniline was used in the next step without further purification $(1.85 \mathrm{~g}, 80 \%)$. In a round bottom flask, the aniline $(1.85 \mathrm{~g}, 10.9 \mathrm{mmol})$ was dissolved in dichloromethane and then triethylamine $(2.88 \mathrm{~mL}, 20.64 \mathrm{mmol})$ was added and the solution was allowed to stir at room temperature for $15 \mathrm{~min}$. In a separate round bottom flask, thiophosgene $(0.26 \mathrm{~mL}, 3.44$ mmol) was dissolved in dichloromethane. Then the solution of the aniline was slowly added into the solution of thiophosgene under argon and allowed to stir overnight at room temperature. The product $(0.683 \mathrm{~g}, 50 \%)$ crashed out of solution and was filtered off and washed with dichloromethane. ${ }^{1} \mathrm{H}$ NMR $\left(\mathrm{DMSO}-d_{6}\right): \delta 0.94(12 \mathrm{H}, \mathrm{d}, J=7.0 \mathrm{~Hz}), 1.61$ 
$(4 \mathrm{H}, \mathrm{q}, J=7.0 \mathrm{~Hz}), 1.79(2 \mathrm{H}, \mathrm{m}), 3.98(4 \mathrm{H}, \mathrm{t}, J=7.0 \mathrm{~Hz}), 6.90(4 \mathrm{H}, \mathrm{d}, J=9.0 \mathrm{~Hz}), 7.10$

$(4 \mathrm{H}, \mathrm{d}, J=9.0 \mathrm{~Hz}), 9.45(2 \mathrm{H}, \mathrm{s})$. RP-HPLC: $t_{R}=7.39 \mathrm{~min}$. ESI-MS $m / z: 423.2[\mathrm{M}+$ $\mathrm{Na}]^{+}$. Mp: $139-141^{\circ} \mathrm{C}$.

\section{MIC Determination}

MIC values were determined against M. tuberculosis $(\mathrm{H} 37 \mathrm{Rv})$ and other bacteria by the microbroth dilution method. ${ }^{108,109} \mathrm{~A}$ broth culture of M. tuberculosis or $M$.

smegmatis $\mathrm{mc}^{2} 155$ was grown in Middlebrook 7H9 medium with $10 \%$ ADC supplement to an $\mathrm{OD}_{600}$ of $0.4-0.6$. The culture was diluted with $7 \mathrm{H} 9$ medium to an $\mathrm{OD}_{600}$ of 0.01 , and $100 \mu \mathrm{L}$ was added to a microtiter plate containing two-fold serial dilutions of the tested compounds for a final volume of $200 \mu \mathrm{L}$. The plates were incubated at $37 \mathrm{C}$ for 7 days. The $\mathrm{MIC}_{90}$ was determined by visual inspection and defined as the concentration that inhibited $90 \%$ of growth. MICs against other bacteria were performed according to the CLSI method and also read by visual inspection. ${ }^{110,111}$

\section{Cytotoxicity Study}

Cytotoxicity assays were performed using the Vero monkey kidney cell line (CCL-81) obtained from the American Type Culture Collection (ATCC, Manassas, VA). Vero cells were propagated in Dulbecco's Modified Eagle's Medium supplemented with $10 \%$ fetal bovine serum and maintained in a humidified incubator $\left(37^{\circ} \mathrm{C}, 5 \% \mathrm{CO}_{2}\right)$. After dislodging cells with a cell scraper, they were collected by centrifugation, resuspended in fresh medium at $\sim 10^{6}$ cells $/ \mathrm{mL}$, dispensed into 96 -well microtiter plates $(100 \mu \mathrm{l} / \mathrm{well})$ and incubated for $18 \mathrm{~h}$ at $37^{\circ} \mathrm{C}$ before being used for cytotoxicity assays. Test compounds were subsequently added at concentrations ranging from $400-0.2 \mu \mathrm{g} / \mathrm{mL}$ and incubation continued for another $72 \mathrm{~h}$ before the cytopathic effects of compounds was determined using the MTT Cell Proliferation Assay (ATCC). The cytotoxic $\mathrm{IC}_{50}$ defined as the concentration causing $50 \%$ reduction in Vero cell viability, was obtained from a dose response curve plotted from percentage activity versus $\log _{10}$ concentration. Therapeutic selectivity was then determined as the Cytotoxic $\mathrm{IC}_{50}$ divided by the $\mathrm{MIC}$ against $M$. tuberculosis. 


\title{
CHAPTER 3: DESIGN OF NOVEL SIDEROPHORE ANTIMICROBIAL AGENTS FOR THE TREATMENT OF GRAM-NEGATIVE BACTERIA
}

\author{
Introduction to Gram-Negative Bacteria
}

Composition

Gram-negative bacterial infections are much more difficult to treat than grampositive bacterial infections. This discrepancy is due to a variety of reasons that ultimately lead back to the fact that penetrating the gram-negative bacterial cell wall is very difficult for drug-like molecules when compared to gram-positive bacteria. Gramnegative bacteria have a unique outer membrane, a thinner peptidoglycan layer, and a periplasmic space between the cell wall and the membrane. In the outer membrane, gram-negative bacteria have lipopolysaccharides, porin channels, and murein lipoprotein all of which gram-positive bacteria lack that limit permeability. ${ }^{112}$

\section{Quorum Sensing}

Quorum sensing is a term that is used to describe the ability of a population of unicellular bacteria to act as a multicellular organism in a cell-density-dependent manner. ${ }^{113-115}$ Bacteria use small diffusible molecules to exchange information between the separate organisms. These small molecules are called "quormones," or autoinducers. One important class of quormones used by gram-negative bacteria is the family of Nacylhomoserine lactones (AHLs). The length of the acyl chain and the oxidation state of the AHLs provide for bacterial strain specificity in the signaling process and the subsequent synchronization of gene expression. ${ }^{116}$ Depending upon the pattern of acylation, most AHLs will diffuse freely across the bacterial cell membrane. Upon reaching a critical threshold concentration, the AHLs bind to their respective receptor proteins triggering the expression of target genes; for example, in Vibrio fischeri, genes located on the lux operon are transcribed that are responsible for the production of bioluminescence. ${ }^{117}$

Pseudomonas aeruginosa is a common environmental microorganism that has obtained the ability to take advantage of weaknesses in their host's immune system to become an opportunistic pathogen in humans. ${ }^{118}$ Pseudomonas aeruginosa is an important pathogen for patients with cystic fibrosis. Due to the nature of cystic fibrosis, infections caused by Pseudomonas aeruginosa, if left untreated, in these patients is often fatal. Pseudomonas aeruginosa can also manifest itself as a nosocomial infection in other immuno-suppressed populations, particularly in burn victims. These infections cause serious complications because of their wide array of virulence mechanisms and high inherent antibiotic resistance to Pseudomonas aeruginosa. These infections continue to become more perilous as the bacteria continues to grow and form biofilms that increase resistance to many antibiotics. ${ }^{116}$ 
A significant amount of research has been done over the past 10 years in elucidating the molecular mechanisms underlying the pathogenicity of Pseudomonas aeruginosa. Two different AHLs, N-(3-oxododecanoyl)homoserin lactone (1), synthesized by LasI, and N-butyrylhomoserine lactone (2), synthesized by RhlI, have been identified as the main quorum-sensing molecules in Pseudomonas aeruginosa (Figure 3.1) ${ }^{119}$ Quorum sensing has been demonstrated to control the expression of other virulence factors as well as the formation of biofilms. ${ }^{120}$ It has been demonstrated that N(3-oxododecanoyl)homoserine lactone (1) itself and its tetramic acid-degradation product, derived from an unusual intramolecular condensation reaction, function as innate bactericidal agents. Also, the AHL degradation product has been shown to tightly coordinate essential metals such as iron, possibly providing a previously unrecognized primordial siderophore. ${ }^{116}$ The iron chelating ability of tetramic acids has been proven and quantified. ${ }^{121}$

\section{Tetramic Acids}

Tetramic acids are a known class of antibacterial compounds. ${ }^{16,122}$ The term was coined in 1901 in reference to the heterocyclic 1,5-dihydro-4-hydroxy-2H-pyrrol-2-one system, 3 (Figure 3.2). This structure is a tautomer of 2,4-pyrrolidinedinone, which is the major tautomeric species in solution, 4 (Figure 3.2). Compounds containing this functionality show a wide range of biological activity and have attracted the attention of medicinal chemists who hope to utilize this unique group in the design of future antibacterial agents. ${ }^{122}$

Naturally occurring tetramic acids have stirred up a great amount of interest due to their wide array of antibacterial activity. However, there currently are not any drugs available on the market that contain the tetramic acid core. ${ }^{123,124}$ The tetramic core is the key component of many natural products such as reutericyclin, tenzuazoic acid, streptolydigin, PF1052, and erythroskyrine (Figure 3.3). ${ }^{124-127}$ All of these compounds show antibacterial activity. Quite a few studies have been conducted on synthesizing and isolating naturally occurring tetramic acids. However, only a few studies exist that report on the SAR of these compounds and emphasize their antibacterial properties. ${ }^{128-130}$

\section{Synthesis of Quorum Sensing Molecule 1 and Its Degradation Product}

In order to test the iron chelating ability of the tetramic acid degradation product of N-(3-oxododecanoyl)homoserine lactone, both compounds were synthesized (Scheme 3.1). ${ }^{116,131}$ Compound 1 was prepared by the DCCI/DMAP catalyzed acylation of Meldrum's acid with decanoic acid in dichloromethane. The isolated product was used in the next step of the reaction without further purification. Amidation of the product with L-homoserine lactone in the presence of triethylamine in acetonitrile afforded the desired $\mathrm{N}$-(3-oxododecanoyl)homoserine lactone in $9 \%$ yield. 


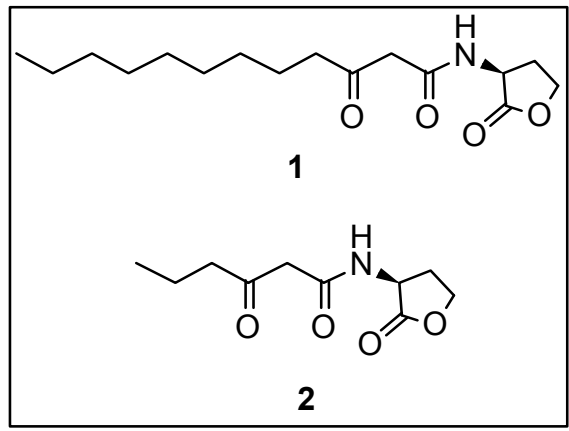

Figure 3.1: Quorum Sensing Molecules 1 and 2

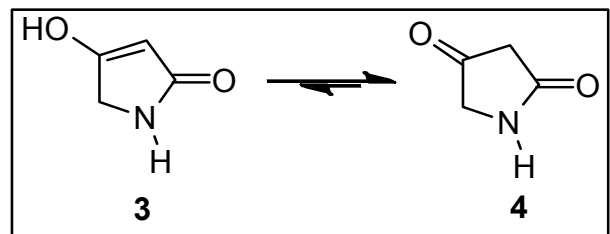

Figure 3.2: Tautomers of Tetramic Acid Moiety

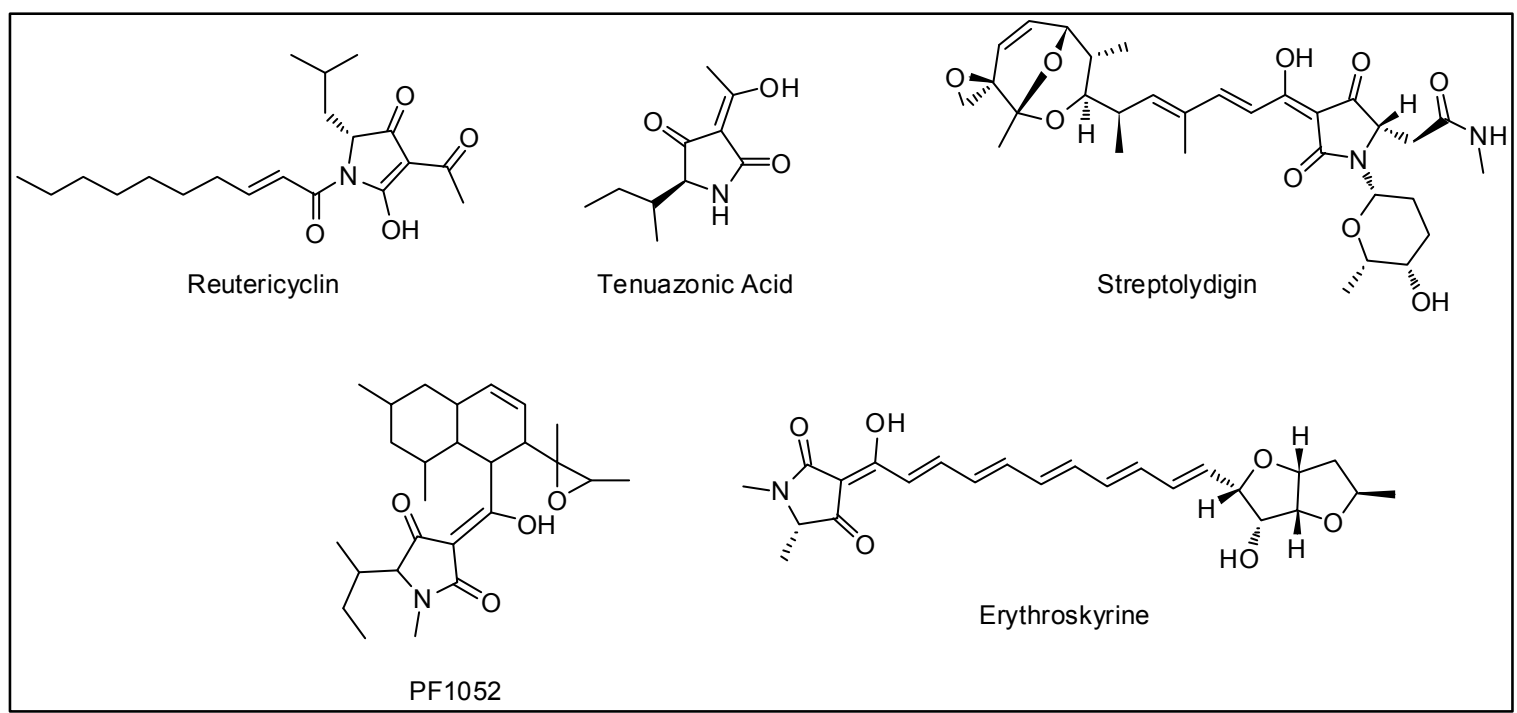

Figure 3.3: $\quad$ Structures of Tetramic Acid Containing Natural Products 
Scheme 3.1: Synthesis of Quorum Sensing Molecule 1 and Its Degradation Product

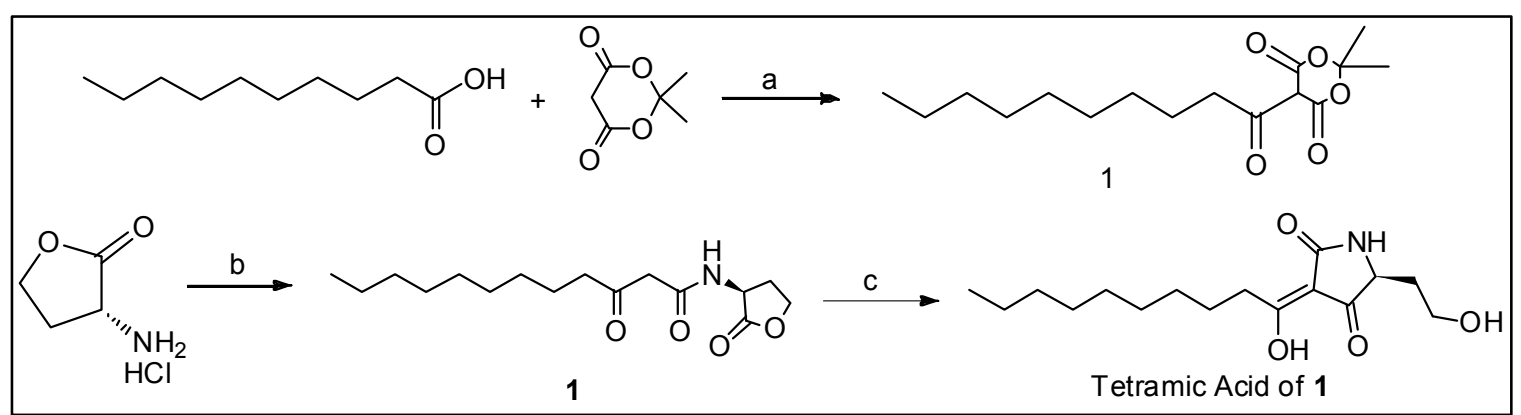

Reagents and Conditions: (a) DCCI, DMAP, Anhy. DCM; (b) 1, TEA, Acetonitrile; (c) $\mathrm{NaOMe}$, Anhy. $\mathrm{MeOH}$ 
The tetramic acid degradation product of $\mathbf{1}$ was prepared by placing $\mathbf{1}$ in a flask containing anhydrous methanol. To this a 0.5 molar $(\mathrm{M})$ solution of sodium methoxide in methanol was added. This reaction was stirred at room temperature, and then passed through an acidic ion-exchange resin (Dowex 50WX2-200) and eluted with methanol. The filtrates were combined and concentrated. The final product was afforded after purification via HPLC. The final compound was obtained in $35 \%$ yield.

\section{Significance of the Tetramic Acid Degradation Product as a Siderophore}

Compound 1 and its tetramic acid degradation product play a pivotal in the life of the gram-negative bacteria Pseudomonas aeruginosa. It has been hypothesized that due to the fact compound $\mathbf{1}$ is the primary quorum sensing molecule for Psuedomonas aeruginosa, and the fact that tetramic acids have proven antibacterial activity, the tetramic acid of 1 plays an important role in bacterial viability. ${ }^{116}$ One study has shown that lipid-like antibiotics have a propensity to localize near the cell surface on grampositive bacteria. ${ }^{132}$ It has been shown that when the tetramic acid of $\mathbf{1}$ is incubated overnight with gram-positive bacteria, significant antibacterial activity is seen. However, when the same experiment is conducted with gram-negative bacteria, no antibacterial activity was seen. ${ }^{116}$ In analogous studies, it has been shown that structurally similar tetramic acids also show toxicity against gram-positive bacteria with little variation in $\mathrm{EC}_{50}$ value across different species and genera. ${ }^{133}$ While the antibacterial activity of this tetramic acid may not be as great as other known bactericidal agents, the fact that this compound is nonenzymatically produced from a cell-cell signaling molecule is significant. ${ }^{116}$

These compounds were synthesized in an attempt, not to demonstrate their antibacterial activity, but to show the iron chelating ability of the tetramic acid in our hands, and its potential role as a siderophore. It has been shown that tetramic acids have the ability to chelate iron in an efficient manner. Iron has an indispensable function in physiological processes and pathogenesis of bacteria. ${ }^{134,135}$ Some bacteria have been known to synthesize a siderophore to aid in the sequestration of iron, an element that is essential for their growth, but is poorly soluble at physiological conditions. ${ }^{136}$ It has been shown that Pseudomonas aeruginosa produces two siderophores, pyoverdin and pyochelin, and can also utilize various heterologous siderophores of microbial origins. ${ }^{134}$ The genome of Pseudomonas aeruginosa encodes for numerous homologues of ironsiderophore receptor genes. This reveals just how important iron is to bacterial survival, and its need to compete with other microorganisms within their environment for this indispensable metal. ${ }^{137,138}$

The tetramic acid iron chelate of compound $\mathbf{1}$ has been sent to collaborators at Northeastern University to explore its potential as a growth promoter for unculturable gram-negative organisms. This group of collaborators are conducting biological evaluations of this compound, which are currently still in their infancy. There has been some promising preliminary data that has arisen from these tests. The collaborators collected intertidal sediment from Canoe Beach in Nahant, MA and air dried it to enrich 
for spore forming microorganisms. The $5 \mathrm{~g}$ of sediment was mixed with $5 \mathrm{~mL}$ of $2 \%$ Artificial Sea Salts (Sigma) and vortexed for 1 minute to remove bacterial cells from the sand biofilm. Next, $100 \mathrm{uL}$ samples were plated on R2A (Difco) agar supplemented with $2 \%$ Artificial Sea Salts. Replicates with and without spotting $10 \mathrm{uL}$ of a $0.24 \mathrm{mg} / \mathrm{mL}$ solution of tetramic acid of compound 1 (1\% DMSO in water) were incubated at room temperature and photographed after one and three days.

This preliminary data clearly shows that while it takes three days for most colonies to appear from these bacterial isolates, the largest and fastest growing colony appears where the tetramic acid of compound 1 was spotted (Figure 3.4). The experiment was performed induplicate, and the results were identical for both runs (Figure 3.5). This data shows the ability of the tetramic acid of compound $\mathbf{1}$ to presumably aid in the sequestration of nutrients from the environment surrounding these bacteria. This allows the bacterial colony to grown larger and more rapidly than the other colonies on the plates. This data clearly demonstrates the ability of bacteria to adapt and use foreign substances in order to provide itself with the best opportunity to survive.

The 3-acetyl-pyrrolidine-2,4-dione heterocycle core found in most tetramic acid, including the tetramic acid of compound $\mathbf{1}$, has been shown to effectively chelate numerous metal cations including iron. ${ }^{121}$ It is unclear as to whether chelation with a metal cation alters the toxicity of this compound as some tetramic acids have shown an increased toxicity upon chelation while others have shown a decrease in toxicity. ${ }^{139}$ Previous studies have demonstrated that the fungal tetramic acid metabolite tenuazoic acid forms an octahedral complex with a 3:1 stoichiometry upon chelation with iron(III). ${ }^{140}$ In accordance with these studies, it is hypothesized that the tetramic acid of compound $\mathbf{1}$ will have the same coordination geometry and stoichiometry. ${ }^{116}$

\section{Synthesis of Iron(III) Chelation Product of Tetramic Acids}

The iron(III) chelation complex of tetramic acid from compound $\mathbf{1}$ was synthesized by dissolving three equivalents of the tetramic acid in methanol (Scheme 3.2). As the tetramic acid dissolved, the solution became a light tan color. Separately, one equivalent of iron(III) chloride was dissolved in methanol. This solution was bright yellow in color. The solution of iron(III) chloride was then added to the solution of the tetramic acid and the resulting solution immediately became dark red in color. The solutions were stirred at room temperature for 30 minutes, and then concentrated by rotary evaporation to afford a dark red viscous liquid. The formation of the 3:1 ratio was confirmed via mass spectrometry and spectrophotometric assay at $440 \mathrm{~nm}$. A chelation complex was also synthesized for another tetramic acid derivative that was previously synthesized, Lee 867 (Scheme3.3). This product was obtained utilizing the same synthetic procedure for the first chelation complex. 


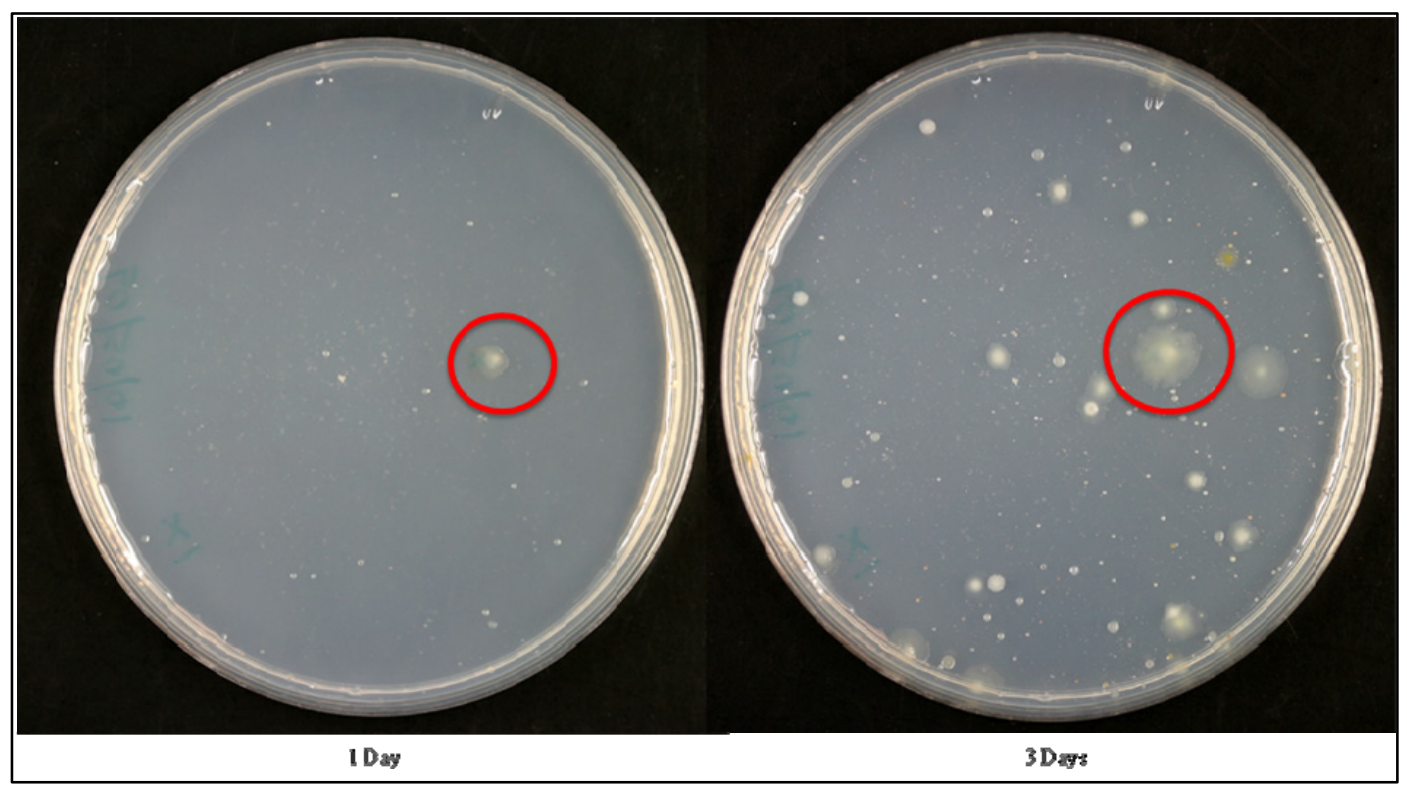

Figure 3.4: $\quad$ Preliminary Biological Evaluation of Tetramic Acid 1

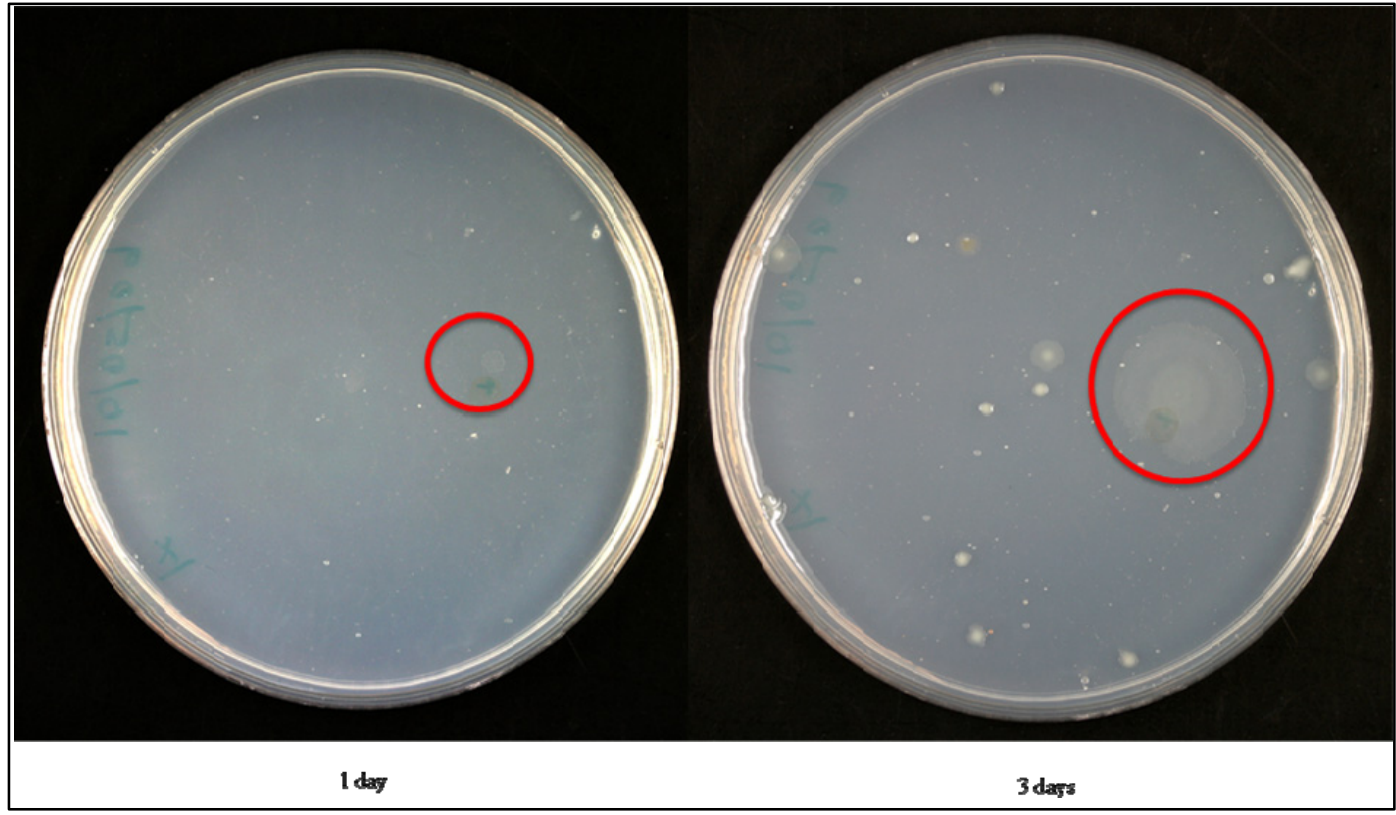

Figure 3.5: Repeat of Preliminary Biological Evaluation of Tetramic Acid 1 
Scheme 3.2: Synthesis of Chelation Product for Tetramic Acid 1

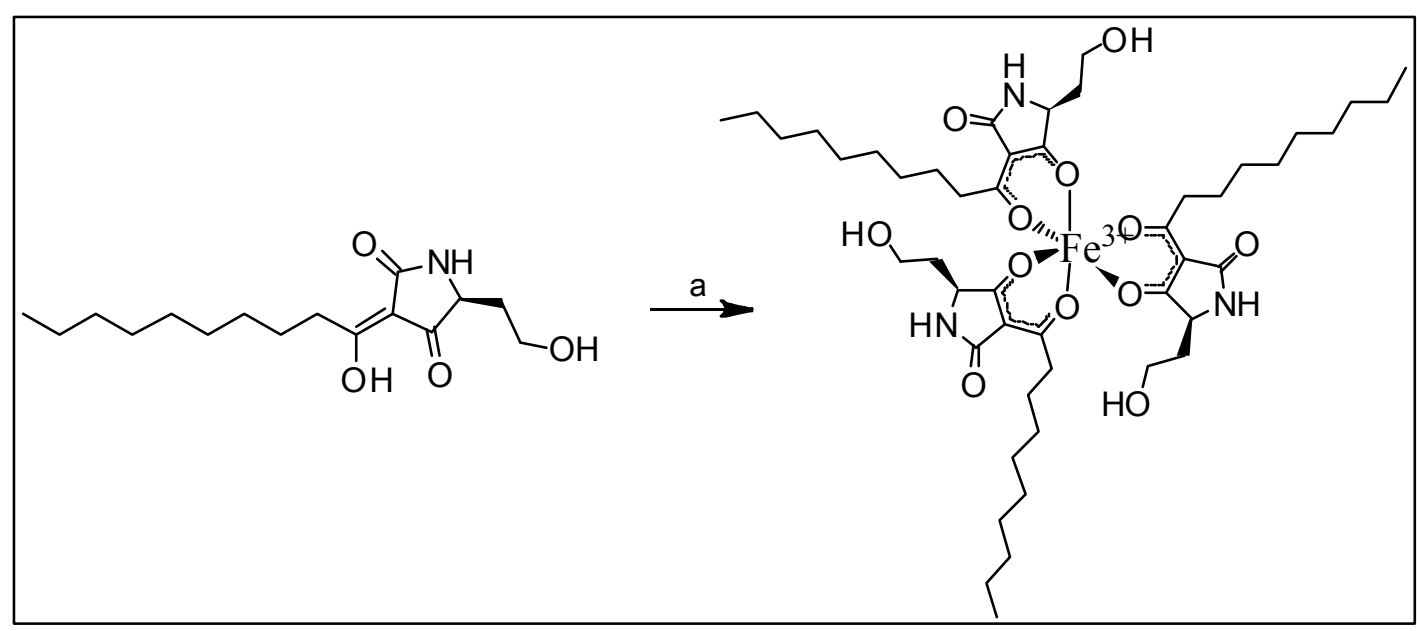

Reagents and Conditions: (a) $\mathrm{FeCl}_{3}$, Methanol, RT, 30 minutes

Scheme 3.3: Synthesis of Chelation Complex for Lee 867

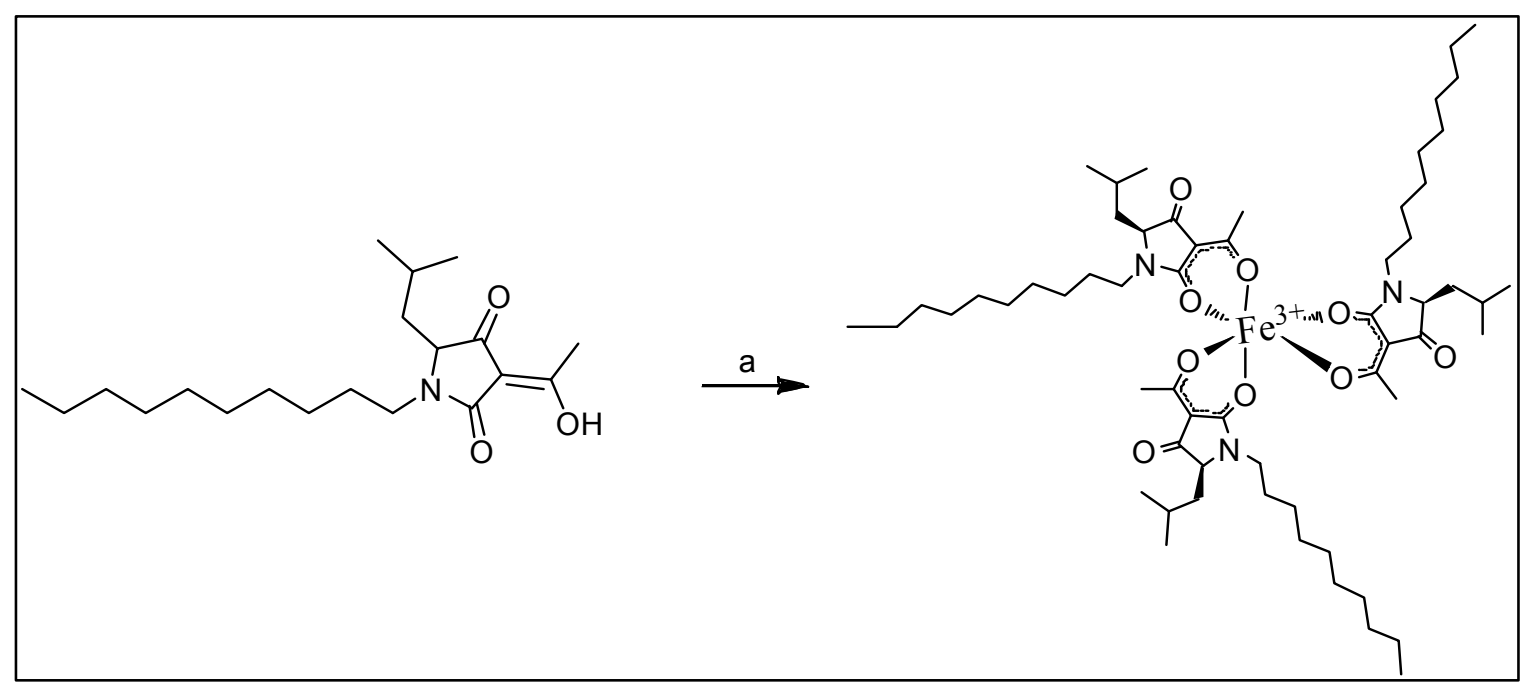

Reagents and Conditions: (a) $\mathrm{FeCl}_{3}$, Methanol, RT, 30 minutes 


\section{Siderophores as Antibacterial Agents}

\section{Background}

As previously discussed, iron plays a vital role in the life of all bacteria. However, due to the nature of the element it is not readily available at physiological conditions. That is due to the fact that it is rapidly oxidized from $\mathrm{Fe}^{2+}$ to $\mathrm{Fe}^{3+}$ and subsequently forms insoluble hydroxides. The concentration of $\mathrm{Fe}^{3+}$ at physiological conditions is as low as $10^{-9} \mathrm{M}$, which makes this commodity very scarce for the bacteria. $^{141-143}$ Bacteria have evolved numerous ways to overcome this shortage of iron. ${ }^{144,145}$ These evolutionary tactics primarily involve the formation of receptor proteins on the surface of the bacteria that bind to a wide range of iron-containing molecules. These receptors caused the iron complexes to become localized on the cell surface, where they then become accessible for transport inside the cell. This process is easily carried out by gram-positive bacteria. They are able to deliver the siderophore to Adenosine Triphosphate (ATP)-binding-cassette (ABC) importers, which transport the siderophore across the cell membrane. The energy for this process comes from the hydrolysis of ATP inside of the cell. A process similar to this occurs in the gram-negative bacteria, but the process is more convoluted due to the presence of the additional lipid layer found in these organisms. $^{143}$

Transportation of nutrients in gram-negative bacteria usually occurs via porins. These porins allow small molecules and ions to diffuse through the membrane. However, this diffusion-driven process is inefficient for the supply of iron that is necessary for cell survival. The inefficiency arises primarily due to the extremely low concentration of iron in the surrounding environment. ${ }^{143}$

\section{TonB Transport System}

Gram-negative bacteria have evolved a method which allows them to overcome the inefficiency of porin diffusion in order to obtain nutrients in a much more efficient manner. This sophisticated method enables the bacteria to supply high-affinity outermembrane receptors with the necessary energy for ligand uptake from the cytoplasmic membrane by the protein complex known as the Ton system. ${ }^{143,146-149}$ This complex consists of numerous proteins, including TonB. TonB is said to experience a series of conformational changes that are driven by the proton-motive force, which allows it mechanically interact with the outer-membrane receptors, thus enabling transport into the interior of the cell.

The importance of TonB has been validated by numerous scientific studies that elucidated the fact that TonB plays a vital role in nutrient transport. These studies showed that TonB mutants were unable to transport siderophores or vitamin $\mathrm{B}_{12}$ into the cell. ${ }^{150,151}$ Another important experiment, conducted in 1980, showed that BtuC mutants, which are unable take up vitamin $B_{12}$ across the cytoplasmic membrane, were able to 
generate a 1000-fold increase in the concentration of vitamin $B_{12}$ in the periplasmic space, when compared to the external medium, as long as the TonB and it energy source were in place. ${ }^{152}$ Therefore, while the mechanism for the TonB pathway may not be entirely elucidated, it is shown to play a vital role in the uptake of nutrients from the cellular environment.

\section{Application}

As stated previously, there is an ever increasing need to develop novel antibiotics for the treatment of gram-negative bacterial infections. Of particular concern is the organism Pseudomonas aeruginosa, it posses intrinsic resistance to numerous currently used antibiotics and it has also acquired additional mechanisms of resistance, including target mutations, increased expression of efflux pumps and of antibiotic-degrading enzymes. ${ }^{153}$ One of the biggest problems associated with treating gram-negative bacteria is getting the drug inside of the bacteria. As discussed previously, gram-negative bacteria, Pseudomonas aeruginosa in particular, have evolved numerous ways in which to get nutrients from the environment into their interior for use. Since the 1980s, numerous attempts have been made by drug developers to take advantage of this fact and utilize siderophore containing antibiotics in hopes to gain entry into the bacteria. ${ }^{154}$ One such agent is BAL30072 (Figure 3.6).

BAL30072 is a novel siderophore monobactam antibiotic that is currently in preclinical trials. It contains a monobactam antibiotic, which is analogous to the agent tigemonam, and a dihydropyridone iron-chelating group. ${ }^{155,156}$ It has been shown that this combination of features provides markedly different antibiotic properties to BAL30072, along with a different mechanism of action. ${ }^{155,157,158}$ BAL30072 has shown activity against $70 \%$ of the carbapenem-resistant Enterobacteriaceae strains tested, including stains with class A, class B, and class D carbapenemases. BAL30072 show promising activity against non-fermentors, especially Acinetobacter spp., Burkholderia spp., and Stenotrophomonas maltophila. It was also the most active $\beta$-lactam against MDR-Pseudomonas aeruginosa in the panel tested. ${ }^{159}$

The promising activity shown by BAL30072 has led to the development of a hypothesis involving the use of a novel siderophore attached to an antibacterial agent (Figure 3.7). It is thought that, as in the case of BAL30072, this siderophore will allow the antibacterial agent to enter the gram-negative bacteria via an alternate route with more efficacy than porin mediated entry, thus allowing the agent to kill the bacteria more effectively. The siderophore that was chosen for this experiment was the tetramic acid core. As previously shown, this core structure can readily chelate iron and therefore shows promise for utilization as a siderophore. 


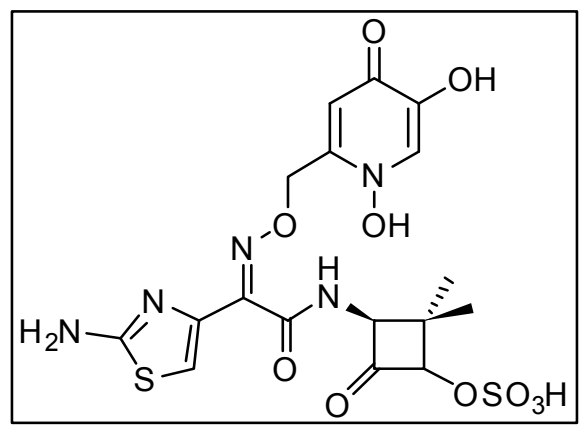

Figure 3.6: $\quad$ Structure of BAL 30072

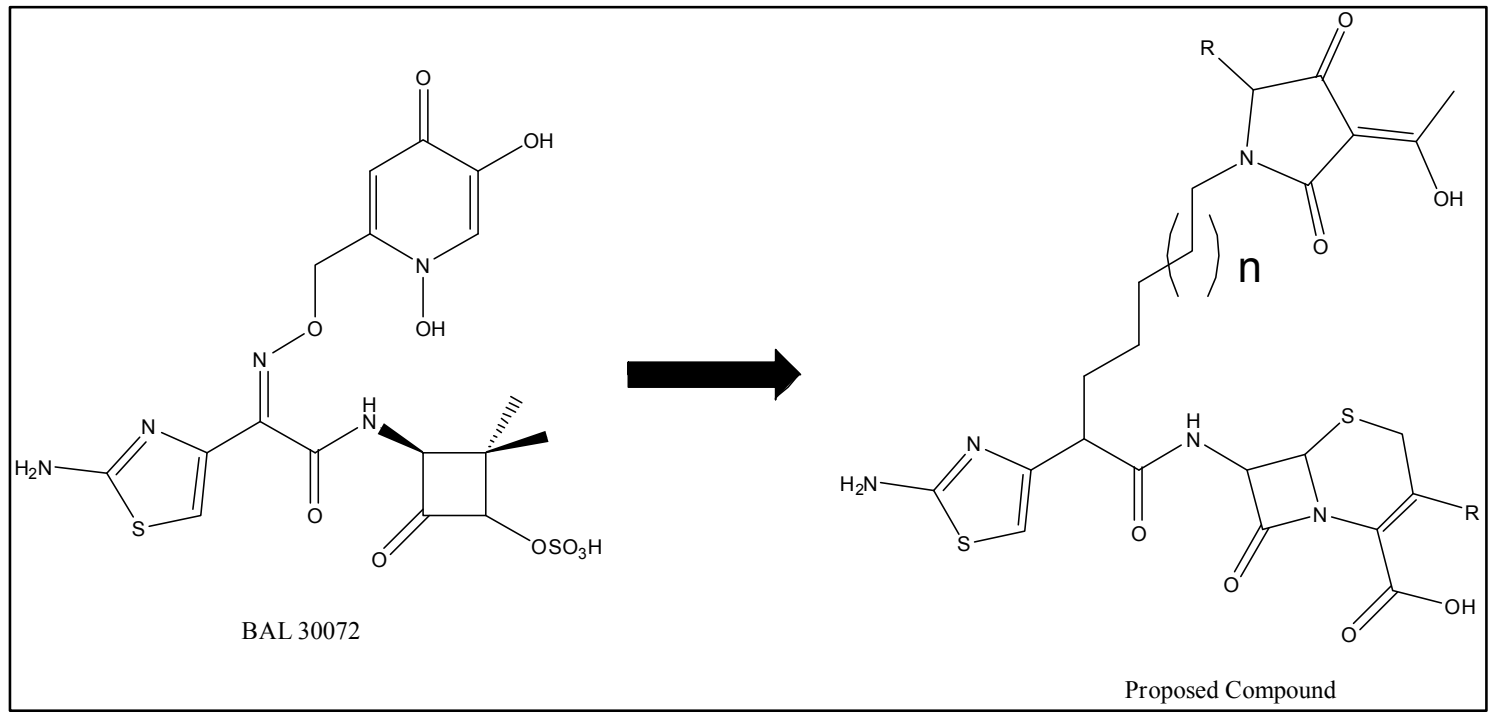

Figure 3.7: Relationship of BAL 30072 to Proposed Compound 


\section{Synthesis of Tetramic Acid Core}

The tetramic acid core was synthesized according to a previously reported procedure (Scheme 3.4). ${ }^{124}$ The synthesis started with the reductive amination of valine ethyl ester hydrochloride salt with 3-((tert-butyldimethylsilyl)oxy)propanal in tetrahydrofuran in the presence of magnesium sulfate and triethylamine. The resulting imine was reduced using sodium borohydride in methanol. The secondary amine was then reacted with diketene in dichloromethane in the presence of triethylamine at reflux to yield the $\beta$-keto amide. ${ }^{160}$ The amide was then cyclized in the tetramic acid core using Amberlyst A-26 hydroxide resin. ${ }^{161,162}$

The starting aldehyde (3-((tert-butyldimethylsilyl)oxy)propanal) is a relatively expensive compound. Therefore, in order to reduce the cost associated with using this starting material; an alternate synthetic route was developed (Scheme 3.5). This route utilizes the same valine ethyl ester hydrochloride salt, but instead of the aldehyde, (3bromopropoxy)(tert-butyl)dimethylsilane was used in its place. The reaction was carried out in the microwave reactor in dimethylformamide in the presence of potassium carbonate. Once the secondary amine was isolated, the reaction continued in the same manner as shown in Scheme 3.4.

This multiple-step synthetic reaction afforded the final compound and the desired intermediates in adequate yields. The first step of this reaction produced the secondary amine intermediate in a $44 \%$ yield. The second step afforded the amide in a $50 \%$ yield. The final step provided the final product in an $88 \%$ yield. Overall these yields are reasonable and are high enough to provide a substantial amount of the final compound in a reasonable timeframe. When attempting to couple the tetramic acid core to the desired antibiotic, in order to complete the desired synthesis, problems were noted and no final compound was obtained. A number of different synthetic techniques were attempted, but none were able to afford the desired compound. One problem may be the fact that there are two alcohol moieties present in the tetramic acid core. Upon trying to couple the primary alcohol to the antibiotic, no reaction was observed. This is probably due to the fact that the secondary alcohol may be interfering with the reaction. In order to alleviate this problem, orthogonal protecting group strategies need to be explored that can provide selective protection for each type of alcohol present. Upon attempting various other synthetic methodologies, none were able to produce the desired final compound.

\section{Conclusions}

This project is only in its infancy, and there is much left to discover. There is still much work to be done involving the use of siderophores as aids in the design of novel antimicrobial agents. The large literature precedence for this type of work is very promising. I feel as though the work done on this project in our hands will only help to further elucidate the role of siderophores, in particular the role of tetramic acids, in how they alter the in vitro and in vivo efficacy of antibacterial agents. The preliminary biological study conducted by our collaborators at Northeastern University provides 


\section{Scheme 3.4: Synthesis of Tetramic Acid Core}

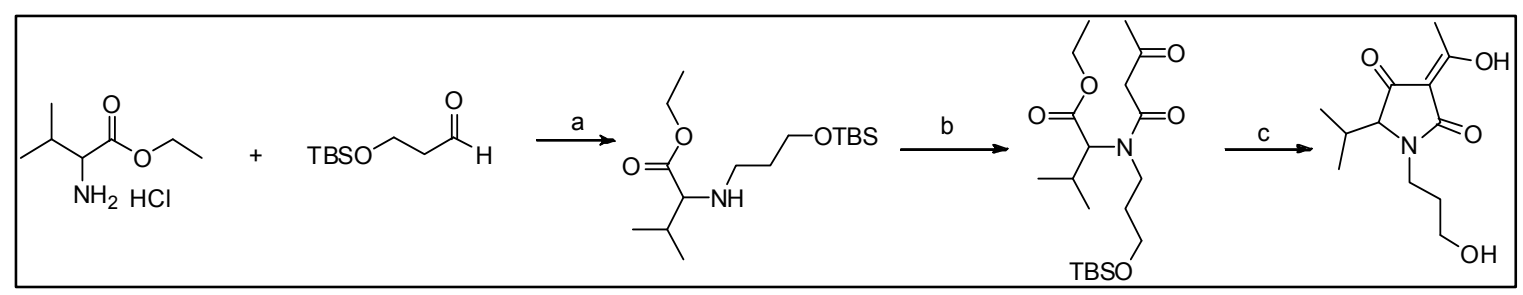

Reagents and Conditions: (a) (i) TEA, MgSO4, THF, RT, 5 hr; (ii) $\mathrm{NaBH}_{4}, \mathrm{MeOH}^{\mathrm{RT}}$, 30 min; (b) Diketene (or 50\% Diketene in DCM), DCM, TEA, 6 hr, relux; (c) (i) Amberlyst A-26 Hydroxide resin, $\mathrm{MeOH}, \mathrm{RT}, 2$ hr; (ii) MeOH, TFA, RT, 20 min

\section{Scheme 3.5: Alternate Synthesis of Tetramic Acid Core}

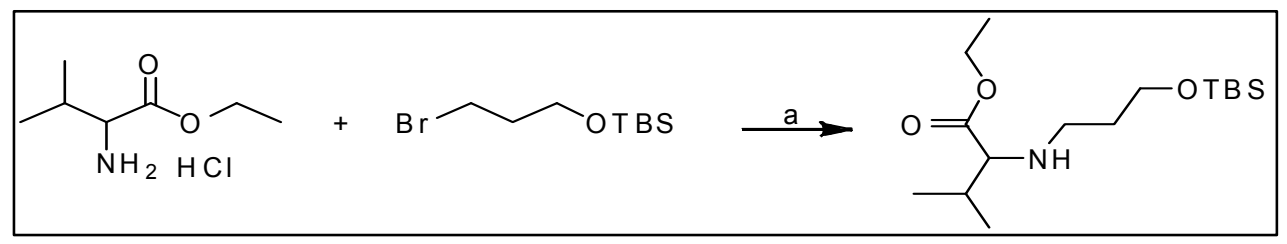

Reagents and Conditions: (a) $\mathrm{K}_{2} \mathrm{CO}_{3}$, DMF, microwave, $130^{\circ} \mathrm{C}, 30 \mathrm{~min}$ 
much hope for our hypothesis that this particular type of siderophore will be useful in providing a route by which an antibiotic can easily enter the gram-negative bacteria. It is obvious that much more work needs to be done in order to truly validate this study. However, this project appears to be headed down a path that will yield a very fruitful study into the intricacies of designing effective gram-negative antibacterial agents.

\section{Experimental Section}

All anhydrous solvents and starting materials were purchased from Aldrich Chemical Co. (Milwaukee, WI). All reagent grade solvents used from chromatography were purchased from Fisher Scientific (Suwanee, GA) and flash column chromatography silica cartridges were obtained from Biotage Inc. (Lake Forest, VA). The reactions were monitored by thin-layer chromatography (TLC) on pre-coated Merch 60 F254 silica gel plates and visualized using ultraviolet (UV) light (254 nm). A Biotage FLASH column chromatography system was used to purify mixtures. All $1 \mathrm{H}$ nuclear magnetic resonance (NMR) spectra were recorded on a Varian INOVA-500 spectrometer. Chemical shifts $(\delta)$ are reported in parts per million relative to the residual solvent peak or internal standard (tetramethylsilane), and coupling constants $(\mathrm{J})$ are reported in hertz $(\mathrm{Hz})$. Mass spectra were recorded on a Bruker Esquire liquid-chromatography mass-spectrometer using electrospray ionization. Purity of the products was confirmed before testing by analytical reverse phase-high performace liquid chromatography on a Shimadzu high-performance liquid-chromatography system, and all final compounds had a purity of $95 \%$ or greater as determined by RP-HPLC. Gradient Conditions: solvent A $(0.1 \%$ Trifluoroacetic Acid (TFA) in water) and solvent B (acetonitrile): 0-2.00 min 100\& A, 2.00-7.00 min 0-100\% B (linear gradient), 7.00-8.00 min 100\% B, UV detection at $254 \mathrm{~nm}$.

$\mathrm{N}$-(3-oxododecanoyl)-l-homoserine lactone (1). To an anhydrous dichloromethane solution $(20 \mathrm{~mL})$ containing decanoic acid $(0.57 \mathrm{~mL}, 4 \mathrm{mmol})$ was added $4-$ (dimethylamino)pyridine $(0.513 \mathrm{~g}, 4.2 \mathrm{mmol}), N, N^{\prime}$-dicyclohexylcarbodiimide $(0.907 \mathrm{~g}$, $4.4 \mathrm{mmol})$, and Meldrum's acid $(0.576 \mathrm{~g}, 4 \mathrm{mmol})$. This solution was stirred at room temperature overnight and then filtered to remove the precipitated $N, N^{\prime}$ dicyclohexylurea. The filtrate was evaporated to dryness, and the residue was redissolved in ethyl acetate. The ethyl acetate solution was washed with $2 \mathrm{M}$ hydrochloric acid, dried over anhydrous magnesium sulfate, and concentrated to afford the acylated Meldrum's acid, which was used without purification in the next step of the reaction. To a stirred solution of the acylated Meldrum's acid $(1.05 \mathrm{~g}, 3.5 \mathrm{mmol})$ in acetonitrile $(30 \mathrm{~mL})$ was added to l-homserine lactone hydrochloride $(0.482 \mathrm{~g}, 3.5 \mathrm{mmol})$ and triethylamine $(0.585 \mathrm{~mL}, 4.2 \mathrm{mmol})$. The mixture was stirred at room temperature for 2 hours and then heated under reflux conditions for 3 hours. The solvent was removed by rotary evaporation to give a residue that was redissolved in ethyl acetate. The organic solution was subsequently washed with saturated sodium hydrogen carbonate solution, $1 \mathrm{M}$ potassium hydrogen sulfate solution, and saturated sodium chloride solution. After drying over anhydrous magnesium sulfate, the organic solution was evaporated and the residue was purified flash chromatography using a hexanes to ethyl acetate gradiant to afford pure $1(0.108 \mathrm{~g}, 9 \%) .{ }^{1} \mathrm{H} \mathrm{NMR}\left(\mathrm{CDCl}_{3}\right): \delta 0.88(3 \mathrm{H}, \mathrm{t}, J$ 
$=7.5 \mathrm{~Hz}), 1.26(12 \mathrm{H}, \mathrm{m}), 1.59(2 \mathrm{H}, \mathrm{m}), 2.24(1 \mathrm{H}$, pentet, $J=11 \mathrm{~Hz}), 2.53(2 \mathrm{H}, \mathrm{t}, J=7.5$

$\mathrm{Hz}), 2.75(1 \mathrm{H}$, pentet, $J=1.5 \mathrm{~Hz}), 3.50(2 \mathrm{H}, \mathrm{s}), 4.28(1 \mathrm{H}, \mathrm{m}), 4.48(1 \mathrm{H}, \mathrm{t}, J=8 \mathrm{~Hz}), 4.59$

$(1 \mathrm{H}, \mathrm{m}), 7.75(1 \mathrm{H}, \mathrm{s})$. RP-HPLC: $t_{R}=7.68 \mathrm{~min}$. ESI-MS $m / z: 320.2[\mathrm{M}+\mathrm{Na}]^{+}$.

3-(1-hydroxydecylidene)-5-(2-hydroxyethyl)pyrrolidine-2,4-dione (Tetramic Acid of 1). To a flask containing $N$-(3-oxododecanoyl)-1-homoserine lactone $(0.090 \mathrm{~g}, 0.3026$ $\mathrm{mmol})$ in anhydrous methanol $(1 \mathrm{~mL})$, sodium methoxide in methanol $(0.5 \mathrm{M}, 0.605 \mathrm{~mL}$, $0.3026 \mathrm{mmol}$ ) was added at room temperature under argon. After stirring at 55 degrees $\mathrm{C}$ for three hours, the reaction mixture was passed through acidic ion-exchange resin (DOWEX 50WX2-200) and eluted with methanol $(20 \mathrm{~mL})$. The combined filtrates were concentrated on a rotary evaporated to give a residue. The resulting residue was purified using RP-HPLC to afford pure compound $(0.020 \mathrm{~g}, 22 \%) .{ }^{1} \mathrm{H} \mathrm{NMR}\left(\mathrm{CD}_{3} \mathrm{OD}\right): \delta 0.90$ $(3 \mathrm{H}, \mathrm{t}, J=7.0 \mathrm{~Hz}), 1.23-1.43(12 \mathrm{H}, \mathrm{m}), 1.66(2 \mathrm{H}, \mathrm{m}), 1.72-1.83(1 \mathrm{H}, \mathrm{m}), 1.96-2.10(1 \mathrm{H}$, $\mathrm{m}), 2.70-2.92(2 \mathrm{H}, \mathrm{m}), 3.61-3.79(2 \mathrm{H}, \mathrm{m}), 3.99(1 \mathrm{H}, \mathrm{s})$. RP-HPLC: $t_{R}=6.708 \mathrm{~min}$. ESIMS $m / z: 320.1[\mathrm{M}+\mathrm{Na}]^{+}$.

Iron(III) Chelate of 3-(1-hydroxydecylidene)-5-(2-hydroxyethyl)pyrrolidine-2,4dione. A small round-bottom flask containing 3-(1-hydroxydecylidene)-5-(2hydroxyethyl)pyrrolidine-2,4-dione $(0.050 \mathrm{~g}, 0.168 \mathrm{mmol})$ in methanol $(1 \mathrm{~mL})$ was stirred at room temperature for 5 minutes. A separate round-bottom flask containing iron(III) chloride $(0.0091 \mathrm{~g}, 0.056 \mathrm{mmol})$ in methanol $(1 \mathrm{~mL})$ was stirred at room temperature for 5 minutes. The solution of iron(III) chloride was then added to the flask containing the solution of 3-(1-hydroxydecylidene)-5-(2-hydroxyethyl)pyrrolidine-2,4dione and this was allowed to stir at room temperature for 30 minutes. The content of the flask was then concentrated to afford pure compound. ESI-MS $m / z$ : $947.49[\mathrm{M}+3 \mathrm{H}]^{+}$.

Iron(III) Chelate of Lee 867. A small round-bottom flask containing Lee 867 (0.0725 $\mathrm{g}, 0.215 \mathrm{mmol})$ in methanol $(1 \mathrm{~mL})$ was stirred at room temperature for 5 minutes. A separate round-bottom flask containing iron(III) chloride $(0.012 \mathrm{~g}, 0.072 \mathrm{mmol})$ in methanol $(1 \mathrm{~mL})$ was stirred at room temperature for 5 minutes. The solution of iron(III) chloride was then added to the flask containing the solution of Lee 867 and this was allowed to stir at room temperature for 30 minutes. The content of the flask was then concentrated to afford pure compound. ESI-MS m/z: 1068.31 $[\mathrm{M}+3 \mathrm{H}]^{+}$.

(Z)-3-(1-hydroxyethylidene)-1-(3-hydroxypropyl)-5-isopropylpyrrolidine-2,4-dione (Tetramic Acid Core). To a stirred solution of valine ethyl ester hydrochloride $(0.408 \mathrm{~g}$, $2.65 \mathrm{mmol})$ in tetrahydrofuran was added magnesium sulfate $(0.543 \mathrm{~g}, 4.51 \mathrm{mmol}), 3$ ((tert-butyldimethylsilyl)oxy)propanal $(1 \mathrm{~g}, 5.31 \mathrm{mmol})$, and triethylamine $(0.37 \mathrm{~mL}$, $2.65 \mathrm{mmol})$. The reaction was then allowed to stir at room temperature under argon for five hours. The reaction mixture was then filtered and the eluent evaporated to give the crude imine intermediate. The imine was directly redisolved in methanol, and sodium borohydride $(0.20 \mathrm{~g}, 5.31 \mathrm{mmol})$ was slowly added to the reaction mixture. The reaction was stirred at room temperature for 30 minutes before being quenched with excess $1 \mathrm{~N}$ sodium hydroxide and extracted with ethyl acetate. The ethyl acetate extracts were combined, washed with brine, and dried over sodium sulfate. The extracts were then concentrated under vacuum. The residue was purified by flash chromatography using a 
petroleum ether to ethyl acetate gradient. The purified intermediate $(0.340 \mathrm{~g}, 1.17 \mathrm{mmol})$ was then dissolved in dichloromethane. To this solution diketene $(0.084 \mathrm{~mL}, 1.17 \mathrm{mmol})$ and five drops of triethylamine were added. The resulting solution was then heated under reflux conditions for six hours. The reaction mixture was then cooled, diluted with dichloromethane and washed with dilute hydrochloric acid followed by water. The dichloromethane fractions were then dried over sodium sulfate and concentrated. This intermediate was then purified with flash chromatography using a petroleum ether to ethyl acetate gradient. This intermediate $(0.238 \mathrm{~g}, 0.593 \mathrm{mmol})$ was then dissolved in methanol. To this solution Amberylyst A-26 resin (4.2 mequiv/g, 3 equiv) was added. The reaction was stirred at room temperature under agron for two hours. The product containing resin was then filtered and washed with methanol $(3 \times 10 \mathrm{~mL})$. The resin was then stirred at room temperature for 30 minutes in methanol $(10 \mathrm{~mL})$ with TFA $(400 \mu \mathrm{L})$. It was then filtered and washed with methanol. Concentration of the eluent afforded pure product $(0.126 \mathrm{~g}, 88 \%)$. ${ }^{1} \mathrm{H}$ NMR $\left(\mathrm{CDCl}_{3}\right): \delta 0.93(6 \mathrm{H}, \mathrm{d}, J=7.0 \mathrm{~Hz}), 1.71-1.77(2 \mathrm{H}$, $\mathrm{m}), 2.05(2.2 \mathrm{H}, \mathrm{s}), 2.20(0.8 \mathrm{H}, \mathrm{s}), 2.64(1 \mathrm{H}, \mathrm{m}), 2.95(2 \mathrm{H}, \mathrm{m}), 3.52-3.60(3 \mathrm{H}, \mathrm{m}), 4.45$ $(1 \mathrm{H}, \mathrm{d}, J=7.0 \mathrm{~Hz})$. RP-HPLC: $t_{R}=6.13 \mathrm{~min}$. ESI-MS $m / z: 264.3[\mathrm{M}+\mathrm{Na}]^{+}$. 


\section{CHAPTER 4: OVERALL DISCUSSION OF DISSERTATION}

\section{Introduction}

The two projects discussed in this dissertation deal with the development of novel antimicrobial agents. These projects play a vital role in the need for continuing research into ways to help combat the ever increasing rise of bacterial resistance. As bacteria continue to evolve new resistant mechanisms, every piece of research into the development of new ways to treat bacterial infections becomes crucial. The projects I have worked on both involved bacteria, but each focused on a different type of bacteria. The first project I worked on focused on new ways to treat infections caused by Mycobacterium tuberculosis. The threat caused by the bacteria is growing, and discovering novel agents with novel mechanisms of action is becoming a very high priority among the scientific community. My second project involved the design of novel treatment for gram-negative bacterial infections. These organisms are becoming increasingly resistant to the antibiotics that are currently on the market, and therefore new agents are desperately needed. The pipeline for combating these agents is sparse, and more focus needs to be placed on this area by the pharmaceutical industry. The purpose of this chapter is to provide a look into the key aspects of each project and to discuss potential future endeavors that can keep these projects fruitful.

\section{Urea Project}

This project was discussed in Chapter 2 of this dissertation. It dealt with the discovery of novel agents to help combat the increasing threat of multi- and extensivelydrug resistant tuberculosis. The agents synthesized in this chapter all possess a novel mechanism of action that can be exploited to avoid resistance associated with current therapies for tuberculosis. This project originated through the use of a current medicinal chemistry technique that allows for the discovery of a small number of active compounds within a large collection of compounds called high-throughput screening. Through this process, the hit compound was discovered and selected for further modification.

The modifications chosen for this compound centered on the idea of obtaining a complete SAR for this series of compounds. The first modifications made to the hit compound involved changing the bulky aliphatic moiety while keeping the trifluorophenyl group constant. A variety of bulky aliphatic groups were chosen to replace the adamantyl moiety. These modifications, for the most part, led to compounds with activity that was comparable to the parent compound. The compounds that lost activity were compounds that contained groups that were not a bulky as the original adamantyl group.

The next set of modifications involved the changing of the trifluorophenyl moiety for other aromatic rings while holding the adamantyl position constant. These modifications seemed to all provide compounds with similar activity to the parent 
compound. All of the groups tested in this set appeared to be well tolerated as the worst MIC for a compound in this set was $3.125 \mu \mathrm{g} / \mathrm{mL}$.

The next modifications involved holding the adamantyl constant and replacing the aromatic ring with various non-aromatic groups consisting primarily of alkyl chains with varying lengths. The majority of these compounds showed poor activity. There were a few exceptions that showed activity comparable to the parent compounds, but these are not candidates for further evaluation due to their poor drugability.

Modifications were made that also involved changing both sides simultaneously so that the only remaining identifier of the parent compound was the urea moiety. These compounds showed activity similar to the parent compounds, but none produced activity that was better than the parent compound.

In order to complete the SAR study, it was crucial to make modifications to the urea moiety itself. This was done using the parent compound. The urea moiety was modified four different ways; (1) the carbonyl oxygen was replaced with a sulfur to make a thiourea, (2) one of the nitrogen atoms was replaced with an oxygen to form a carbamate, (3) one hydrogen atom attached to one of the nitrogen atoms was replaced with a methyl group, (4) both hydrogen atoms on the nitrogen atoms were replaced with methyl groups. These modifications produced a very clear and well defined SAR concerning the urea moiety. As the modifications progress, from the parent compound, the activity incrementally decreases with each modification. Replacement of the oxygen atom with sulfur decreased the MIC from $0.01 \mu \mathrm{g} / \mathrm{mL}$ to $0.8 \mu \mathrm{g} / \mathrm{mL}$. This decrease inactivity can possible be related to the fact that sulfur is a larger atom than oxygen and this could disrupt parts of the hydrogen bonding network found in the active site. Replacement of a nitrogen atom with oxygen and methylation of one nitrogen atom both decreased the MIC to $6 \mu \mathrm{g} / \mathrm{mL}$. This appears to be due to the loss of the hydrogen atom as a hydrogen bond donor to amino acid residues within the active site. Finally, methylation of both nitrogen atoms resulted in an MIC of $12 \mu \mathrm{g} / \mathrm{mL}$. This is follows the previously mentioned hypothesis in that both hydrogen bond donating hydrogen atoms have now been replaced.

This project, while producing compounds with excellent activity against Mycobacterium tuberculosis, is not without faults. The compounds that have been submitted for in vivo efficacy testing have not shown favorable results. This is more than likely due to the high lipophilicity of these compounds. The next generation of these compounds should focus on reducing the lipophilicity of these compounds in an effort to improve their in vivo efficacy. The lead compound for this series has been identified as compound $\mathbf{3 6}$ in Table 2.3. The compounds in this table were synthesized in an effort to reduce the lipophilicity of this series. However, the majority of the compounds synthesized showed a decrease in activity and were not acceptable for further optimization. Compound $\mathbf{3 6}$ retained respectable activity and is less lipohilic. It has shown to be orally bioavailable. ${ }^{107,163}$ 
This series of compounds is also riddled with another hindrance. There is a human form of the epoxide hydrolase enzyme, and these compounds need to selectively inhibit the Mycobacterium tuberculosis form of the enzyme without interfering with the human enzyme. Compound $\mathbf{3 6}$ may help with the lipophilicity issues associated with these compounds, but it is also a known human epoxide hydrolase inhibitor. The next generation of these compounds will need to be modified in a way that selectivity for Mycobacterium tuberculosis can be achieved. There have already been three general scaffolds identified that will be the future direction of this project (Figure 4.1). The continuation of this project is already underway by a fellow member of the Lee Lab, and the results will be reported in due time.

\section{Tetramic Acid Project}

This project is discussed in Chapter 3 of this dissertation. This project is truly in its infancy. I have undertaken a lot of literature study with this project in an effort to fully understand the scope of this project. I also set out to synthesize a few final compounds for this project, but ultimately I was unsuccessful in synthesizing a complete siderophore antibacterial agent. Although, I was not able to fully complete the synthesis of on the desired compounds, this project should remain a focus in the Lee Lab due to the potential it presents.

The potential of this project to be high impact is evident from the literature precedence seen during my searches. It is shown in the pre-clinical candidate, BAL30072, that the idea of attaching a siderophore to an antibacterial agent in an effort to increase its efficacy is a valid hypothesis. Also, the initial experiments done by our collaborators at Northeastern University show that the iron chelated tetramic acid of the quorum sensing molecule synthesized in Scheme 3.1 helps an unknown microorganism grow more abundantly and may be used as a growth enhancer for unknown microorganisms. This is postulated to be due to the fact that the microorganism is utilizing the tetramic acid to aid in its uptake of iron from the environment. The novel siderophore used in our laboratory, the tetramic acid core, has numerous points of diversity which can allow us to alter the structural diversity of this moiety in order to ensure optimal activity.

The possibilities for this project seem to really cover a wide spectrum. In my synthetic attempts during this project I was attempting to connect the tetramic acid molecule synthesized in Scheme 3.4 to a cephalosporin antibiotic (Figure 4.2) However, this is just the beginning of the possibilities for this type of compound. The direction of this project is ultimately to see improved efficacy of gram-negative agents so as to help alleviate burden associated with gram-negative infections. It would be interesting to see the change in activity associated with attaching this class of siderophore to a variety of antibacterial agents.

It would be very interesting to see if by taking an agent that only shows activity against gram-positive bacteria, then attaching this class of siderophore, you can impart 


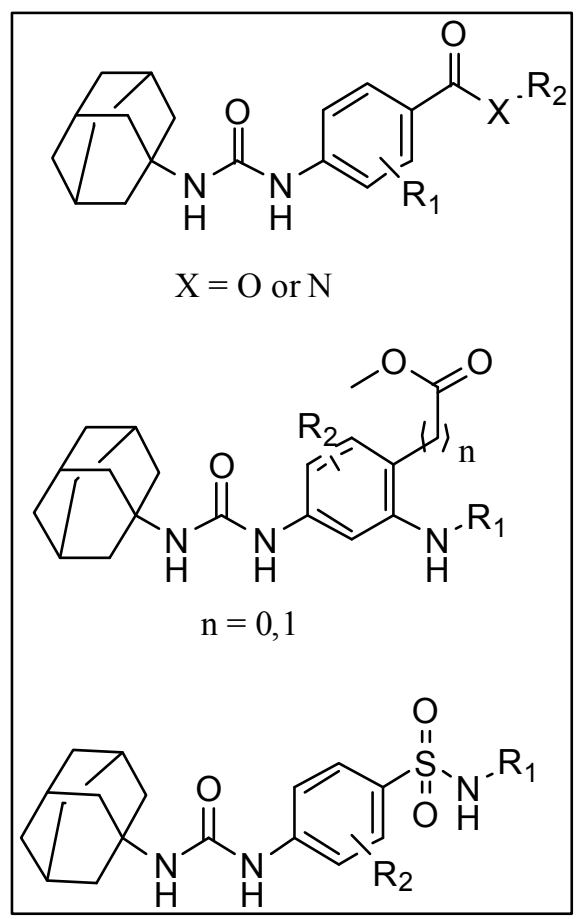

Figure 4.1: $\quad$ Structures for Future Direction of Urea Project

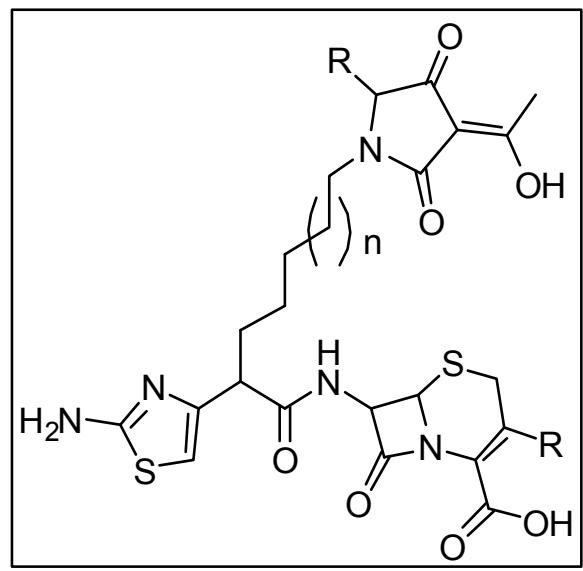

Figure 4.2: $\quad$ Structure of Proposed Siderophore Antibiotic 
gram-negative activity as well. Also, the idea of taking an agent that was initially designed to be active against gram-negative bacteria, but showed no activity in vivo, and attaching this class of siderophore to see if any gram-negative activity can be obtained.

One of the shortcomings of this project at this time is that I have not been able to successfully synthesize a compound from which data can be extracted. Therefore, one of the issues appears to be that the chemistry associated with coupling the tetramic acid moiety and the antibiotic of choice is difficult. The yield obtained from the synthesis of the tetramic acid compound is also low, and thus there is room for improvement in that aspect. The development of new synthetic schemes should be a top priority as this project progresses into the future in an effort to overcome these shortcomings. If these issues can be overcome, or at least attenuated, then the future of this project appears to be very fruitful for the discovery of novel antibacterial agents.

\section{Final Thoughts}

During my tenure in graduate school, I have had the pleasure of being able to conduct cutting edge research in an area that shows a clear need for new development. Although my training has been as a synthetic chemist, my educational experience has allowed me to become a well-rounded scientist. The idea of being more than just a chemist is what initially attracted me to the field of medicinal chemistry. I realized that I wanted to be in a field where the implications of my research can be seen and understood immediately. The fact that one day I can synthesize a compound in the laboratory, then have it tested in an in vitro system, and then determine the next course of action really shows how the field of medicinal chemistry can and has changed the way that bacterial infections are treated.

Medicinal chemistry is a very interdisciplinary science. It utilizes knowledge from a variety of scientific fields in order to effectively create a well-rounded scientist. Working as a medicinal chemist involves working in an interdisciplinary environment where collaboration is the key to success. Training as a medicinal chemist can differ depending upon one's experience and interests, but in the end a medicinal chemist is a person who can bridge some of the gaps between chemistry and biology. This ability makes a well-trained medicinal chemist an invaluable asset to any interdisciplinary research team. Interdisciplinary training should be included as a requirement in all science-based Ph.D. training. Such a concept would lead to a better understanding of the overall connectivity of science between fields and ultimately produce more well-rounded scientists.

The projects that I have worked on during my time in graduate school have been projects that serve a purpose. They have afforded me ample hands-on experience in the chemistry laboratory. I have had the opportunity to expand my knowledge base on a variety of different synthetic techniques. In addition to my expanded chemistry knowledge, I have been able to grow my knowledge on the biological significance for these projects. These projects allowed me to build up a significant knowledge base on 
the infectious agents associated with these projects; Mycobacterium tuberculosis and gram-negative infections. The ability to work on projects that required me to expand my knowledge has really benefited me in my quest to become a well-rounded scientist. It is my goal to continue to grow my knowledge base for each project that I undertake during my professional career. 


\section{LIST OF REFERENCES}

1. Bryskier, A., Antimicrobial agents: antibacterials and antifungals. American Society for Microbiology Press: Washington DC, 2005.

2. Bosch, F.; Rosich, L., The contributions of Paul Ehrlich to pharmacology: a tribute on the occasion of the centenary of his Nobel prize. Pharmacology 2008, $82(3), 171-179$.

3. Stork, W., Top pharmaceuticals that changed the world: prontosil. Chem. Eng. News 2005, 83 (25).

4. Fuller, A. T., Is p-aminobenzenesulfonamide the active agent in prontosil therapy. Lancet 1937, 1, 194-198.

5. Williams, D. A.; Lemke, T. L., Foye's principles of medicinal chemistry. 5 th ed.; Lippincott, Williams, \& Wilkins: Baltimore, MD, 2002.

6. Walsh, C., Antibiotics: actions, origins, resistance. American Society for Microbiology Press: Washington DC, 2003.

7. Lee, B., Conformation of penicillin as a transition-state analog of the substrate of peptidoglycan transpeptidase. J. Mol. Biol. 1971, 61 (2), 463-469.

8. Scholar, E. M.; Pratt, W. B., The antimicrobial drugs. 2nd ed.; Oxford University Press: New York, NY, 2000.

9. Grimes, K. D. Design, synthesis, and evaluation of small molecules in the discovery of novel antimicrobial agents. University of Tennessee Health Science Center, Memphis, 2008.

10. Birnbaum, J.; Kahan, F. M.; Kropp, H.; MacDonald, J. S., Carbapenems, a new calss of beta-lactam antibiotics: discovery and development of imipenem/cilastatin. Am. J. Med. 1985, 78 (6A), 3-21.

11. Hellinger, W. C.; Brewer, N. S., Carbapenems and monobactams: imipenem, meropenem, and aztreonam. Mayo Clin. Proc. 1999, 74 (4), 420-434.

12. Breuer, H.; Cimarusti, C. M.; Denzel, T.; Koster, W. H.; Slusarchyk, W. A.; Treuner, U. D., Monobactams - structure-activity relationships leading to SQ 26,776. J. Antimicrob. Chemother. 1981, 8 (Suppl E), 21-28.

13. Livermore, D. M.; Williams, J. D., In-vitro activity of the monobactam, SQ 26,776, against gram-negative bacteria and its stability to their $\beta$-lactamases $J$. Antimicrob. Chemother. 1981, 8 (Supp E), 29-37. 
14. Percival, A.; Thomas, E.; Hart, C. A.; Karayiannis, P., In-vitro activity of monobactam, SQ 26,776, against gram-negative bacteria. J. Antimicrob. Chemother. 1981, 8 (Supp E), 49-55.

15. Reeves, D. S.; Bywater, M. J.; Holt, H. A., Antibacterial activity of the monobactam SQ 26,776 against antibiotic resistant enterobacteria, including Serratia spp. J. Antimicrob. Chemother. 1981, 8 (Supp E), 57-68.

16. Russell, A. D., In-vitro studies on SQ 26,776, a new monobactam antibiotic $J$. Antimicrob. Chemother. 1981, 8 (Supp E), 81-88.

17. Lancini, G. C., Fermentation and biosynthesis of glycopeptide antibiotics. Prog. Ind. Micobiol. 1989, 27, 283-287.

18. Lim, S. M.; Webb, S. A., Nosocomial bacterial infections in intensive care units. Anaesthesia 2005, 60 (9), 887-902.

19. Carter, A. P.; Clemons, W. M.; Brodersen, D. E.; Morgan-Warren, R. J.; Wimberly, B. T.; Ramakrishnan, V., Functional insights from the structure of the 30S ribosomal subunit and its interactions with antibiotics. Nature 2000, 407, 340-348.

20. Pipersberg, W., Molecular biology, biochemistry and fermentation of aminoglycoside antibiotics. 2nd ed.; Marcel Dekker Inc.: New York, NY, 1997.

21. Ban, N.; Nissen, P.; Hansen, J.; Moore, P. B.; Steitz, T. A., The complete atomic structure of the large ribosomal subunit at 2.4 A resolution. Science 2000, 289, 905-920.

22. Shlunzen, F.; Zarivach, R.; Harms, J.; Bashan, A.; Tocilj, A.; Albrecht, R.; Yonath, A.; Franceschi, F., Structural basis for the interaction of antibiotics with the peptidyl transferase centre in eubacteria. Nature 2001, 413, 814-821.

23. Champney, W. S.; Burdine, R., Macrolide antibiotics inhibit 50S ribosomal subunit assembly in Bacillus subtilis and Staphylococcus aureus. Antimicrob. Agents. Chemother. 1995, 39 (9), 2141-2144.

24. Bronson, J. J.; Barrett, J. F., Recent developments in antibacterial research. Annu. Rep. Med. Chem. 2001, 36, 89-98.

25. Chopra, I.; Roberts, M., Tetracyline antibiotics: mode of action, applications, molecular biology, and epidemiology of bacterial resistance. Microbiol. Mol. Biol. Rev. 2001, 65 (2), 232-260.

26. Yoshida, H.; Nakamura, M.; Bogaki, M.; Ito, H.; Kojima, T.; Hattori, H.; Nakamura, S., Mechanism of action of quinolones against Escherichia coli DNA gyrase. Antimicrob. Agents. Chemother. 1993, 37 (4), 839-845. 
27. Goldstein, E. J., Norfloxacin, a fluoroquinolone antibacterial agent. Classification, mechanism of action, and in vitro activity. Am. J. Med. 1987, 82 (6B), 3-17.

28. Bermingham, A.; Derrick, J. P., The folic acid biosynthesis pathway in bacteria: evaluation of potential for antibacterial drug discovery. Bioessays 2002, 24 (7), 637-648.

29. Finch, R. G.; Greenwood, D.; Norrby, S. R.; Whitley, R. J., Antibiotic and chemotherapy: anti-infective agents and their use in therapy. 8th ed.; An imprint of Elsevier Science Limited: United Kingdom, 2003.

30. Miller, A. K.; Bruno, P.; Berglund, R. M., The effect of sulfathiazole on the in vitro synthesis of certain vitamins by Escherichia coli. J. Bacteriol. 1947, 54 (1), 9 (G20).

31. Richey, D. P.; Brown, G. M., The biosynthesis of folic acid. J. Biol. Chem. 1969, 244 (6), 1582-1592.

32. Lacey, R. W., Mechanism of action of trimethoprim and sulphonamides: relevance to synergy in vivo. J. Antimicrob. Chemother. 1979, 5 (B), 75-83.

33. Markowitz, N.; Quinn, E. L.; Saravolatz, L. D., Trimethoprim-sulfamethoxazole compared with vancomycin for the treatment of Staphylococcus aureus infection. Ann. Intern. Med. 1992, 117 (5), 390-398.

34. Projan, S. J.; Bradford, P. A., Late state antibacterial drugs in the clinical pipeline. Curr. Opin. Microbiol. 2007, 10, 441-446.

35. Theuretzbacher, U., Future antibiotics scenarios: is the tide starting to turn? Int. J. of Antimicrob. Agents 2009, 34, 15-20.

36. Fischbach, M. A.; Walsh, C. T., Antibiotics for emerging pathogens. Science 2009, 325, 1089-1093.

37. Gill, V. The trouble with antibiotics. http://www.rsc.org/chemistryworld/Issues/2008/March/TheTroubleWithAntibioti cs.asp (accessed February 12, 2010).

38. Infectious disease experts call for 10 new antibiotics by 2020 . http://www.sciencedaily.com/releases/2009/11/091123132633.htm (accessed February 8, 2010).

39. Colson, A., The anitibiotic pipeline. In Policy responses to the growing threat of antibiotic resistance, Robert Wood Johnson Foundation: Princeton, NJ, 2008; Vol. Policy Brief 6.

40. Alanis, A., Resistance to antibiotics: are we in the post-antibiotic era? Arch. Med. Res. 2005, 36, 697-705. 
41. Falagas, M. E.; Bliziotis, I. A., Pandrug-resistant gram-negative bacteria: the dawn of the post-anitbiotic era? Int. J. of Antimicrob. Agents 2007, 29 (6), 630636.

42. Nathan, C.; Goldberg, F. M., The profit problem in antibiotic R\&D. Nat. Rev. Drug Discov. 2005, 4 (11), 887-891.

43. Nathan, C., Antibiotics at the crossroads. Nature 2004, 431 (7011), 899-902.

44. Nussbaum, F. V.; Brands, M.; Hinzen, B.; Weigand, S.; Habich, D., Antibacterial natural products in medicinal chemistry - exodus or revial? Angew. Chem. Int. Ed. 2006, 45 (31), 5072-5129.

45. Klevens, R. M., Invasive methaicillin-resistant Staphylococcus aureus infections in the United States. J. Am. Med. Assoc. 2007, 298 (15), 1763-1771.

46. Weigel, L. M., Genetic analysis of a high-level vancomycin-resistant isolate of Staphylococcus aureus. Science 2003, 302 (5650), 1569-1571.

47. Falagas, M. E., Outcome of infections due to pandrug-resistant (PDR) gramnegative bacteria. BMC Infect. Dis. 2005, 5, 24.

48. Dorman, S. E.; Chaisson, R. E., From magic bullets back to the magic mountain: the rise of extensively drug-resistant tuberculosis. Nat. Med. 2007, 13 (3), 295298.

49. Kim, D. H., Treatment outcomes and long-term survival in patients with extensively drug-resistant tuberculosis. Am. J. Respir. Crit. Care Med. 2008, 178 (10), 1075-1082.

50. Outterson, K., Will longer antimicrobial patents improve global public health? Lancet Inf. Dis. 2007, 7 (8), 559-566.

51. FDA. FDA Announces Label and Indication Changes for the Antibiotic Ketek 2007.

http://www.fda.gov/NewsEvents/Newsroom/PressAnnouncements/2007/ucm1088 $\underline{42 . h t m}$ (accessed March 14, 2010).

52. Manallack, D. T.; Crosby, I. T.; Khakham, Y.; Capuano, B., Platensimycin: a promising antimicrobial targeting fatty acid synthesis. Curr. Med. Chem. 2008, $15,705-710$.

53. O'Fallon, E.; Pop-Vicas, A.; D'Agata, E., The emerging threat of multidrugresistant gram-negative organisms in long-term care facilties. J. Gerontol. A Biol. Sci. Med. Sci. 2009, 64A (1), 138-141. 
54. Wang, Y. C.; Lipsitch, M., Upgrading antibiotic use within a class: tradeoff between resistance and treatment success. Proc. Natl. Acad. Sci. USA 2006, 103, 9655-9660.

55. Koch, R., Die atiologie der tuberkulose. Berliner Kliniscben Wocbenschift 1882, $15,221-230$.

56. Comstock, G. W., Epidemiology of tuberculosis. Am. Rev. Respi. Dis. 1982, 125 (3 Pt 2), 8-15.

57. Schlossberg, D., Tuberculosis. 3rd ed.; Springer-Verlag: New York, NY, 1994.

58. Tripathi, R. P.; Tewari, N.; Dwivedi, N.; Tiwari, V. K., Fighting tuberculosis: an old disease with new challenges. Med. Res. Rev. 2005, 25 (1), 93-131.

59. World Health Organization, http://www.who.int/mediacentre/factsheets/fs104/en/ (accessed February 4, 2010).

60. Mooran, N., World health organization issues another gloomy tuberculosis report. Nat. Med. 1996, 2, 377.

61. Jr, D. E. S.; Raviglione, M.; Kochi, A., Tuberculosis. In Pathogensis, protection \& control, Bloom, B. R., Ed. Am. Soc. Microbiol.: Washington DC, 1994; pp 211 .

62. Dye, C.; Scheele, S.; Dolin, P.; Pathania, V.; Raviglione, M. C., Global burden of tuberculosis: estimated incidence, prevalence, and mortality by country. J. Am. Med. Assoc. 1999, 282, 677-686.

63. Farmer, P.; Bayona, J.; Beccera, M.; Furin, J.; Henry, C.; Hiarr, H.; Kim, J. Y.; Mimic, C.; Nardell, E.; Shin, S., The dielemma of MDR TB in global era. Int. J. Tuberc. Lung Dis. 1998, 2, 896-876.

64. Wayne, L. G., Dormancy of Mycobacterium tuberculosis and latency of disease. Eur. J. Clin. Microbiol. Infect. Dis. 1994, 13 (11), 908-914.

65. Flynn, J. L.; Chan, J., Tuberculosis: latency and reactivation Infect. Immun. 2001, 69 (7), 4195-4201.

66. Selwyn, P. A.; Hartel, D.; Lewis, V. A.; Schoenbaum, E. E.; Vermund, S. H.; Klein, R. S.; Walker, A. T.; Friedland, G. H., A prospective study of the risk of tuberculosis among intravenous drug users with human immunodeficiency virus infection. N. Engl. J. Med. 1989, 320 (9), 545-550.

67. Davidson, P. T.; Lee, H. Q., Drug treatment of tuberculosis-1992. Drugs 1992, 43, 651-673. 
68. Tilotson, G. S., Tuberculosis-new aspects of chemotherapy. J. Med. Microbiol. 1996, 44, 16-20.

69. Grange, J., Antimycobacterial agents. In Antibiotics and chemotherapy, 7th ed.; O'Grady, F.; Lambert, H. P.; Finch, R. G.; Greenwood, D., Eds. Churchill Livingston: Edinbug, 1997; pp 449-512.

70. Greenwood, D., Historical introduction. In Antiobitoc and chemotherapy, 7th ed.; O'Grady, F.; Lambert, H. P.; Finch, R. G.; Greenwood, D., Eds. Churchill Livingston: Edinburg, 1997; pp 2-9.

71. Councils, H. K., First-line chemotherapy in the retreatment of bacteriological relapses of pulmonary tuberculosis following a shortcourse regimen. Lancet 1976, $1,162-163$.

72. Bernadou, J.; Nguyen, M.; Meunier, B., The mechanism of action of isoniazid. A chemical model of activation. Ann. Pharm. Fr. 2001, 59 (5), 331-337.

73. Vilcheze, C.; Jr, W. R. J., The mechanism of isoniazid killing: clarity through the scope of genetics. Ann. Rev. Microbiol. 2007, 61, 35-50.

74. Heym, B.; Alzari, P. M.; Honroe, N.; Cole, S. T., Missense mutations in the catalase-peroxidase gene, $\mathrm{katG}$, are associated with isoniazid resistance in Mycobacterium tubersulosis. Mol. Microbiol. 1995, 15, 235-245.

75. Mdluli, K.; Slayden, R. A.; Zhu, Y.; Ramaswamy, S.; Pan, X.; Mead, D.; Crane, D. D.; Musser, J. M.; 3rd, C. E. B., Inhibition of a Mycobacterium tuberculosis beta-ketoacyl ACP synthase by isoniazid. Science 1998, 280, 1608-1611.

76. Johnson, K.; Schultz, P. G., Mechanistic studies of the oxidation of INH by the catalase peroxidase from Mycobacterium tuberculosis. J. Am. Chem. Soc. 1994, $116,7425-7426$.

77. Chopra, I.; Brennan, P., Molecular action of antimycobacterial agents. Tuber. Lung Dis. 1998, 78 (2), 89-98.

78. $\quad 3 r d$, F. R. C.; Uhl, J. R.; Temesgen, Z.; Zhang, Y.; Stockman, L.; Roberts, G. D.; Williams, D. L.; Kline, B. C., Rapid identification of a point mutation of the Mycobacterium tuberculosis catalase-peroxidase (katG) gene associated with isoniazid resistance. J. Infect. Dis. 1995, 171 (1), 240-245.

79. Yu, S.; Girotto, S.; Lee, C.; Magliozzo, R. S., Reduced affinity of Isoniazid in the S315T mutant of Mycobacterium tuberculosis KatG is a key factor in antibiotic resistance. J. Biol. Chem. 2003, 278 (17), 14769-14775. 
80. Zhang, Y.; Garbe, T.; Young, D., Transformation with katG restores isoniazidsensitivity in Mycobacterium tuberculosis isolates resistant to a range of drug concentrations. Mol. Microbiol. 1993, 8, 521-524.

81. Gale, E. F.; Cundliffe, E.; Reynolds, P. E.; Richmond, M. H.; Waring, M. J., The molecular basics of antibiotic action. 2nd ed.; John Wiley and Sons: London, 1981.

82. Mariam, D. H.; Mengistu, Y.; Hoffner, S. E.; Anderson, D. I., Effect of rpoB mutations conferring rifampin resistance on fitness of Mycobacterium tuberculosis. Antimicrob. Agents. Chemother. 2004, 48 (4), 1289-1294.

83. Zhang, Y.; Wade, M. M.; Scorpio, A.; Zhange, H.; Sun, Z., Mode of action of pyrazinamide: disruption of Mycobacterium tuberculosis membrane transport and energetics by pyrazinoic acid. J. Antimicrob. Chemother. 2003, 52 (5), 790-795.

84. Konno, K.; Feldman, F. M.; McDermat, W., Pyrazinamide suceptibillity and amidase activity of tubercular bacilli. Am. Rev. Respi. Dis. 1967, 95, 461-469.

85. McDermott, W.; Tompsett, R., Activation of pyrazinamide and nicotinamide in acidic environment in vitro. Am. Rev. Tuberculosis 1954, 70, 748-754.

86. Scorpio, A.; Zhang, Y., Mutations in pncA, a gene encoding pyrazinamidase/nicotinamidase, cause resistance to antituberculous drug pyrazinamide in tubercule bacillus. Nat. Med. 1996, 2, 1-6.

87. McCune, R. M.; Feldman, F. M.; McDermat, W., Microbial persistence II. Characteristics of the sterile state of tubercular bacilli. J. Exp. Med. 1966, 123, 468-486.

88. Inderlied, C. B.; Barbara-Burnham, L.; Wu, M.; Young, L. S.; Bermudez, L. E. M., Activities of the benoxazinorifamycin KRM 1648 and ethambutol against Mycobacterium avium complex invitro and in macrophages. Antimicrob. Agents. Chemother. 1994, 38, 1838-1843.

89. Mikusova, K.; Slayden, R. A.; Besra, G. S.; Brennan, P. J., Biogenesis of the mycobacterial cell wall and the site of action of ethambutol. Antimicrob. Agents. Chemother. 1995, 39, 2484-2489.

90. Rastogi, N.; Labrousee, V., Extracellular and intracellular activities of clarithromycin used alone and in association with ethambutol and rifamycin against Mycobacterium avium complex. Antimicrob. Agents. Chemother. 1991, $35,462-470$.

91. Lee, R. E.; Protopopova, M.; Crooks, E.; Slayden, R. A.; Terrot, M.; 3rd, C. E. B., Combinatorial lead optimization of [1,2]-diamines based on ethambutol as 
potential antituberculosis preclinical cadidates. J. Comb. Chem. 2003, 5 (2), 172187.

92. Yendapally, R.; Lee, R. E., Design, synthesis, and evaluation of novel ethambutol analogues. Bioorg. Med. Chem. Lett. 2008, 18 (5), 1607-1611.

93. Telenti, A.; Philipp, W. J.; Sreevatsan, S.; Bernasconi, C.; Stockbauer, K. E.; Wieles, B.; Musser, J. M.; Jr, W. R. J., The emb operon, a gene cluster of Mycobacterium tuberculosis involved in resistance to ethambutol. Nat. Med. 1997, 3 (5), 567-570.

94. Blanchard, J. S., Molecular mechanism of drug resistance in Mycobacterium tuberculosis Annu. Rev. Biochem. 1996, 65, 215-239.

95. Sacchettini, J. C.; Rubin, E. J.; Freundlich, J. S., Drugs versus bugs: in pursuit of the persistent predator Mycobacterium tuberculosis. Nat Rev Microbiol 2008, 6 (1), 41-52.

96. Payne, D. J.; Gwynn, M. N.; Holmes, D. J.; Pompliano, D. L., Drugs for bad bugs: confronting the challenges of antibacterial discovery. Nat Rev Drug Discov 2007, 6 (1), 29-40.

97. Andries, K.; Verhasselt, P.; Guillemont, J.; Gohlmann, H. W.; Neefs, J. M.; Winkler, H.; Van Gestel, J.; Timmerman, P.; Zhu, M.; Lee, E.; Williams, P.; de Chaffoy, D.; Huitric, E.; Hoffner, S.; Cambau, E.; Truffot-Pernot, C.; Lounis, N.; Jarlier, V., A diarylquinoline drug active on the ATP synthase of Mycobacterium tuberculosis. Science 2005, 307 (5707), 223-7.

98. Makarov, V.; Manina, G.; Mikusova, K.; Mollmann, U.; Ryabova, O.; SaintJoanis, B.; Dhar, N.; Pasca, M. R.; Buroni, S.; Lucarelli, A. P.; Milano, A.; De Rossi, E.; Belanova, M.; Bobovska, A.; Dianiskova, P.; Kordulakova, J.; Sala, C.; Fullam, E.; Schneider, P.; McKinney, J. D.; Brodin, P.; Christophe, T.; Waddell, S.; Butcher, P.; Albrethsen, J.; Rosenkrands, I.; Brosch, R.; Nandi, V.; Bharath, S.; Gaonkar, S.; Shandil, R. K.; Balasubramanian, V.; Balganesh, T.; Tyagi, S.; Grosset, J.; Riccardi, G.; Cole, S. T., Benzothiazinones kill Mycobacterium tuberculosis by blocking arabinan synthesis. Science 2009, 324 (5928), 801-4.

99. Sun, D.; Scherman, M. S.; Jones, V.; Hurdle, J. G.; Woolhiser, L. K.; Knudson, S. E.; Lenaerts, A. J.; Slayden, R. A.; McNeil, M. R.; Lee, R. E., Discovery, synthesis, and biological evaluation of piperidinol analogs with anti-tuberculosis activity. Bioorg Med Chem 2009, 17 (10), 3588-94.

100. Morisseau, C.; Hammock, B. D., Epoxide hydrolases: mechanisms, inhibitor designs, and biological roles. Annu Rev Pharmacol Toxicol 2005, 45, 311-33.

101. Biswal, B. K.; Morisseau, C.; Garen, G.; Cherney, M. M.; Garen, C.; Niu, C.; Hammock, B. D.; James, M. N., The molecular structure of epoxide hydrolase B 
from Mycobacterium tuberculosis and its complex with a urea-based inhibitor. $J$. Mol. Biol. 2008, 381, 897-912.

102. Kordulakova, J.; Janin, Y. L.; Liav, A.; Barilone, N.; Vultos, T. D.; Rauzier, J.; Brennan, P. J.; Gicquel, B.; Jackson, M., Isoxyl activation is required for bacteriostatic activity against Mycobacterium tuberculosis. Antimicrob. Agents. Chemother. 2007, 51, 3824-3829.

103. Phetsuksiri, B.; Jackson, M.; Scherman, H.; McNeil, M.; Besra, G. S.; Baulard, A. R.; Slayden, R. A.; DeBarer, A. E.; 3rd, C. E. B.; Baird, M. S.; Crick, D. C.; Brennan, P. J., Unique mechanism of action of the thiourea drug isoxyl on Mycobacterium tuberculosis. J. Biol. Chem. 2003, 278, 53123-53130.

104. Knölker, H.-J.; Wolpert, M., Transition metal complexes in organic synthesis. Part 68: Iron-mediated total synthesis of mukonine and mukonidine by oxidative cyclization with air as the oxidizing agent. Tetrahedron 2003, 59 (28), 5317-5322.

105. Kasagami, T.; Kim, I.-H.; Tsai, H.-J.; Nishi, K.; Hammock, B. D.; Morisseau, C., Salicylate-urea-based soluble epoxide hydrolase inhibitors with high metabolic and chemical stabilities. Bioorganic \& Medicinal Chemistry Letters 2009, 19 (6), 1784-1789.

106. Chen, P.; Gearhart, J.; Protopopova, M.; Einck, L.; Nacy, C. A., Synergistic interactions of SQ109, a new ethylene diamine, with front-line antitubercular drugs in vitro. J. Antimicrob. Chemother. 2006, 58, 332-337.

107. Kasagami, T.; Kim, I.-H.; Tsai, H.-J.; Nishi, K.; Hammock, B. D.; Morisseau, C., Slicylate-urea-based soluble epoxide hydrolase inhibitors with high metabolic and chemical stabilities. Bioorg. Med. Chem. Lett. 2009, 19, 1784-1789.

108. Hurdle, J. G.; Lee, R. B.; Budha, N. R.; Carson, E. I.; Qi, J.; Scherman, M. S.; Cho, S. H.; McNeil, M. R.; Lenaerts, A. J.; Franzblau, S. G.; Meibohm, B.; Lee, R. E., A microbiological assessment of novel nitrofuranylamides as antituberculosis agents. J Antimicrob Chemother 2008, 62 (5), 1037-45.

109. Ananthan, S.; Faaleolea, E. R.; Goldman, R. C.; Hobrath, J. V.; Kwong, C. D.; Laughon, B. E.; Maddry, J. A.; Mehta, A.; Rasmussen, L.; Reynolds, R. C.; 3rd, J. A. S.; Shindo, N.; Showe, S. N.; Sosa, M. I.; Suling, W. J.; White, E. L., Highthroughput screening for inhibitors of Mycobacterium tuberculosis H37Rv. Tuberculosis (Edinb) 2009, 89, 334-353.

110. Hurdle, J. G.; Lee, R. B.; Budha, N. R.; Carson, E. I.; Qi, J.; Scherman, M. S.; Cho, S. H.; McNeil, M. R.; Lenaerts, J. J.; Franzblau, S. G.; Meibohm, B.; Lee, R. E., A microbial assessment of novel nitrofuranylamides as anti-tuberculosis agents. J. Antimicrob. Chemother. 2008, 62, 1037-1045. 
111. Institute, C. a. L. S., Methods for dilution antimicrobial susceptibility tests for bacteria that grow aerobically. 7th ed.; Clinical and Laboratory Standards Institute: Wane, PA, 2006; Vol. Approved Standard M7-A7.

112. Alberts, B., Molecular biology of the cell. 3rd ed.; Garland Publishing, Inc.: New York, 1994.

113. Schauder, S.; Bassler, B. L., The languages of bacteria. Genes Dev. 2001, 15 (12), $1468-1480$.

114. Miller, M. B.; Bassler, B. L., Quorum sensing in bacteria. Annu. Rev. Microbiol. 2001, 55, 165-199.

115. Fuqua, C.; Parsek, M. R.; Greenburg, E. P., Regulation of gene expression by cell-to-cell communication: acyl-homoserine lactone quorum sensing. Annu. Rev. Genet. 2001, 35, 439-468.

116. Kaufmann, G. F.; Sartorio, R.; Lee, S.-H.; Rogers, C. J.; Meijler, M. M.; Moss, J. A.; Clapham, B.; Brogan, A. P.; Dickerson, T. J.; Janda, K. D., Revisiting quorum sensing: discover of additional chemical and biological functions for 3-oxo-Nacylhomoserine lactones. PNAS 2005, 102 (2), 309-314.

117. Dunlap, P. V., Quorum regulation of luminescence in Vibrio fischeri. J. Mol. Microbiol. Biotechnol. 1999, 1 (1), 5-12.

118. Lyczak, J. B.; Cannon, C. L.; Pier, G. B., Estabishment of Pseudomonas aeruginos infection: lessons from a versatile opportunist. Microbes Infection 2000, 2, 1051-1050.

119. Pearson, J. P.; Passador, L.; Iglewski, B. H.; Greenberg, E. P., A second Nacylhomoserine lactone signal produced by Pseudomonas aeruginosa. Proc. Natl. Acad. Sci. USA 1995, 92 (5), 1490-1494.

120. Smith, R. S.; Iglewski, B. H., Pseudomonas aeruginosa quorum snesing as a potential antimicrobial target. J. Clin. Invest. 2003, 112 (10), 1460-1465.

121. Henning, H.-G.; Gelbin, A., Advances in tetramic acid chemistry. $A d v$. Heterocycl. Chem. 1993, 57, 139-185.

122. Ghisalberti, E. L., Bioactive tetramic acid metabolites. Studies Nat. Products Chem. 2003, 28, 109-163.

123. Royals, B. J. L., Naturally occuring tetramic acids: structure, isolation, and synthesis. Chem. Rev. 1995, 95 (6), 1981-2001.

124. Yendapally, R.; Hurdle, J. G.; Carson, E. I.; Lee, R. B.; Lee, R. E., N-subtituted 3acetyltetramic acid derivatives as antibacterial agents. J. Med. Chem. 2008, 51, $1487-1491$. 
125. Gitterman, C. O., Antitumor, cytotoxic, and antibacterial activities of tenuazonic acid and congeneric tetramic acids. J. Med. Chem. 1965, 8 (4), 483-486.

126. Deboer, C.; Dietz, A.; Savage, G. M.; Silver, W. S., Streptolydigin, a new antimicrobial antibiotic. Antibiot. Annu. 1955, 3, 886-892.

127. Howard, B. H.; Raistrick, H., Coloring matters of penicillium islandicum. $J$. Biochem. 1954, 57, 212-222.

128. Rosen, T.; Fernandes, P. B.; Marovich, M. A.; Shen, L.; Mao, J.; Pernet, A. G., Aromatic dienoyl tetramic acids. novel antibacterial agents with activity against anaerobes and staphylococci. J. Med. Chem. 1989, 32 (5), 1062-1069.

129. Matsuo, K.; Kitaguchi, I.; Takata, Y.; Tanaka, K., Structure-activity relationships in tetramic acids and their copper (II) complexes. Chem. Pharm. Bull. (Tokyo) 1980, 28 (8), 2494-2502.

130. Harris, S. A.; Fisher, L. V.; Folkers, K., The synthesis of tenuazonic and congeneric tetramic acids $J$. Med. Chem. 1965, 8 (4), 478-482.

131. Chhabra, S. R.; Harty, C. H.; Hooi, D. S. W.; Daykin, M.; Williams, P.; Telford, G.; Pritchard, D. I.; Bycroft, B. W., Synthetic analogues of the bacterial signal (quorum sensing) molecules N-(3-oxododecanoyl)-1-homoserine lactone as immune modulators. J. Med. Chem. 2003, 46, 97-104.

132. Dong, S. D.; Oberthur, M.; Losey, H. C.; Anderson, J. W.; Eggert, U. S.; Peczuh, M. W.; Walsh, C. T.; Kahne, D., The structural basis for induction of VanB resistance. J. Am. Chem. Soc. 2002, 124 (9064-9065).

133. Ganzle, M. G.; Holtzel, H.; Walter, J.; Jung, G.; Hammes, W. P., Characterization of reutericyclin produced by Lactobacillus reuteri LTH2584. Appl. Environ. Microbiol. 2000, 66, 4325-4333.

134. Cox, C. D.; Adams, P., Siderophore activity of pyoverdin for Pseudomonas aeruginosa. Infect. Immun. 1895, 48 (1), 130-138.

135. Gensberg, K.; Hughes, K.; Smith, A. W., Siderophore-specific induction of iron uptake in Pseudomonas aeruginosa. J. Gen. Microbiol. 1992, 138, 2381-2387.

136. Payne, S. M., Detection, isolation, and characterization of siderophores. Methods Enzymol. 1994, 235, 329-344.

137. Poole, K.; McKay, G. A., Iron acquisition and its control in Pseudomonas aeruginosa: many roads lead to Rome. Front. Biosci. 2004, 8, d661-d686.

138. Takase, H.; Nitanai, H.; Hoshino, K.; Otani, T., Requirement of the Pseudomonas aeruginosa tonB gene for high-affinity iron acquisition and infection. Infect. Immun. 2000, 68, 4498-4504. 
139. Gandhi, N. M.; Nazareth, J.; Divekar, P. V.; Kohl, H.; Souza, N. J. d., Magnesidin, a novel magnesium containing antibiotic. J. Antibiot. 1973, 26 (12), 797-798.

140. Lebrun, M. H.; Nicolas, L.; Boutar, M.; Gaudemer, F.; Ranomenjanahary, S.; Gaudemer, A., Relationships between the structure and the phytotoxicity of the fungal toxin tenuazonic acid. Phytochemistry 1988, 27 (1), 77-84.

141. Ratledge, C.; Dover, L. G., Iron metabolism in pathogenic bacteria. Annu. Rev. Microbiol. 2000, 54, 881-941.

142. Crichton, R. R., Inorganic biochemistry of iron metabolism: from molecular mechanisms to clinical consequences. John Wiley \& Sons: New York, NY, 2001.

143. Faraldo-Gomez, J. D.; Sansom, M. S. P., Acquisition of siderophores in gramnegative bacteria. Nat. Rev. Mol. Cell Biol. 2003, 4, 105-116.

144. Braun, V.; Killmann, H., Bacterial solutions to the iron-supply problem. Trends Biochem. Sci. 1999, 24, 104-109.

145. Clarke, T. E.; Tari, L. W.; Vogel, H. J., Structural biologyof bacterial ion uptake systems. Curr. Top. Med. Chem. 2001, 1, 7-30.

146. Postle, K., TonB protein and energy transduction between membranes. $J$. Bioenerg. Biomembr. 1993, 25, 591-601.

147. Klebba, P. E.; Rutz, J. M.; Liu, J.; Murphy, C. K., Mechanisms of TonB-catalyzed iron transport through the enteric bacterial cell envelopes. J. Bioenerg. Biomembr. 1993, 25, 603-611.

148. Braun, V., Energy-coupled transport and signal transduction through the gramnegative outer membrane via TonB-ExbB-ExbD-dependent receptor proteins. FEMS Microbiol. Rev. 1995, 16, 295-307.

149. Moeck, G.; Coulton, J. W., TonB-dependent iron acquisition: mechanisms of siderophore-mediated active transport. Mol. Microbiol. 1998, 28, 675-681.

150. Postle, K., TonB and the gram-negative dilemma. Mol. Microbiol. 1990, 4, 20192025.

151. Wang, C.; Newton, A., An additional step in the transport of iron defined by the TonB locus of Escherichia coli. J. Biol. Chem. 1971, 246, 2147-2151.

152. Reynolds, P. R.; Mottur, G. P.; Bradbeer, C., Transport of vitamin $B_{12}$ in Escherichia coli. Some observations on the roles of the gene products of ButC and TonB. J. Biol. Chem. 1980, 255, 4313-4319. 
153. Page, M. G. P.; Heim, J., Prospects for the next anti-Pseudomonas drug. Curr. Opin. Pharm. 2009, 9, 558-565.

154. Mollmann, U.; Heinisch, L.; Bauernfeind, A.; Kohler, T.; Ankel-Fuchs, D., Siderophores as drug delivery agents: application of the "Trojan Horse" strategy. Biometals 2009, 22, 615-624.

155. Gill, A. E.; Taylor, K.; Lewendon, A.; Unemi, N.; Uji, T.; Nishida, K.; Salama, S.; Singh, R.; Micetich, R. G., Comparative in vitro activity of PTX 2416, a dihydroxypyridone moonobactam, against gram-negative clinical isolates. 43rd Interscience Conference on Antimicrobial Agents and Chemotherapy 2003.

156. Livermore, D. M.; Mushtaq, S., PTX 2416, a dihydroxypyridone monobactam, vs. Pseudomonas aeruginosa strains with characterised resistances. 43rd Interscience Conference on Antimicrobial Agents and Chemotherapy 2003.

157. Fuchs, P. C.; Jones, R. N.; Barry, A. L.; Ayers, L. W.; Gavan, T. L.; Gerlach, E. H., In vitro activity of carumonam (RO 17-2301), BMY-28142, aztreonam and ceftazidime against 7,620 consecutive clinical bacterial isolates. Diagn.

Microbiol. Infect. Dis. 1986, 5, 345-349.

158. Tanaka, S. K.; Summerill, R. A. S.; Minassian, B. F.; Bush, K.; Visnic, D. A.; Bonner, D. P.; Sykes, R. B., In vitro evaluation of tigemonam, a novel oral monobactam Antimicrob. Agents. Chemother. 1987, 31, 219-225.

159. Page, M. G. P.; Dantier, C.; Desarbre, E., In-vitro gram-negative activity of BAL30072. Antimicrob. Agents. Chemother. published ahead of print on 22 March 2010, (doi: 10.1128/AAC.01525-09).

160. Brewster, A. G.; Jayatissa, J.; Mitchell, M. B.; Schofield, A.; Stoodley, R. J., Memory of chirality effects in aldol cyclizations of 1-(3-oxobutyryl) derivatives of 1-4-oxaproline and 1-proline isopropyl esters. Tetrahedron Lett. 2002, 43 (21), 3919-3922.

161. Ley, S. V.; Smith, S. C.; Woodward, P. R., Further reactions of tert-butyl 3oxobutanethioate and tert-butyl 4-diethylphosphono-3-oxobutanethioate: carbonyl coupling reactions, amination, use in the preparation of 3 -acytetramic acids and application to the total synthesis of fuligorubin A. Tetrahedron 1992, 48 (6), 1145-1174.

162. Kulkarni, B. A.; Ganesan, A., Ion-exchange resins for combinatorial synthesis: 2,4-pyrrolidinediones by Dieckmann condensation. Angew. Chem. Int. Ed. 1997, 36 (22), 2454-2455.

163. Hwang, S. H.; Tsai, H.-J.; Liu, J.-Y.; Morisseau, C.; Hammock, B. D., Orally bioavailable potent epoxide hydrolase (sEH) inhinitors. J. Med. Chem. 2007, 50, 3825-3840. 


\section{VITA}

Joshua Randal Brown is a native of Monticello, AR. He graduated from Drew Central High School in May of 2001. He attended the University of Central Arkansas in Conway, AR where he obtained his Bachelors of Science degree in Chemistry in May of 2001. In the summer of 2001, he entered Dr. Richard Lee's laboratory as a summer student and in August of 2001 he enrolled in the University of Tennessee Health Science Center (UTHSC) as a graduate student under the mentorship of Dr. Lee. During his time at UTHSC he thoroughly enjoyed his job as a teaching assistant in the College of Pharmacy at UTHSC. Upon graduation Josh will join the faculty at the Harding University College of Pharmacy as an Assistant Professor of Pharmaceutical Science. Joshua plans on graduating with a doctoral degree from UTHSC in May of 2010. 